\title{
Unintended consequences:
}

\section{The Montessori story of the early childhood education qualification requirement - 2000-2007}

By

Sola Freeman

\begin{abstract}
A thesis
submitted to Victoria University of Wellington

in partial fulfillment of the requirements for the degree of

Masters of Arts in Education.
\end{abstract}

Victoria University of Wellington

2008 


\section{Abstract}

In 2002, the Ministry of Education in New Zealand released Pathways to the Future: Nga Huarahi Arataki. This 10-year strategic plan for early childhood education was the culmination of years of advocacy, research and consultation within the early childhood sector. A key component of the plan is a staged requirement for teachers in early childhood centres to have a Diploma of Teaching ECE or equivalent qualification. The study analyses the impact on the Montessori early childhood sector of the requirement that teachers in a centre be qualified with a Diploma or equivalent. This thesis draws on the results of a qualitative study involving interviews with key policy informants and focus groups of teachers and the story that emerges describes the complexities, frustrations and positive outcomes for centres and their teachers. The story points to a need for support, intervention and creative strategies to ensure no part of the early childhood sector is left behind, and diversity within early childhood education in New Zealand is maintained. The final outcome of the study raises the dilemma faced by the Montessori community; how can the approach accommodate the current ideas of early childhood education brought to centres through the policy requirement and remain identifiably Montessori? 


\section{Acknowledgements}

This thesis is one part of the story of Montessori education in New Zealand, I am indebted to the many others who have gone before me. They have inspired me. Thank-you to you all.

I would like to thank my supervisors - I have been fortunate to have the input of three of New Zealand's leading early childhood researchers. Firstly, Professor Helen May, who provided vital information and guidance at the very beginning. Secondly, Dr. Carmen Dalli who provided reassurance, direction during the data collection phase, and valuable feedback at the initial writing stage. And thirdly, Sarah Te One; thank-you for the advice, critiques and faith; you kept me on track, understood my other priorities, gave me permission to attend to those, and was a patient champion to my cause!

To Ross Boyd, Rose Cole, Dr. Anne Meade, Nicola Chisnall and Ana Pickering thank-you for your time and wisdom. Your opinions and insights have provided the backbone to this thesis.

To the focus group participants, I would like to say a heart felt thank-you. Several shared some very personal difficulties; break-up of relationships, impact on families, conflict with teaching colleagues and for one, the loss of her school.

To all at Wa Ora Montessori School, and the Eastbourne Barnardos Early Learning Centre; thank-you for caring for my children and giving me time and encouragement.

To my mother, Barb Freeman, her encouragement has always been there, but having you able to step in to look after your grand-children has been hugely appreciated. To the rest of my family and friends; a huge thank-you to you too.

To my children, Fiann, Cared, Nea and Cashel, you were all born during the process of my Masters (Cashel during this thesis) and I look forward to being able to concentrate more on my role as your Mum, while you take your own Montessori journeys.

Finally to my husband Mark, thank-you for listening, for editing, and supporting me; I would not have had the courage to take on this project without you. 


\section{Table of Contents}

ABSTRACT

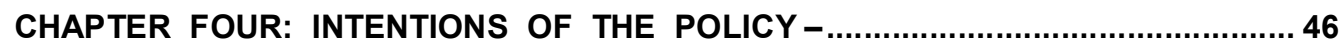

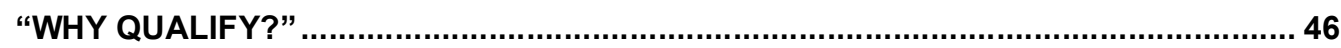

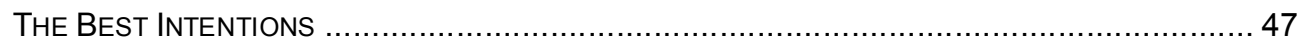

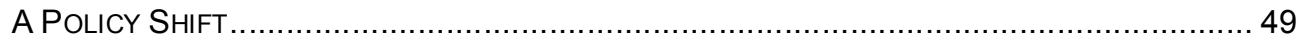

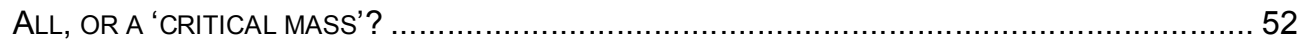

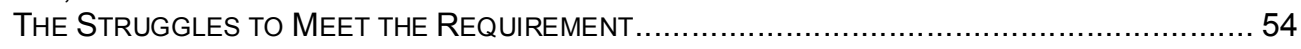

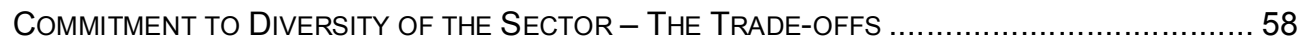

CHAPTER FIVE: GETTING QUALIFIED - THE EXPERIENCE FOR INDIVIDUAL

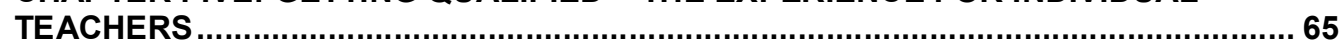

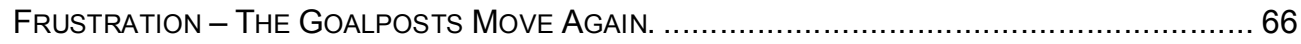

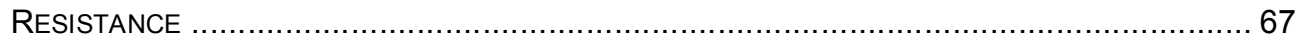

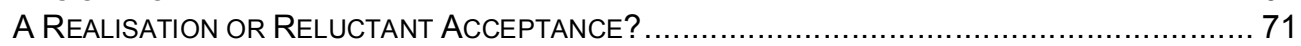

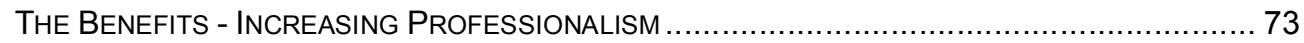

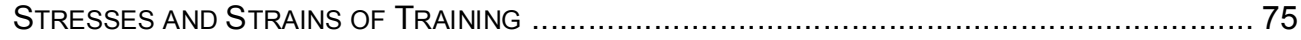

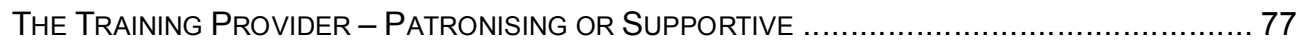

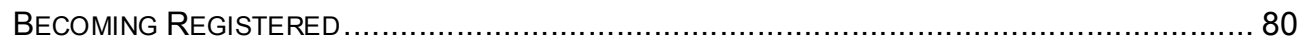

CHAPTER SIX: GETTING QUALIFIED - THE EXPERIENCE FOR CENTRES ............... 83

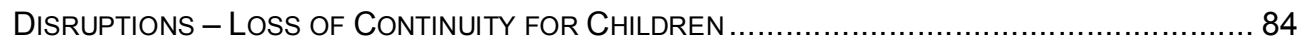

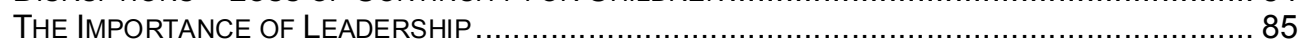

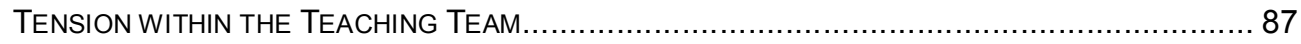

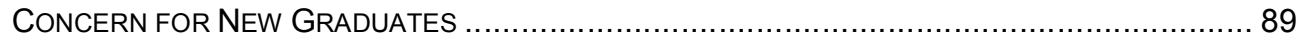

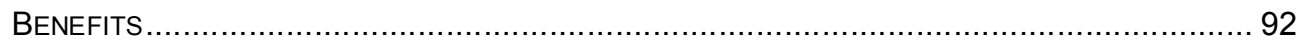




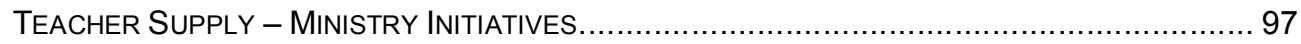

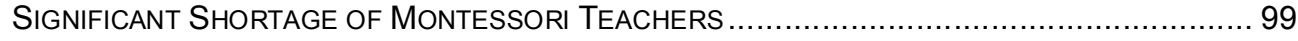

UNINTENDED CONSEQUENCE - LOSS OF CENTRE ................................................ 100

100\% FUNDING OR STRONG MONTESSORI PROGRAMME ....................................... 102

MONTESSORI TEACHERS FROM OVERSEAS ……............................................... 104

DESPERATE NEED FOR MONTESSORI MENTORS ................................................... 107

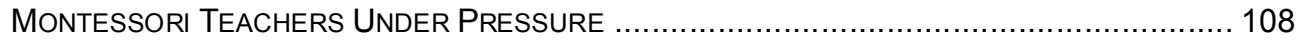

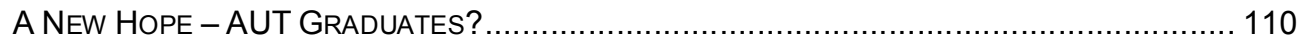

A 'WATERED-DOWN' VERSION OF MONTESSORI EDUCATION ..................................... 111

PART OF THE WIDER EARLY CHILDHOOD PROFESSION .......................................... 114

CHAPTER EIGHT: A NEW MONTESSORI APPROACH IN NEW ZEALAND? ...............118

BLENDING MONTESSORI WITH OTHER APPROACHES............................................. 119

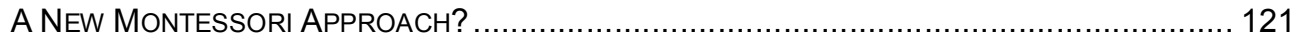

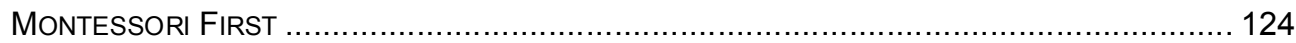

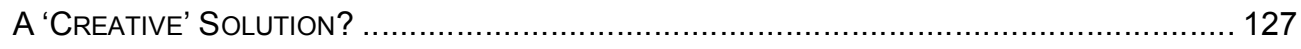

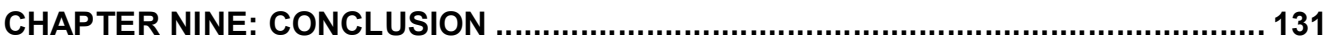

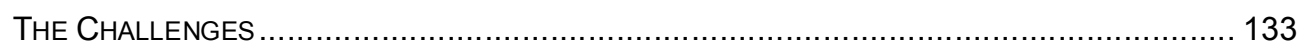

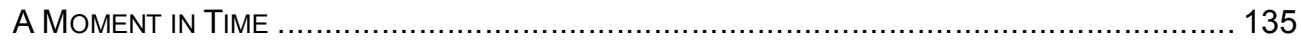

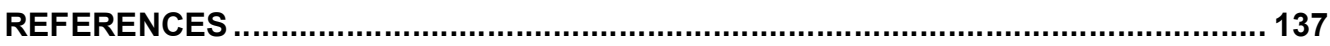

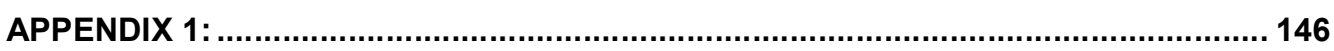

APPENDIX 2:

APPENDIX 3:

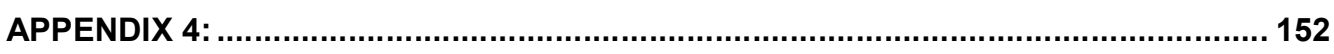

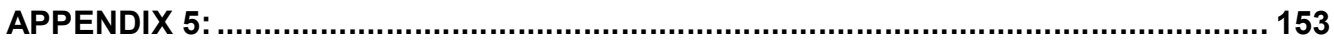

APPENDIX 6:

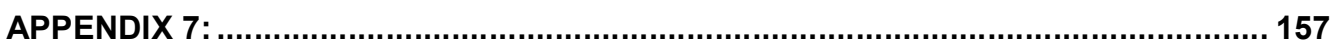

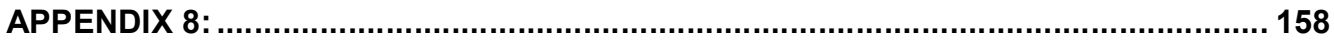

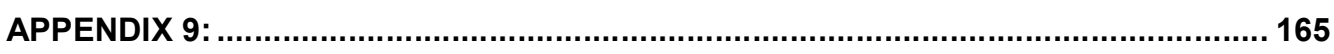

APPENDIX 10:

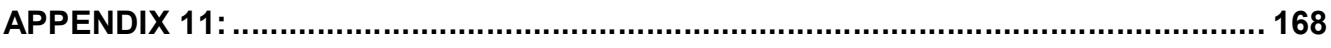

APPENDIX 12:

APPENDIX 13: 170

APPENDIX 14: 


\section{Chapter One: Introduction}

This thesis provides an analysis of a specific early childhood education policy requirement, and its effect on the Montessori community of New Zealand. The policy initiative for the early childhood sector of New Zealand; Pathways to the Future: Nga Huarahi Arataki, the 10 year strategic plan for the early childhood sector, identified three important goals; to increased participation, to improve quality, and, to promote collaborative relationships between agencies (Ministry of Education, 2002). To help meet the goal of improved quality there is a requirement that all teachers in early childhood centres are qualified and registered by 2012. It is this requirement that this qualitative study seeks to analyse, in particular its impact on the Montessori community of New Zealand.

The research set out to;

- explore the tensions and complexities created through the implementation of the policy requirement.

- understand the broad positive intentions of the policy (the aim for quality early childhood educational experiences for young children) and the intention to maintain diversity within the sector, through the voices of the 'education policy elite' (Ozga \& Gewirtz, 1994)

- capture the consequences for those working with the policy.

Ball (1994, p. 18) argues "policies pose problems to their subjects, problems that must be solved in context" and says these problems cannot be assumed or predicted and therefore the role of researcher is to discover what these are. My intention was to capture the story of those working within the Montessori sector of New Zealand as they experienced the requirement to be qualified with a Diploma of Teaching (Early Childhood Education) (DipTch ECE). 
This study shows that the policy forced the Montessori community into a position of deciding what it means to be Montessori in New Zealand in the $21^{\text {st }}$ century. The Montessori sector participants' experience has been one of survival - Montessori teachers surviving the personal sacrifices of doing additional training, Montessori centres surviving the struggles and frustrations in meeting the requirement, and exploring how the Montessori approach will survive in New Zealand. By investigated the policy intention and implementation, this study highlighted the unintended consequences affecting Montessori teachers, Montessori centres and the Montessori early childhood community.

Working within the critical theory and policy analysis frameworks meant exploring the complexities of policy implementation for those actually experiencing it and exposing the unfairness that this might generate (Ball, 1994; McNeil \& Coppola, 2006; Ozga, 2000). This was the purpose of this study.

\section{Thesis structure}

Following this chapter is a literature review examining the policy reforms from the 1980s to post-2000. Part one - the literature review - provides the historical policy and political context prior to the formation of Pathways to the Future: Nga Huarahi Arataki (Ministry of Education, 2002). Part two of the literature review explores the discourse and research surrounding the relationship between teachers' qualifications and quality experiences for young children. Part three explores the historical origins of the Montessori Method, including teachers with particular reference to the training options available in New Zealand.

Chapter Three describes how the study was conducted; declaring the role of the researcher in this study, the methods used in the research, the ethics surrounding the study, analysis of the data, and exploring the trustworthiness of the research. 
The methodological approach is an exploratory qualitative framework, using four interpretive paradigms; critical theory, phenomenological view, narrative theory and policy analysis.

Five major themes emerged from the data;

o the intentions of the policy requirement,

- the impact on the Montessori teachers at a personal level,

- the impact on and consequences for Montessori centres,

o the consequences for the Montessori community of New Zealand,

0 and how these consequences are going to affect the provision of Montessori early childhood education in New Zealand.

These themes are explored in Chapters Four to Eight respectively.

The first theme analysed the primary intention of the policy requirement for qualified teachers with a DipTch (ECE) or equivalent; to raise the level of quality experiences for young children in early childhood settings in New Zealand. There was also the intention to professionalise the sector and raise the profile of early childhood education. These intentions are explored through the interview data gathered from the 'policy elite', and expose the assumptions held by many policy makers that the policy will impact on homogenous recipients in the same way (McNeil \& Coppola, 2006; Ozga, 2000; Ozga \& Gewirtz, 1994).

The impact on the Montessori teachers was the second theme; exploring the frustrations and struggles of those who were required to do additional training to gain a DipTch (ECE) or equivalent. In Chapter Five the teachers' experience of the policy is captured in their stories of initial resistance; sacrifices while training, frustrations with the training providers and the realisation of the benefits of the training. 
Montessori centres had difficulties in dealing with the policy implementation on a daily basis. Chapter Six uncovers how they struggled due to the number of teacher changes, to provide as little disruption as possible for the children in their centres. Also how they found the tensions that arose amongst the teaching teams difficult to deal with, and the concern for the new graduates coming into centres - often in positions of responsibility before they were ready. Consistent and strong leadership in the centres came through as an important factor in the ability of the centres to cope with the change.

The fourth theme is the consequences for the Montessori community in New Zealand. The severe shortage of teachers provides the main reason for many of the unintended consequences discussed in this chapter; the lack of experienced Montessori teachers to guide Montessori programmes or to mentor new graduates, this leading to the strain on current Montessori teachers, the pressure on centres to employ teachers without a Montessori qualification (for more funding or because there was no choice) and the resultant loss of Montessori centres.

The progression towards a 'watered-down' version of Montessori identified by some participants in this study indicates the challenge facing the Montessori community right now. The Montessori movement has always faced challenges (Goffin \& Wilson, 2001) - and in New Zealand the Montessori community is faced with the dilemma of how the approach can accommodate the current ideas of early childhood education brought to centres through the policy requirement to have qualified teachers with a DipTch (ECE) and remain identifiably Montessori. The questions surrounding this dilemma, the final theme, are explored in Chapter Eight. 
This thesis concludes by raising a number of questions and challenges;

- Where to next for the Montessori approach in New Zealand?

- What role does this research have for other minority philosophies and diverse early childhood settings in New Zealand?

- What support should the Ministry provide to these diverse groups of the sector?

- What role do teacher training providers play?

- And what contribution does Montessori have to make to the wider early childhood sector? 


\section{Chapter Two: Literature Review}

The New Zealand early childhood sector has been affected by numerous policy changes over the last 20 years. One area that has been heavily contested throughout this time has been the level of qualifications needed to teach in early childhood (May, 2001).

This chapter will explore three areas of the literature which provide insights and background to this study; the historical policy pathway in New Zealand prior to Pathways to the Future: Nga Huarahi Arataki, the New Zealand and international discourse on quality that supports the importance of teacher qualifications in early childhood settings, and the qualification journey taken by the Montessori community prior to this policy decision.

\section{The Historical Pathway}

\section{Before Five}

Many shifts in Government attempts to improve qualification standards in the early childhood sector can be observed through various policy statements over the last two decades.

The first was Before Five, released in 1988 by the Minister of Education, Hon. David Lange of the fourth Labour Government (elected 1984). Before Five (Department of Education, 1988) was the government's response to the report Education to be More (Meade Report) produced by the Early Childhood Care and Education Working Group (Meade, 1988). It was released alongside reform documents for the school and tertiary sectors and was part of a significant transformation of the country's compulsory education systems (Barrington, 1998; Codd, 1994; Fiske \& Ladd, 2000; Ladd \& Fiske, 2003; Lauder \& Hughes, 1999). 
The committee chair, Anne Meade has described the Meade Report as an opportunity to bring together all the "shared understanding and discourse" that had developed over the previous decade; the sector was in agreement of what it wanted and needed (Meade, 1994b, p. 52) and the recommendations were built upon the work of earlier reports, committees and campaigns (May, 1990a, 1990b, 1999, 2000; Meade, 1994a).

The government's report, Before Five, retained much of the recommendations of Education to be More, (May, 1990a, 1990b, 2001; Meade, 1990; Wells, 1991) and made a commitment to improve participation in quality early childhood education and care, and to "improve the status and remuneration of teachers" (May, 1999, p. 19). This commitment was reinforced with a four year staged funding plan (signalled significant funding increases) and guidelines to increase quality early childhood provision through improved staff:child ratios and higher qualification requirements for early childhood teachers, in particular identifying a three year pre-service qualification (Dalli \& Te One, 2003).

With Before Five the early childhood sector breathed a sign of relief - there was a feeling of optimism and a sense that the battle had been won (Dalli, 1993; Dalli \& Te One, 2003; May, 2001; Meade, 1990; Wells, 1991).

\section{A new government}

However the funding plan attached to Before Five was dependent on the reelection of the Labour government into a third term (as May, 1990b, predicted). Within weeks of National winning the 1990 election the victories of the Before Five policies and funding became short-lived (Dalli \& Te One, 2003; May, 2001; Wells, 1991).

Not only was the staged funding plan frozen, the government introduced a system which annulled the requirement of the quality guidelines for higher standards than the regulations (Meade \& Dalli, 1991). 
This system was The Statement of Desirable Objectives and Practices (DOPS) - introduced in 1990 (Dalli, 1993; Meade \& Dalli, 1991; Smith \& Farquhar, 1994). Now services needed to meet only the minimum standards of the regulations and record them in their DOPs.

The following Budget of 1991 brought further changes; along with reductions in funding and lowering of the quality standards, there was a change in training requirements - moving away from the three year qualification to a 'licensing points system' (Dalli, 1993; Meade, 1994a; Meade \& Dalli, 1991; Smith \& Farquhar, 1994).

The 'licensing points system' - whereby a teacher could accumulate points through various training courses to meet licensing requirements - was to become confusing and frustrating for many. It is outlined in further detail in the following section.

There were advances during these hard times; the Code of Ethics - an independent sector initiative, the "Competent Children" study - a longitudinal research on the influences of early childhood education, the strengthening of Te Kohunga Reo under the Ministry of Education umbrella, and $\mathrm{Te}$ Whāriki - a internationally recognised national early childhood curriculum document embraced by the sector after significant consultation (Dalli \& Te One, 2003; Meade, 1999; Mitchell, 1999; Te One, 2003).

Another noteworthy development of the decade was the Early Childhood Education Project, a group of representatives from within the sector who aimed to focus on the "structures and funding required to deliver education services that will provide best quality education and care" (Early Childhood Education Project, 1996, p. 3). Their report "Future Directions" influenced thinking and policy making for the following decade.

With a new decade came a new government - a Labour-Alliance Coalition in 1999. The Labour party's manifesto incorporated many of the Future Directions plans (Mitchell, 2002), including the objective of developing "a 
long term strategy for the early childhood sector, in collaboration with the sector" (as cited in Dalli \& Te One, 2003, p. 181).

\section{Pathway to the Future}

In 2000 the Minister of Education, Hon. Trevor Mallard, announced a Strategic Plan Working Group, selected to represent the diversity of the sector and given the task of developing a 10 year strategic plan for early childhood education in New Zealand. It was a large group (31), of which I was a member, and was convened by Anne Meade.

After much consultation, within a timeframe of just over a year, the Strategic Plan Working Group released its recommendations Final Report of the Strategic Plan Working Group to the Minister of Education in October (Early Childhood Education Strategic Plan Working Group, 2001). The Government's response was released nearly a year later in September 2002; Pathways to the Future: Nga Huarahi Arataki; A 10-year strategic plan for early childhood education (Ministry of Education, 2002). Pathways to the Future incorporated three of the Strategic Plan Working Group's directions; increasing participation, improving quality and promoting collaborative relationships (Dalli \& Te One, 2003; Ministry of Education, 2002), with the fourth direction on sustainability and funding being left for another working group.

The previous National government had introduced a requirement for the person responsible to hold a degree or diploma (N. Smith, 1999). The Labour led Government continued with this policy. Any teacher new to a 'person responsible' position must hold at least a Diploma of Teaching (ECE) (Mallard, 2000b). 
This was incorporated into the Strategic Plan with the implementation proposed as a staged plan with various requirements to be met along the way;

- 1 January 2005 - all persons responsible to be registered teachers

- $2007-50 \%$ of all regulated staff to be fully or provisionally registered teachers

- $2010-80 \%$ of all regulated staff to be fully or provisionally registered teachers

- 2012 - all regulated staff to be fully or provisionally registered teachers.

\section{The Quality and Qualification Discourse}

The following section will outline in more detail the political background of the roller coaster ride experienced by many early childhood teachers through numerous qualification policy changes over the decades preceding the release of Pathways to the Future 2002. In particular; the quality and qualification dialogue overseas and within NZ and the key policy shifts in qualification requirements.

The key focus of the twenty years preceding Pathways to the Future (Ministry of Education, 2002) is that of quality (May, 2002), and this forms the backbone to the qualification discourse over this time. The main questions were about "quality experiences for children: what was the recipe, who was responsible, what was the cost, and how could quality be measured?" (May, 2001, p. 232).

The governmental policy statement that tried to answer these questions was Before Five (Department of Education, 1988). It had a clear aim of quality provision of early childhood education (Meade \& Dalli, 1991). The 1988 policy statement articulated a strong role for government in quality assurance. 
It identified the quality mechanisms needed; regulations, advisers at the Early Childhood Development Unit, monitors with the Education Review Office, and provision of training through Colleges of Education (Meade \& Dalli, 1991).

While some of these mechanisms have remained relatively unchanged, the two areas subject to the most change have been regulations and qualifications. The changes in qualification requirements for early childhood teachers has meant a turbulent journey for many, with significant confusion over the "moving frontiers" of qualifications and/or equivalency points needed for licensing (Dalli, 1993, p. 236).

This was particularly the case for Montessori teachers in New Zealand who seemed to continuously slip through the cracks of the various point-based requirements and pathways to qualification upgrades (Chisnall, 2002, 2003). This will be discussed in more detail in the next section.

It is important to identify the difference between kindergartens and the remaining teacher-led early childhood sector in New Zealand. Kindergartens have always had their teachers trained. They were never affected by the changes in qualification requirements and went through this period as observers of the qualification issues affecting 'education and care services'.

In 1975, the first training programme for early childcare workers was established - a one year training only. The addition of field-based training and encouragement of centres to have at least one staff member qualified reflected international research that showed the importance of having trained staff working with children (May, 2001).

This illustrates how, even at the beginning of the qualification debate, research was a significant contributor to the policy discourse in early childhood education. 


\section{New Zealand Research}

Throughout this time the quality dialogue in early childhood education in New Zealand revolved around issues such as;

- the benefits of quality provision for children (Podmore, Meade, \& Kerslake Hendricks, 2000; Smith, 1996a, 1996b; Smith et al, 2000; Wylie, 2001),

- who defines quality and the multiple perspectives of quality (Moss, 1994; Smith \& Farquhar, 1994; Farquhar, 1990 as cited in May, 2001),

- the indicators of quality (Podmore et al, 2000; Smith, 1996b; Smith et al, 2000; Wylie, 2001),

- and the evaluation of quality programmes (Education Review Office, 2000; Podmore et al, 2000).

There are two parts to quality provision in early childhood education; structural quality and process quality (Smith et al, 2000). Process quality consists of "the general environment and the social relationships and interactions taking place in the early childhood setting which are directly experienced by children and families ... [and] involves the measurement of the actual education and care received by children" (Smith et al, 2000, p. $59)$.

The structural quality components are the "easily observed and measured, and therefore regulatable aspects of quality", identified as;

- Adult-child ratio

- Group size

- Staff training, education and working condition

- Staff wages and working conditions

- Staff stability (Smith et al, 2000, p. 49) 
The one component that has been easily identified through regulatory and policy documents as a key factor in quality in early childhood education is that of qualifications (Podmore et al, 2000). Two literature reviews identify research that illustrates the role of qualifications in quality provision. They show significant international research that identifies the importance of the teacher's qualifications and how that relates to quality educational outcomes for young children (Podmore et al, 2000; Smith et al, 2000).

The main New Zealand research reviewed by Smith et al (2000) and Podmore et al (2000) is the longitudinal research project, Competent Children, started by Anne Meade, Cathy Wylie and Anne Kerslake Hendricks in 1993, and continued by Wylie. This research has provided significant material which highlighted the beneficial impacts of quality early childhood education right through to age 12 (Wylie, 2004) and in particular indicated the factors that make up quality early childhood education experiences for young children (Wylie, 1998).

Amongst those key factors that contribute to quality early childhood education, the study identified the highest quality early childhood education centres as having all staff with a Diploma of Teaching ECE and earning at least \$15 per hour (Wylie, 1998).

Other New Zealand research identified is the work done by Anne Smith and her colleagues, in which they studied the quality of childcare for infants and toddlers in 200 centres for under 2 year olds (Podmore et al, 2000). The role of the Education Review Office in defining what quality provision might/ or should look like was also reviewed.

Policy initiatives such as Future Directions (Early Childhood Education Project, 1996) and Pathways to the Future (Ministry of Education, 2002) are also representative of the quality debate around qualifications. 
$\underline{\text { International Research }}$

Reviews of research from the United States by Marcy Whitebook (2003a, 2003c) goes even further and articulates that it is the type of qualification of the teacher that makes the most impact on quality practice;

Specifically, classrooms where the teachers have at least a Bachelor's degree are more likely to be of higher quality - as in richer language environments, richer literacy environments, and better teacher-child interactions. Moreover, the teachers themselves are more likely to appropriately approach instruction - they are more sensitive, less punitive, and more engaged. (p. 1).

The Organisation for Economic Co-operation and Development (OECD) (OECD, 2001) noted the trend towards longer and higher qualification levels for early childhood teachers; finding that "at least three years of tertiary education is the norm for pre-school staff in Western Europe" (p. 99).

Other areas that are discussed in relation to staff qualifications are the pay and conditions for qualified teachers. The impact of funding issues in relation to qualification requirements in New Zealand has been investigated and the issue of wages, conditions and lack of funding is significant. (Farquhar, 2003; Mitchell, 2001)

International research has indicated a strong association between the teacher's wages and classroom quality, showing the importance of the relationship between the "'iron triangle' structural variables (adult:child ratios, group size and teacher education/training)" of quality and the process quality for children (Phillipsen, Burchinal, Howes, \& Cryer, 1997, p.281). Others show the impact of low wages and conditions of early childhood teachers and the difficulties of recruiting and keeping highly effective teachers (Barnett, 2003). 
One of the key theoretical frameworks that underlie the research in the area of quality and qualifications is post-positivist; where there is a different criterion which is appropriate for all - where there are social facts which exist for everyone (Scott \& Usher, 1999). When it comes to structural quality in early childhood education, some components remain the same irrespective of the context of the research - such as qualifications for the teacher.

However, when it comes to defining what "quality" actually is, the theoretical framework is based around post-modernist approach. There is a multiperspectival view (Scott \& Usher, 1999) and an acceptance that the researchers will be influenced by values and the political context in which they work (Smith as cited by Moss, 1994, p. 6). Moss (1994) and Podmore et al (2000) argue that definitions of quality are based on collective values and are therefore relative.

Similarly Linda Keesing-Styles (2003) has raised the question of who defines "what constitutes a qualified teacher?" While she has no problem with the idea of "well-educated, quality teachers", she believes the diverse nature of the early childhood sector raises the issue of who defines what the right qualification is. She believes "that the current definition of a quality teacher is inadequate when applied within the diverse ECE sector in New Zealand" (p. 236).

There is, however, an acceptance of the structural components of quality early childhood provision; the 'iron triangle' - ratios, group size and teacher qualifications, and that these factors cannot be left to interpretation. They must be defined in governmental policy - as they have been in Pathways to the Future (Ministry of Education, 2002). 


\section{The early childhood qualification policy story}

The governmental policy statement that tried to put in place these key indicators was Before Five (Department of Education, 1988). And as a result of significant advocacy and research the Before Five policy document identified a three year pre-service qualification as "the benchmark to which early childhood practitioners aspire as a means of achieving a high quality service" (Dalli, 1993, p. 234).

The political climate following Before Five had significant policy shifts. As discussed previously, a change in government in 1990 saw a dramatic impact on the recommendations of Before Five; in particular the 1991 Budget meant an immediate effect on the qualification requirements - no longer was the 3 year training to be the benchmark qualification - the use of 100 points was to be the licensing 'benchmark' (Dalli, 1993), creating significant confusion over the "moving frontiers" of qualifications and/or equivalency points needed for licensing (Dalli, 1993, p. 236).

For licensing purposes an early childhood centre must have a 'person responsible', who was required to hold initially 80 then 100 'licensing points' - having 100 points was merely a marker that enough licensing points had been accumulated but it was not a qualification in itself (Dalli \& Te One, 2003; May, 2001; Meade, 1994a). Many were hugely disappointed that this would mean many centres would not meet the desired aim of having teachers in positions of responsibility with a three year coherent qualification (Dalli, 1993; Early Childhood Group, 1994; May, 1996; Meade \& Dalli, 1991).

These centres were therefore considered to be unable to offer the characteristics integral to better quality provision for children; such as more positive, sensitive and responsive interactions with children, richer language experiences, less authoritarian or punitive responses to the children and where children are more cooperative and persistent with activities. 
These characteristics have been identified as belonging to teachers with a coherent qualification of at least two to three years (Barnett, 2004; Whitebook, 2003b; Whitebook, Howes, \& Phillips, 1989).

In addition to the confusion of the 'licensing points' system, the funding reviews of 1991 and 1993 saw significant reductions and dismantling of the quality funding and regulations set out in Before Five, this left the early childhood sector in disarray and confusion (Dalli, 1993; Dalli \& Te One, 2003).

Despite the disarray, a group of representatives from various national organisations was formed to review the current situation and devise a collaborative direction for the sector and identified policies to support quality early childhood education (Dalli \& Te One, 2003; Mitchell, 1995). The resulting document; Future Directions: Early childhood education in New Zealand (Early Childhood Education Project, 1996) had a significant impact on the policy manifesto of the Labour Party prior to the 1999 general election (Chisnall, 2002; Dalli \& Te One, 2003; Mitchell, 2002). This in turn, with a Labour-Alliance Coalition in 1999, meant the formation of a Strategic Plan Working Group, gathered to represent the diversity of the sector and with the task of developing a 10 year strategic plan for early childhood education in New Zealand (Mallard, 2000a).

The Strategic Plan Working Group recommended that by $201060 \%$ of teaching staff will be registered, with the remaining staff in training (Early Childhood Education Strategic Plan Working Group, 2001). The Government's response; Pathways to the Future (Ministry of Education, 2002) went further - a staged plan for $100 \%$ qualified teachers by 2012. 


\section{The Montessori Story}

While early childhood qualifications have really only been intensely debated over the last two decades, the Montessori qualification story covers over 100 years. The background to Dr. Maria Montessori and the Montessori approach $^{1}$ to education will be provided briefly, as others have done this in more detail (Chisnall, 2002; Kramer, 1976; Shuker, 2005; Standing, 1957/1998).

This section will explore the qualification policy changes and their implications for the Montessori movement in New Zealand over the last two decades, which will provide the background to the Montessori community's response to the policy requirement for teachers to be qualified.

Dr Maria Montessori was born in 1870; her life has been described as 'remarkable' and her influence 'significant' (Chisnall, 2004; Kramer, 1976; Standing, 1957/1998).

The following is a very brief outline of her life and work. I am indebted to Rita Kramer (1976) for her thorough and honest biography of Maria Montessori and E.M Standing (1957/1998) for his reverent account of her life. Also to both Nicola Chisnall (2002), for her succinct timeline of Maria Montessori's life and information on Montessori training options in New Zealand, and Mary-Jane Shuker (2005) for further information on Montessori training options.

Maria Montessori was the first woman to graduate from the University of Rome with a medical degree in 1896. She went on to work in various hospital positions, ran a private medical practice, studied pedagogy, attended and spoke at a number of international conferences.

\footnotetext{
${ }^{1}$ For ease of use I will refer to the educational approach - the method and philosophy of Dr Maria Montessori as 'Montessori', when referring to her as a person I will use 'Dr. Montessori'.
} 
Dr Montessori's main areas of study were in the fields of pedagogy, anthropology, hygiene and psychology.

This was all prior to and during the development of her teaching materials and techniques, initially designed for mentally disabled children; they were also successful with 'normal' children. The opportunity to put her ideas into practice came when she was approached to open a school for some unoccupied pre-school children in a recently renovated tenement or apartment block. The Casa dei Bambini (Children's House) opened in 1907. The results of her approach; the active, happy and productive community of children were considered a phenomenon and many visitors came to see the 'Casa' in operation.

Two years later the first training course in Montessori teaching opened with 100 students. Dr Montessori was to then write her method down - the English translation in 1912 being The Montessori Method. For the next 40 years she was to continue training Montessori teachers in various parts of the world, including Italy, USA, Spain, England, Holland, India, and Pakistan.

Alongside this work Dr Montessori developed and extended her educational approach to primary aged children and adolescents, as well as infants. Her approach was influenced and supported by many other theorists of the time, including Erik Erikson, Sigmund and Anna Freud and Jean Piaget. During the 1920s and 30s the Montessori approach was to spread and influence much of the education systems within Europe. Her refusal to support Mussolini's fascist regime in Italy meant the closure of all Montessori schools in Italy and the onset of World War II meant many others around Europe were to close. Dr. Montessori and her son Mario and his wife Helen and their four children were to continue her work - developing her educational approach and providing teacher trainings in India during the war. 
In 1929, Dr Montessori and Mario founded the Association Montessori Internationale (AMI), a society established to organise trainings and the International Montessori Congress for Montessori teachers - an English branch was established in 1930. This organisation continues today and believes they are the only provider of an authorised Montessori teacher training. The AMI training is provided in a variety of ways but usually fulltime and over an academic year or several summers (www.montessoriami.org).

Other training organisations have also been established, including the American Montessori Society (AMS) founded by Nancy Rambusch in 1960 (Shuker, 2005), this training offers a face-to-face summer programme with an internship under an experienced teacher for up to one year (Chisnall, 2002; www.amshq.org).

The St Nicholas training institute was established by Margaret Homfray and Phoebe Child in 1946, with Dr Montessori's blessing. At some point this authority was removed due to a break with the Montessori family, however it remained a well established and important source of face-to-face and correspondence courses for many Montessori teachers for 50 years. During the 1980s Homfray and Child retired from St Nicholas and were persuaded to establish a new training; named Montessori World Educational Institute (MWEl) (Chisnall, 2002).

Around the same time Lesley Britton and Keith Parker began the London Montessori Centre (LMC); their aim was to provide a Montessori training that took into account recent theorists and ideas. They provided a year long face-to-face course and correspondence courses that were significantly less demanding than the St Nicholas course: 10 assignments as opposed to 50 . This meant their courses became increasingly popular and were offered in many different countries. In 1998 LMC and St Nicholas joined to form the Montessori Centre International $(\mathrm{MCl})$. They are based in London and continue to provide full time and part time face-to-face and correspondence courses in Montessori teacher training (Shuker, 2005) 
During the 1980s and 90s, in Australia and New Zealand most people wanting a Montessori training either went overseas or studied via a correspondence course, either through St Nicholas, LMC (and more recently $\mathrm{MCl}), \mathrm{MWEI}$ or the Aperfield Montessori course.

MWEI had an Australasian branch run by Beth Alcorn, who took the first workshop training under Homfray and Child in New Zealand, she has provided correspondence and workshops in Montessori teacher training in Australia and New Zealand since.

Aperfield was established in 1989 by Binda Goldsborough, who wrote her own Diploma course in an effort to meet the demand for Montessori trained teachers in New Zealand, and due to dissatisfaction with the overseas correspondence courses (Shuker, 2005). During the 1990s this course made a significant contribution to the number of Montessori teachers and therefore the growth of Montessori centres in New Zealand. The details of this story and the life and influence of Binda Goldsborough on Montessori in New Zealand is told by Nicola Chisnall (2002) and Mary Jane Shuker (2005).

While some Montessori centres choose to only employ teachers with an AMI training, or with a face-to face training such as AMI, AMS or LMC, the majority of New Zealand based teachers would have an Aperfield, MWEI or $\mathrm{MCl}$ (correspondence) training. The local Montessori sector's preference for face-to-face training was behind the drive for dedicated face-to-face Montessori training facility in New Zealand (Chisnall, 2002).

\section{A Montessori degree programme in New Zealand}

With the establishment of a national organisation, the Montessori Association of New Zealand (MANZ), in 1982 (Chisnall, 2002; Shuker, 2005), the Montessori sector had a collective voice. 
The issue of qualifications has always been a significant one for the Montessori sector. During the 1980 s and 90 s the only training option was via distance learning and centres struggled to find teachers (Chisnall, 2002; Shuker, 2005). A Training Panel was established (1985) to look at positioning a Montessori qualification within New Zealand (Chisnall, 2002). Massey University provided a strong option with Montessori advocates, Pat Conway and Betsy Miltich-Conway, within the institution. At this point the intention was for a three year degree qualification with a Montessori component N. Chisnall, (personal communication, May 15, 2005).

This was also the aim for the rest of the 'childcare' sector, who had only a one year training available in four training colleges (May, 2001). The Montessori qualification success relied heavily on the supportive lecturers and a supportive political climate - with the demise of both, the aims for the Montessori involvement with Massey University eventually dropped to a 50 hour module (offered in 1989 only) and then nothing (Chisnall, 2002).

The optimism of the late 80 s had meant a sense of progress and recognition within the early childhood sector (Dalli, 1993), including Montessori (to a degree) (Chisnall, 2002), but this was short lived and as explained already, the sector suffered significant set backs in the area of qualifications over the following decade. The impact for the Montessori movement was even more significant, with Montessori teachers continuously slipping through the cracks of the various point requirements and pathways to qualification upgrades (Chisnall, 2002, 2003).

Due to the establishment of the licensing points system, for the 'person responsible' or Supervisor of an early childhood centre in 1991, methods for teachers already in the sector to meet the licensing requirements were needed. During the 1990s there were two options available for teachers already working in the sector to gain equivalency to or work towards the three year Diploma. 
In 1990 the report "Qualifications and Training: A Blueprint for the Future" was released and established a qualification structure for early childhood centres - minimum qualifications required for licensing and a higher level of qualifications for chartered centres aiming for better quality experiences for children. It also suggested a pathway to 'reaching equivalence' to the Diploma. It was a complicated task due to the many diverse qualifications and experience teachers had within the sector, the process was managed by the New Zealand Qualifications Authority (NZQA) - teachers would accumulate their qualifications and experience to meet the required number of points, have it assessed by NZQA who would issue a "certificate of equivalency" to the Diploma (Ministry of Education, 1990). The 'grandparenting' process provided a path for some of the experienced Montessori qualified teachers in New Zealand. It was designed as an interim measure and the option closed in January 1995 (Dalli, 1993; May, 2001; Meade \& Dalli, 1991; Te One, 1996).

In 1996, as a result of the governments 'quality funding package' and to meet the early childhood sectors' need to have qualified teachers with the Diploma (now reinstated as the benchmark), an advisory panel to NZQA devised the Pathways Programme. Here the training providers of the Diploma were encouraged to provide third year courses for teachers with a base qualification of 80 points (as assessed by NZQA) (Dalli \& Te One, 2003; May, 2001). They could then upgrade their training in a holistic manner - "an integrated short term course which [led] to the Diploma" (Te One, 1996, p. 10)

The Pathways Programme was a short term solution, and it was at this point in the qualification roller coaster ride that many Montessori teachers got off. In assessing qualifications NZQA gave a two year training 80 points and a one year training 40 points (Ministry of Education, 1990). The result was 40 points for a one year face-to face Montessori training and 30 points for a Montessori training through distance learning (such as the St Nicholas or LMC trainings) (Chisnall, 2002). 
Therefore very few Montessori teachers in New Zealand were able to access the Pathways programme towards a DipTch (ECE); this left many accumulating 100 points or more but with no recognised qualification for licensing or chartering purposes. Many Montessori teachers would have made up the 1198 teachers in this position in 1999 (Chisnall, 2002; May, 2001, p. 250).

This resulted in frustration for many Montessori teachers by the end of the 90s. Some felt strongly that a move with the rest of the early childhood sector back to the three year qualification benchmark requirement was not in the best interests of the Montessori movement in New Zealand (Chisnall, 2002). However it was the view of the national organisation (MANZ) that a move to a three year qualification was vital for the long term viability of Montessori in New Zealand. ${ }^{2}$ MANZ responded to the announcement by Dr. Nick Smith for the three year qualification to be the benchmark for licensing (N. Smith, 1999) with support ${ }^{3}$, and recommended Montessori teachers work towards their Diploma of Teaching (ECE) in preparation for the requirement and not to rely on 100 points remaining enough for licensing requirements. 4

However this was not the feeling of all in the Montessori community, there were some who attacked the view of MANZ, arguing the support for the qualification requirement would mean Montessori becoming lost in the tangle of 'state' requirements, losing its distinction and difference, and removing alternative educational choices for parents (Libertarianz Party, 2000; Perigo, 1999). There was also a strong opinion against the requirement voiced in the focus groups held by Nicola Chisnall for her research (Chisnall, 2002).

\footnotetext{
${ }^{2}$ Letter to MANZ members, March 1999, from S. Freeman, President, MANZ, outlining the Association's work towards a qualification meeting both Montessori and New Zealand licensing requirements.

${ }^{3}$ Media Release, 12 July 1999.

${ }^{4}$ Letter to members, July 1999, from S. Freeman, President, MANZ.
} 
The view of the President of MANZ at the beginning of this decade was that the qualification requirement would see the Montessori approach embrace what others had to offer and in turn expand its influence. In particular the move towards a three year degree specialising in Montessori would mean Montessori teachers being taken seriously within mainstream education (Annual Report: Expanding horizons gains acceptability for Montessori, Montessori NewZ, 2000, p. 17).

It was therefore the decision of MANZ to provide a long term solution that would meet the needs of Montessori centres in the future - teachers meeting the DipTch (ECE) requirements and who had a strong Montessori training (MANZ Qualification Committee, 2000). The collaboration between MANZ and the Auckland University of Technology (AUT) come to fruition with the BEd (MECT), a degree in early childhood teaching, specialising in Montessori in the third year, in 2002 (Stott, 2001).

While MANZ worked hard to establish a three year Montessori qualification, they also worked to provide a process for those already holding a Montessori qualification (MANZ Qualification Committee, 2000). MANZ was very aware of the number of Montessori teachers that did not meet the requirement, therefore a RPL pathway was negotiated with AUT. The role of the Qualification committee was to breakdown the most common Montessori trainings into a language recognised by New Zealand training providers, that teachers could then use in their portfolios for their 'recognition of prior learning process' (MANZ Qualification Committee, 2000).

MANZ received 140 expressions of interest in the AUT degree path (Chisnall, 2002). However the conservative recognition given by AUT to Montessori qualified teachers led to a significant drop in interest - the result meant only 20 teachers enrolled in the flexi course pathway with AUT (Chisnall, 2002), with 9 finally graduating in 2005 (Pickering, 2005). 
The lack of enrolments in the BEd (ECT) pathway through AUT and that AUT made a loss from the exercise has meant it is unlikely to be offered again. C. McLachlan-Smith, (personal communication, September 25, 2007).

In the meantime most Montessori teachers, like others in the early childhood sector, have worked through the RPL (recognition of prior learning) process with a variety of early childhood teacher training providers and have or are currently working towards a diploma or degree in early childhood teaching in order to meet the requirements of Pathways to the Future (Ministry of Education, 2002).

\section{Summary}

This study is situated within three contexts; the early childhood education policy history of New Zealand over the last twenty years, the discourse and research relating to quality early childhood experiences for children and the role of qualifications in this, and the history of qualifications and policy within the Montessori community, both internationally and in New Zealand. This literature review has explored these three contexts.

The history of early childhood education policy provides a useful background to both the lead up to Pathways to the Future and the response of the sector. The sector had been pushing for greater recognition of early childhood education within the larger education sector. It has demanded strong and supportive policy statements. The call for longer and higher qualifications for those working with young children has occurred many times over the last twenty years. Therefore a ten year strategic plan, setting a clear and consistent policy and regulatory outline for the early childhood sector, was welcomed by many.

The discourse in early childhood education over the last two decades, within New Zealand, has focussed mainly on participation in high quality early childhood services. 
There has been research specifically looking at this area in New Zealand (Farquhar, 2003; Podmore et al, 2000; Smith, 1996; Smith et al, 2000). All identify teachers' qualifications as having a significant influence on the quality of the early childhood education experienced by children.

The intention to move towards a three year qualification as the benchmark for teachers in early childhood settings was signalled in 1988. However it took another twelve years before the first announcement, which required all teachers in positions of responsibility to have a DipTch (ECE) or equivalent. Following this; in 2002, Pathways to the Future put in place a staged plan towards all teachers to have a DipTch (ECE). The intention and implementation of this is considered in this study.

While this qualification policy requirement has had ramifications for all within the early childhood sector, this study has explored the implementation process for Montessori centres and their teachers only. In order to provide a context for this part of the early childhood landscape in New Zealand this chapter has explored the history of teacher education for the Montessori approach internationally and the early childhood policy decisions over the last twenty years and their implications for the Montessori community.

The findings of this study draw on the literature covered in this chapter, as the unintended consequences of the qualification policy requirement for the Montessori sector of New Zealand are revealed. 


\section{Chapter Three: Methodology}

My study employed an exploratory, qualitative approach; using the analysis of interview and focus group data to investigate the impact of the education policy for qualified teachers in Montessori early childhood centres in New Zealand.

\section{Rationale for Qualitative Approach}

A qualitative approach to research was appropriate for this study; I wanted to capture the impact of the policy implementation on a specific group of teachers within the early childhood sector of New Zealand. "Qualitative researchers generally aim to show something's meaning or significance to particular people or groups of people" intending "to explain events and actions through the eyes and in the words of the people involved" (Hughes, 2001, p.53).

In addition, qualitative research takes an interpretive approach, meaning that researchers "study things in their natural settings, attempting to make sense of, or interpret, phenomena in terms of the meanings people bring to them" (Denzin \& Lincoln, 1994, p.3).

I used teachers' own stories of their experience to explore how the requirement for teachers to have a Diploma of teaching ECE qualification was impacting on Montessori centres. The stories would capture how they were interpreting or making sense of this event in their working and personal lives.

I also wanted to capture the story of those working with the policy at another level; within the Ministry of Education, teacher education, the Montessori sector or as independent observers - how they made sense of the policy development and implementation process. 
Consequently I used a variety of methods "hoping to get a better fix on the subject matter at hand" (Denzin \& Lincoln, 1994, p. 3); interviews, focus groups and data from Ministry of Education statistics.

\section{Interpretive Paradigms}

The researcher frames her approach to her research within a "paradigm or interpretive framework", a "basic set of beliefs that guide action" (Guba, 1990, p.17, as cited by Denzin \& Lincoln, 1994, p.26). Working within that interpretive paradigm then influences how the researcher frames her study determining what questions to ask, how to interpret the data and the form of knowledge produced (Denzin \& Lincoln, 1994; Hughes, 2001).

This study was situated within four interpretive paradigms; critical theory, phenomenological approach, narrative theory and policy analysis.

\section{Critical Theory}

When using a critical theory framework the researcher is attempting to use their "work as a form of social or cultural criticism" (Kincheloe \& McLaren, 1994, p. 263) and "places requirements on the researcher to pursue ethical research principles and to assess research activity in relation to what might be broadly termed social justice concerns (Gewirtz \& Ozga, 1994 as cited by Ozga, 2000, p. 46).

So when undertaking educational policy research one can firstly "draw attention to, and challenge, the assumptions informing policy and it can expose the effects of policy on the ground, in particular where policy can increase inequality and impact unfairly on particular groups. Second, research can set out to explain how injustices and inequalities are produced, reproduced and sustained" (Ozga \& Gewirtz, 1994, p. 123). 
My critical theory research approach (Kincheloe \& McLaren, 1994; Scott \& Morrison, 2005) means I intend to uncover the inequalities and maybe even the privileges and oppression that might exist or develop due to the implementation of this policy.

In addition criticalist researchers "are never satisfied with merely increasing knowledge" they often regard "their work as a first step toward forms of political action that can redress the injustices found in the field site" (Kincheloe \& McLaren, 1994, p. 264). This study sought to uncover the injustices and through the participants, discover possible solutions.

\section{$\underline{\text { Phenomenological View }}$}

Using a phenomenological view attempts to understand the way people have experienced a phenomenon or event. Phenomenologists explore what a group of people have in common in their experience of the event - using their specific statements and experiences to illustrate the event or to discover the "universal essence" of the phenomenon (Creswell, Hanson, Plano Clark, \& Morales, 2007, p. 252).

This study used focus groups to collect the experiences of the Montessori teachers who were working within the policy requirement and capture "what they experienced and how they experienced it" (Moustakas, 1994 as cited in Creswell et al, 2007, pp. 252-3). In addition I used interviews - a key source of data in a phenomenological research approach (Suzuki, Ahluwalia, Kwong Arora, \& Mattis, 2007) to capture a participant's lived experience through their reflections on the event or phenomenon - allowing them to express their views, opinions and experiences; "to uncover their lived world" (Kvale, 1996, p. 1). 
The phenomenological view, according to Moustakas (1994, as cited in (Creswell et al, 2007), means approaching research in the following way; “identifying a phenomenon to study, bracketing out one's experiences and collecting data from several persons who have experienced the phenomenon. The researcher then analyzes [sic] the data by reducing the information to significant statements or quotes, combines the statements into themes" which describe their collective experiences, and then taking those descriptions to identify the "essence of the experience" (p.254).

\section{Narrative theory}

Narrative research involves revealing the stories a participant shares about themselves and their experiences, the way they experience the world (Connelly \& Clandinin, 1990; Riessman, 2002). "Narratives ... provide important insights and understandings into the subjective experiences and understandings of individuals and groups" (Scott \& Morrison, 2005, p. 162).

In this study the main narrative tools used were interviews and focus groups, through an emotionalist perspective (Silverman, 2001, as cited in Scott \& Morrison, 2005, p. 160). This involves producing data that provides an authentic investigation into the participants' experiences.

The participant is the narrator in the stories used in this study. Their stories were captured through a recorded semi-structured interview, then transcribed directly into text. Allowing the interview to progress in a less formal structure provides a 'natural' conversation, which is often viewed as more reflective (Scott \& Morrison, 2005).

Steph Lawler (2002) argues that narratives must "contain transformation, plot line and characters" (p.245). She defines the need for a plot or 'emplotment', and cites Ricoeur, who said a plot incorporates a number of events, disparate ideas or "unintended consequences" into one story (1991, cited in Lawler,2002, p. 245). Lawler argues for a narrative to explore a "transformation" or a change over time (p. 247). 
For this study the event - the requirement to be qualified with a DipTch $(E C E)$ - is the main plot, with the participants' reflections and interpretations of this event and their personal transformations due to this event providing the essence of the story.

\section{Policy analysis}

Stephen J. Ball (1994) has described research in the field of educational policy implementation as a process where it is important to acknowledge and analyse the tensions and "complexity of the relationship between policy intentions, texts, interpretations and reactions" (p.20).

This insight is important to this study because I wanted to capture not only the intentions and views of the policy implementation from those at a policy level but also to find whether their views were similar to or contrary to the views expressed by those experiencing, and consequently those most effected by, the policy requirement.

In addition "there is a pressing need for information on the implementation process per se" (Rist, 2000, p. 1008). In particular there is an important role for the data to be gathered from the "day-to-day realities of bringing a new program or policy into existence. This 'ground-level' view of implementation is best done through qualitative research" (Rist, 2000, p. 1008).

Jenny Ozga (2000) identifies two definitions of educational policy research; firstly, policy research that is "relevant and useful to the policy makers" and secondly, policy research that provides a "critical and independent analysis of education policy making" or "making the policy in education the subject of scrutiny" (p. 4). It is my intention that this study will serve as both. 
Ozga (2000) agues specifically for education policy research in relation to teachers;

By looking at the different models of the teaching profession that are currently available, and by looking at the ways in which teachers have modified and adjusted the historical models .... we can better understand the complex and fluid interrelationships between policy purposes, intentions or planned outcomes, and the interpretation, mediation and enactment of policy 'on the ground'. (p.11)

\section{The Role of the Researcher}

Within the qualitative approach to research there is often a close relationship between the researcher and their study, which needs to be acknowledged. Denzin and Lincoln (1994) argue that "qualitative researchers stress the socially constructed nature of reality, the intimate relationship between the researcher and what is studied, and the situational constraints that shape inquiry" (p. 8).

In this study, there is a close relationship between me, as the researcher, and the 'policy elite' who I interviewed.

As a member of the Strategic Plan working group I was closely involved in the formation of the policy, working alongside Dr. Anne Meade, convenor of the Working group, and Rose Cole, another Working group member. In addition, as a Working group member and as President of the Montessori Association of New Zealand from 1998 to 2000, I regularly met with Ross Boyd in his role as a Senior Manager in the Ministry of Education.

Following the release of Pathways to the Future in 2002 my sons began their Montessori education at a Wellington Montessori early childhood centre. This, and my subsequent role as Chair of the School's Board, has meant a close involvement in the management of a Montessori centre dealing with the policy implementation. My background is as a Montessori early childhood teacher. 
All these things provide me with a strong understanding and connection with the people who told me their stories.

It also meant all participants knew my background and were very aware of my passion and commitment to the Montessori sector of New Zealand. Kincheloe and McLaren (1994) say "critical researchers enter into an investigation with their assumptions on the table, so no one is confused concerning the epistemological and political baggage they bring with them to the research site" (p. 265). Therefore the researcher should acknowledge that their belief systems and political leanings will be caught up in their collection and analysis of the data (Scott \& Morrison, 2005).

The phenomenological view places the researcher as part of the social world they are studying; the assumption being that because the researcher is part of the reality they are studying, their neutrality is impossible. Alfred Schultz (as cited in Holstein \& Gubrium, 1994, p. 138) argues "the safeguarding of the subjective point of view is the only but sufficient guarantee that the world of social reality will not be replaced by a fictional non-existing world constructed by the scientific observer".

Scott and Morrison (2005) argue that under a critical framework of researching "the political project takes precedence over the careful citing and collecting of evidence or data", (p. 49). I acknowledge that I wanted people to see the unfair experience of the Montessori sector in New Zealand, but I wanted to do this via careful collection of evidence and data revealing the story of how the Montessori community responded to the qualification requirement - in their words.

While my close involvement and commitment to Montessori was known to all participants and provided a depth of understanding and knowledge for the analysis, I was very conscious of not letting it speak louder than the participants' voices. 
So I used a narrative analysis framework where the emphasis of the investigation is the story as told by the participants - their personal experiences of the policy intentions and the implementation process (Riessman, 2002).

\section{Method}

This study consisted of five interviews and three focus groups, carried out in Auckland, Wellington and Dunedin.

\section{The Interviews}

The interviews were with five key policy informants; policy makers, independent observers and those involved in teacher education and/or the Montessori sector;

- Dr. Anne Meade, whose involvement in the early childhood sector of New Zealand has been a long and influential one, from the Meade Report and Before Five in the early 1980s through to convenor of the Strategic Plan Working Group. Anne has remained connected to the implementation of Pathways via the Centres for Innovation project in particular. As an independent observer she is able to use her long experience and knowledge of the early childhood sector to critically reflect on how the sector is responding to the Strategic Plan.

- Rose Cole, as Chief Executive of Te Tari Puna Ora O Aotearoa /NZ Childcare Association, was a member of the Strategic Plan Working Group. Since the beginning of 2004 she has held the role of Senior Programme Manager for ECE within the Ministry of Education. This role overseas the implementation of Pathways and other ECE policy initiatives.

- Ross Boyd in his role as a Senior Manager Education Management Policy in the Education Management Policy team had responsibility for all ECE policy development in the Ministry of Education. Ross was one of the senior Ministry officials involved in the Strategic Plan Working 
group. He is currently working in the Department of the Prime Minister and Cabinet.

- Nicola Chisnall has had a long involvement within Montessori education in New Zealand, since 1984. She has been involved with a number of Montessori centres, including starting her own in 1995. Since 2002 she has been a Lecturer at Auckland University of Technology, specifically in the Montessori ECE specialty degree.

- Ana Pickering became the Executive Officer for the Montessori Association of New Zealand (MANZ) in 2002 after 12 years involvement in Montessori education.

$\Rightarrow$ Gathering the data

I knew the five key informants well. I chose to interview them for their knowledge and experience in the formation of the policy or for their knowledge and experience of the general Montessori community of New Zealand. I conducted semi-structured interviews to investigate their thoughts on the intention of the policy and what consequences they had either experienced or seen through the implementation of the policy.

I sent them a letter requesting their involvement in my research in August 2005 (Appendix 2). Included was a consent form (Appendix 3), an outline of my research (Appendix 1) and the questions that would guide our interview (Appendix 4). I followed the letter with a phone call and we arranged a time to meet either by phone or email. The interviews were conducted between September 2005 and May 2006, they were carried out either at the participant's place of work or another mutually agreed place and the discussion was framed around the questions below. Four were done in Wellington, one was conducted in Auckland. 
The nature of the interviews was semi-structured to allow me to "identify a clear list of issues to be addressed and questions to be answered" and be "flexible in... the order in which the topics are considered, and... to let the interviewee develop ideas and speak more widely on the issues raised" (Denscombe, 1998, p. 113).

To provide a framework I sent them the questions we would be discussing (Appendix 4);

- What have been the consequences of the Strategic Plan's policy implementation for Montessori teachers and their centres - both positive and negative?

- To what extent has the Strategic Plan's policy for qualified teachers been able to incorporate the special character of Montessori centres?

It is important here to acknowledge that due to the inductive approach to my research, I began collecting data with "no clear, preconceived view about the significance of that data" (Hughes, 2001, p.53). This became significant because, as three of the informants were directly involved in the development of the policy, I discovered during my first interview the need to explore their understandings of the intentions of the policy requirement and whether through these intentions the diversity of the early childhood sector in New Zealand was acknowledged. I therefore added the following question when we met;

- What do you think were the intentions of the policy for Dip ECE or equivalent qualified teachers in all early childhood centres?

$\Rightarrow$ Organising the data

I tape recorded the interviews which ran for up to an hour and a half. I also took hand written notes. The recordings were sent away to be professionally transcribed. My research grant of $\$ 500$ was used to pay for these and the focus group transcriptions. I checked the transcriptions against the recording to clarify any areas misunderstood by the transcriptionist. The transcripts were then sent to the participants for them to check and return. 


\section{$\underline{\text { The Focus Groups }}$}

I conducted three focus groups, one each in Auckland, Wellington and Dunedin.

$\Rightarrow$ Gathering the data

The Auckland focus group was held in May 2006 and included five participants. The Wellington focus group was held in June 2006, the group included five Montessori teachers. The Dunedin focus group involved two participants in July 2006, with another participant providing information via email. I conducted the focus groups while travelling to Auckland or Dunedin for family reasons.

All participants were Montessori early childhood teachers who were all qualified with a Montessori qualification and had since gone on to obtain their Diploma or Degree in ECE teaching. The participants were drawn from the Montessori community of New Zealand and in order to provide a variety of perspectives from within that community, they ranged from Head teachers to co-teachers to centre managers. The centres were a mix of parent/community run or privately run Montessori pre-schools who cater for 3-6 year old children.

I selected participants based on suggestions from MANZ and from my own knowledge of the community. I rang them to investigate their willingness to be involved and followed this with a letter (Appendix 5), a consent form (Appendix 6), and an outline of my research (Appendix 1). I emailed them over a month prior to set the date, then in the weeks preceding the focus group I emailed the venue, time and the questions that would guide the discussion (Appendix 7). 
The focus-group discussion explored their experience and the consequences of either "upgrading" their own qualifications to the Diploma or Degree in Early Childhood Teaching and/or the impacts on their centre and Montessori programme in having to meet the qualification requirement. It was my intention as facilitator to provide some questions which would spark discussion but to then let the interaction of the group provide deeper insights into the impacts the policy had had on them and their centres (Bloor, Frankland, Thomas, \& Robson, 2001; Wellington, 2000).

Using focus groups of Montessori teachers meant collecting data from one of five contexts defined by Ball (1994) in the policy implementation process the "context(s) of practice". I wanted to record, the "struggle and compromise and ad hocery" that occurs within these contexts (p. 26).

When undertaking group interviews I was aware of the advantages and disadvantages identified by Denscombe (1998). In particular the ability to identify a consensus within the group; which may have indicated a possible pattern or theme. But also the possibility for certain members to dominate with other views not being aired and thus not recorded. This did not occur as the participants within each group knew each other and each member was able to tell their story with support and understanding. This was particularly important as some stories were personal and at times emotionally sensitive.

$\Rightarrow$ Organising the data

The focus group discussions ran for about an hour and were tape recorded and I kept pen and paper notes. In the Auckland group I employed a student to type the conversations into my laptop as the discussion occurred. We decided the priority was identifying and recording the first few words of each participant, as has been suggested by Suzuki et al, (2007). This proved useful when transcribing this focus group myself. 
I decided against having someone transcribe during the focus group for the Wellington and Dunedin groups, and used my research grant for professional transcription services. The recorded focus groups were transcribed into Word documents, which were sent via email or post for the participants to check, change and add to if they wished. All focus group participant details have remained confidential and all names have been altered.

\section{Ethics}

An application to the Victoria University Human Ethic Committee was presented in June 2005 (Appendix 8), with examples of all letters, consent forms and a Research information flyer attached. Ethical Approval was gained 2 August 2005 (Appendix 9).

As this study used an interpretive paradigm it meant not being able to give an accurate account of how the interview or focus data would be used, the participants were instead informed of the nature of the research (Scott \& Morrison, 2005). There is also a risk of researchers "'contaminating' their research by informing subjects too specifically about the research question to be studied" (Silverman, 2000, p. 200).

My ethical approach to this study was "open autocratic" where the "researcher takes responsibility for the collection and subsequent reporting of data "(Scott \& Morrison, 2005, p. 88). However there is also the "open democratic" approach, where the researcher allows participants to be involved in what is and what is not included in the report (Scott \& Morrison, 2005, p.88), while this did not happen within this study, I did recognise a need for two interview participants to see how their data would be used and to therefore consider their initial consent, as suggested by Silverman (2000). In this case it meant them reviewing their initial decision to remain anonymous. 
For these participants seeing how their quotes were to be used and understanding my reason for wanting to identify them resulted in them agreeing to be identified. Therefore I consider my ethical approach to be somewhere between the two identified by Scott and Morrison (2005).

\section{Analysis}

My theoretical framework is an interpretive one, where I tried to avoid, as much as possible, having preconceptions of what I might discover and analysed the data collected through a post-modern paradigm, where "there is no absolute knowledge, no absolute reality waiting 'out there' to be discovered" (Dahlberg, Moss, \& Pence, 1999, p. 23). As Edwards (2001) argued "qualitative research tries to be responsive to what the evidence tells the researcher" (pp. 117-118). My question to guide myself during this time was "What story are they telling me?"

Using a Phenomenological and a Narrative approach to the analysis of the interview and focus group data meant the process involved a mixture of both; Phenomenological - identifying significant statements, uncovering broader themes, and describing the essence (Creswell, 2003; Creswell et al, 2007), Narrative - identifying the plot, setting and the 'transformation' (Creswell, 2003; Lawler, 2002).

My process of data analysis closely followed the "Framework" approach developed by Jane Ritchie and Liz Spencer (2002).

- "Familiarisation" - getting involved in the data. I heard, checked the transcription, read and re-read the text of all data I collected. During this process clear themes were already emerging.

- "Identifying a thematic framework" - identifying and making judgements about the importance, meaning and relevance of the key issues, themes and concepts. Using a 'mind map' I was able to illustrate the themes and how they were connected or not. 
I used colour coding to identify the main themes and then within these further colours were used to identify the plots, sub-plots, settings and transformations (See Appendix 10).

- "Indexing" - identifying the issues and themes within the text. I highlighted the text and used colour post-it tabs, matching the coding in the 'mind map', on the transcripts to organise the text data into groupings; relating to the themes, plots and transformations (See Appendix 11).

- "Charting" - rearranging the text into groups. I placed the post-it tabs on the wall above my desk in a flow-chart/tree system which helped maintain a 'sense of order' though out the data analysis process (See Appendix 12). It helped me group issues together and find patterns. I then used mind maps for each main theme, with specific reference to areas in the transcripts. I then took quotes and sorted them into these key themes.

- "Mapping and interpretation" - bringing together key characteristics and interpreting them as a whole; finding associations, providing explanations and developing strategies for change. By using colours I was able to visually see the associations within the data and when sorting the quotes into themes/chapters I was able to interpret the data further. Further analysis of the data occurred when referring back to the literature.

This approach is consistent with the inductive research methodology, where the researcher has a more "fluid and intuitive" method when analysing the data (MacNaughton \& Rolfe, 2001, p. 12).

Another perspective which provides a useful epistemological window to analyse the data through is critical policy analysis as outlined by Ball (1994). He argues the need to use an analytical method which provides "a mechanism for linking and tracing the discursive origins and possibilities of policy, as well as the intentions embedded in, responses to and effects of policy". Citing Bowe, Ball and Gold (1992) Ball calls this a "trajectory method". This method identifies three contexts of policy-making; "the context of influence, the context of policy text production and the context(s) of practice" (p.26). 
While analysing the texts of the interview and focus group, I discovered both disparities and similarities between these three contexts: the independent observers or teacher educators (context of influence), the "policy elite" (context of policy text production) and the Montessori teachers (the context of practice).

\section{Establishing Trustworthiness}

In this study I use the term 'trustworthiness' as defined by Harrison, MacGibbon, and Morton (2001) where trustworthiness is established by conducting the research to "meet the criteria of validity, credibility, and believability of [the] research" (p.324).

Harrison et al (2001) argue that trustworthiness is inherent throughout the research process and the researcher should consider reciprocity in all aspects of how she or he conducts their research - when exploring the research questions, access to participants, data production, data analysis, and authorising accounts.

In addition qualitative researchers "need to demonstrate that their studies are credible" (Creswell \& Miller, 2000, p.124); to establish validity of the research the research can employ one or more of the following; member checking, triangulation, thick description, peer reviews and external audits. This study has sought to use all of the above in some way.

The nature of the validity procedures is influenced by the paradigm used by the researcher. As this study sits within a critical theory paradigm, the validity procedures suggested by Creswell and Miller (2000), would involve researcher reflexivity, collaboration and peer debriefing. 
Researcher reflexivity involves researchers disclosing their assumptions, beliefs and biases - accepting that the researcher is "part and parcel of the setting, context, and culture he or she is trying to understand and represent" (Altheide \& Johnson, 1998, p. 285). This has been attempted earlier in this chapter.

Approaching this study through a critical theory paradigm has meant my involvement with the participants is a more cooperative relationship - not discovering findings from them but rather with them (Toma, 2006). The involvement of all participants in checking the data and in some cases checking and discussing the interpretation of the data during this study has formed a collaborative relationship between the researcher and participants - this is identified as 'member checking' and is seen as a means to ensure credibility and trustworthiness (Creswell \& Miller, 2000; Harrison et al, 2001).

In addition, the qualitative data of the interviews and focus groups lend themselves to being used alongside other sources of data to "cross-check for accuracy" (Denscombe, 1998, p. 112). To establish an element of triangulation I obtained statistical data produced and analysed by the Ministry of Education (see Appendix 13) - this has been used to provide statistical support to the observations made by some of the participants and provides further credibility to the participants observations (Creswell \& Miller, 2000; Golafshani, 2003).

\section{Summary}

This study took the policy requirement for early childhood teachers to have a Diploma of Teaching (ECE) and analysed its impact on Montessori early childhood centres, through the data collected from the focus groups and interviews. I analysed the transcripts to find themes and similarities, and using the participants own words I have attempted to uncover the core issues surrounding this event. 
My close involvement with the context, culture and participants of this study has meant my interpretations and analysis of the data has been done with a depth of understanding and knowledge. It has also meant I care deeply for the Montessori community of New Zealand and where it will be in years to come. I have therefore used a critical theory paradigm, amongst others, to provide the framework for this study - this has meant my seeking to expose the injustices I see occurring within the Montessori sector of New Zealand.

However I have attempted to use as many quotes as the word limit would allow so the voices of the participants are at the forefront of this study, not just my interpretation. This will allow the reader to relive the experiences with those who have been involved in or impacted by this policy decision. 


\section{Chapter Four: Intentions of the Policy -}

\section{"Why qualify?"}

This chapter outlines the intentions of the policy to have all teachers qualified with a Diploma of Teaching (ECE).

It explores how these intentions would fit into the diverse early childhood landscape in New Zealand. Ozga and Gewirtz (1994) suggest using a critical theory approach when interviewing what they term the 'policy elite' to expose the assumptions informing policy making. The policy elite in this research included key policy informants Ross Boyd (RB) and Rose Cole (RC). While Anne Meade (AM) was a significant contributor to the policy formation and could therefore be considered part of the 'policy elite', her previous and subsequent involvement in the sector also places her as an informed observer - therefore her participation in this research provided a dual perspective. Nicola Chisnall (NC) and Ana Pickering (AP) were informed observers from a Montessori perspective in particular.

In this chapter, according to the interviewees, the main intention of the qualification policy for qualified teachers is to raise the quality of education provision for children in early childhood settings. There are secondary aims, such as raising the standards of professionalism of the sector; and increasing the value of early childhood education.

The chapter explores the policy informants' views of how they saw the policy fitting into the range of early childhood education settings. Their insights provided another view of the assumptions often held by policy makers policy makers "assume a homogeneity in recipients of policy" (Ozga, 2000, p. 23). Or as Anne Meade put it; "it's a "one shoe fits all" policy for teacherled services." (Interview 3, p.2, line 63) With this in mind, I wanted to explore the policy's impacts on the sector as seen by the interviewees. 
Had they assumed the teacher qualification requirement would impact all within the sector in the same way, or had they noticed unintended consequences from the policy and, if so, what measures were made to accommodate or prevent these?

\section{The Best Intentions}

The key policy informants were well aware of the research into quality, and the factors that contributed to good outcomes for children.

I was very well aware of the research evidence that quality is strongly associated with the training of teachers and getting qualified .... So, we were looking to lift quality. (Anne Meade, Interview 3, p.1, lines 413)

That the research bore out that you get better quality outcomes for children when you have qualified teachers in early childhood centres. So it's part of the structural changes that they made under the quality goal. (Ana Pickering, Interview 4, p.1, lines 5-7)

One of the key ways of improving quality in early childhood seemed to be ... the Iron Triangle ${ }^{5}$ - the teacher ratios and groups size... Increase the number of teachers. Then you would increase the level of quality teaching in a service. (Rose Cole, Interview 2, p. 1, lines 31-34)

In addition Ross Boyd and Nicola Chisnall held the view that the push for qualifications was also an industrial and political move from within the sector - a move to professionalise early childhood teachers. Both believed this would mean better early childhood provision for children, alongside an increase in the recognition and valuing of the early childhood teaching profession.

I think it had been a move from the profession ... a long way back. In terms of professionalising early childhood teaching ... It was a very political move from within the profession; it was a ground-swell from within. (Nicola Chisnall, Interview 5, p.1, lines 4-6)

\footnotetext{
${ }^{5}$ The 'Iron Triangle' refers to three most important structural variables of quality early childhood education; adult-child ratios, group size and staff training, education and experience. (Smith, 2000)
} 
Part of it was industrial. ... by putting in place a three-year qualification requirement which was professionalising the sector if you like, and what would follow from that was more money, for teachers, ... then coming on top of that, were the kindergartens winning pay parity. And then the rest of the sector could also see okay, if we get our teachers up to that same qualification level, then we can achieve pay parity as well. (Ross Boyd, Interview 1, p.2, lines 56-63)

This story of political and industrial struggles in the early childhood sector has been told by others (Chisnall, 2002; Dalli, 1993; Dalli \& Te One, 2003; Meade, 1990, 1994, 2000; Meade \& Dalli, 1991; Mitchell, 1995, 1999; Wells, 1991), in particular Helen May (1990, 1992, 1997, 1999, 2001) who identified the disparities between 'working' in childcare (care, baby-minding) and 'teaching' in kindergarten (education). Even when the two were brought together under the umbrella of the Department of Education with the Before Five policies in 1989, and with the introduction of a three year training for both childcare and kindergarten teachers in 1987, there was still a long battle for recognition of the educational role of childcare and therefore the importance of qualified teachers working with children in that part of the sector (Early Childhood Group, 1994, Early Childhood Education Project, 1996, May, 1996). The 2002 qualification requirement and the final move towards pay-parity, beginning with kindergarten teachers in 2006, have been the most recent steps in that process.

Helen May (1997) noted how the political fight for better training and therefore higher wages was closely linked to the debate around the "worth and status of early childhood teachers" (p. 7).

Ross Boyd commented as follows:

I think that people on the [Strategic Plan] working party - whether consciously or sub-consciously - were trying to upgrade the position of early childhood education in the education hierarchy, so it was seen as something that's significant. There's very much - and a lot of this has gone away with the qualification changes - there's very much a 'poor cousin' sort of thing ... early childhood was underfunded, under-recognised, under-valued and early childhood teachers weren't seen as being on the same professional level as primary teachers or secondary teachers. And now, increasingly, they are. (Ross Boyd, Interview 1, p. 2, lines 72-79) 
Boyd believed that the early childhood teaching profession and therefore early childhood in general was under valued, and that the qualification requirement was an important part in turning this perception around.

The intention of the policy requirement for all teachers to be qualified was for, above all, higher quality early childhood learning environments for children. The move was seen by the sector as also bringing a higher level of professionalism; better wages, even pay parity with the other education sectors, better working conditions and better recognition of the field of early childhood teaching. And this in turn would all help raise the profile of early childhood education.

\section{A Policy Shift}

As outlined previously the move towards a three year qualification for early childhood teachers was a roller-coaster ride for many in the sector. Having to deal with the "moving frontiers" (Dalli, 1993) of the qualification requirements was frustrating and created what May $(1997$, p.11) referred to as a "shambolic" and chaotic situation during the 1990s. So it was not surprising that many within the sector welcomed the 2000 announcement. In addition the previous policies, such as 'licensing points', and the "Quality Funding" package of 1996, had not produced the desired increase in qualified teachers:

there wasn't sufficient response to the financial incentive which had been put in place. (Ross Boyd, Interview 1, p.2, lines 46-47)

After the points system had been in place, and we explored the consequences of that system, it seemed like it wasn't helpful for improving quality in centres. In some centres it would have been, but it hadn't been widely successful. When the government of that day recognised that they had put a policy in place that really wasn't working all that well, they put in the quality funding to try and get people to finish qualifications. (Anne Meade, Interview 3, p.1, lines 16-19) 
According to Nicola Chisnall, within the Montessori community the points system provided an excuse to avoid doing the DipTch (ECE) in addition to their Montessori training;

you know my story in terms of the nineties and the hiccups that we had in the Montessori movement, because of the points system. That gave people a way out. (Interview 5, p.1, lines 12-14)

The points system allowed for Montessori trained teachers to accumulate a variety of courses that added up to enough licensing points for a position as 'person responsible'. This was contrary to research clearly identifying the importance of a coherent three year qualification and the link to quality provision of early childhood education (OECD, 2001; Whitebook, 2003a, 2003b). New Zealand research indicates a strong correlation between teachers having training of 2 or more years or at a three year Diploma level, and higher quality experiences for children (as cited in May, 1997; Podmore, Meade, \& Kerslake Hendricks, 2000; Smith, 1996).

The Labour Government's response to the points system and 'quality funding' was to change regulations to require all early childhood teachers to have the DipTch (ECE) or its equivalent. Some see it as a long awaited benchmark which raises the early childhood sector alongside the professional requirements of the other educational sectors and meets research indicators (Bruce, 2004). This was also the view of most of the interviewees;

I think that Government was very, very sensible in setting the stage and saying "right, this has to happen", and 2005 was the first step. We had to have this qualification as a minimum. So then the push went on. And people started to think, "Okay, they're really serious. We have to do it". And I think now, the expectation is there. ... I think, I hope, it's in the psyche now and that people understand that's how you become an early childhood teacher. (Nicola Chisnall, Interview 5, p.1, lines 14-20)

You need to have a vision to aim for, to get to, to enable the change to happen. Because if you set your sights too low, then you'll only get half way to where you're going and that won't be enough. (Rose Cole, Interview 2, p.2, lines 50-52)

And the other advantage of regulation is that it sends very strong signals about "we are serious about this. We are so serious about it we are going to make it a base requirement in regulation to do it." 
And provided that they give sufficient warning for people to respond to that, then it's usually quite effective, because people know that it's black and white. They know that if they don't meet that requirement, they'll close. Whereas if you just do a funding incentive, then okay, they get less money, but they can still operate. (Ross Boyd, Interview 1, p.2, lines 47-52)

As Smith et al (2000) has noted it is the structural components of quality in early childhood provision, including the teachers qualifications, that can be regulated and therefore controlled. However as Ross Boyd identified, having the requirement as a regulation meant it was very black and white and there was no room for exceptions. He said this meant significant pressures for the sector;

One of the problems with using regulation is that it's very black and white. It has to be ... a regulation has to be ... you have to have this, to be a person responsible, so there can be no exceptions. And that makes it harder on the sector because you can get a centre where they may have a perfectly capable person responsible, given their experience and mix of qualifications. But if they haven't got a diploma of teaching in early childhood education, then they can't be considered to be a teacher at the centre. And there is not room for the government to say, oh, okay, in this case its okay. (Interview 1, p.1, lines 31-37)

Others see the qualification requirement as an unrealistic expectation of a sector continually struggling with low funding and a shortage of qualified teachers (Thorne, 2004).

They argue the regulation is too heavy handed and warn that an unintended consequence could be smaller centres forced out of the sector (LaRocque, 2003, as cited in Dalli \& Te One, 2003, p.188).

However with the acceptance by many within the sector that there needed to be qualified teachers working in early childhood, the decision became how many needed to be qualified within an early childhood centre. 


\section{All, or a 'critical mass'?}

The initial requirement, from 1 January 2002, was for any person new to the position of 'persons responsible' to have the DipTch (ECE). This was announced by Trevor Mallard in November 2000 (Mallard, 2000b). The requirement would then move to those currently in 'person responsible' positions and would come into effect from 1 January 2005. This discussion preceded the formation of the Strategic Plan working group, however the group did discuss whether that initial 2005 requirement was enough, or as Ross Boyd put it;

It became a question of "okay, is quality represented by having just the person responsible qualified? Or do you need a critical mass of the teachers qualified? Say, 50 or 60 per cent. Or should all early childhood teachers be qualified?" (Interview 1, p.3, lines 85-87)

Rose Cole argued the proportion of qualified teachers needed to be $100 \%$;

[my organisation] supported 100 per cent qualification for teachers teaching in early childhood. (Interview 2, p.1, lines 8-10)

In the professional teacher quarters, there was very, very strong support from the colleges, from the unions and our organisation to aim for that 100 per cent target. (Interview 2, p.2, lines 63-64)

Anne Meade felt it was more important to aim for a critical mass of qualified teachers;

For me, personally, and looking at the research, centres need to have a critical mass of qualified teachers. I did not, and still do not, think it has to be 100 per cent qualified, but centres certainly have got to have a qualified critical mass - and I mean the majority. (Interview 3, p.1, lines 21-23)

In response to a serious concern at the slow rate of teachers becoming qualified, and after much discussion, the Working group agreed on $60 \%$ of staff to be qualified with a staged process to allow centres to work towards the requirement. 
The Strategic Plan Working group produced their Final Report in October 2001;

By 2005, all "persons responsible" would be registered teachers. By 2007, half of the staff in each centre would have a Teacher Registration Board (TRB) recognised qualification and would be registered, and other regulated staff would be in training for a TRB recognised qualification. By 2010 , at least $60 \%$ of the regulated staff would be registered teachers and the other regulated staff would be in training for a TRB recognised qualification. (Early Childhood Education Strategic Plan Working Group, 2001, p.20-21)

The Government responded by changing the requirement to $100 \%$ with a revised staged process, as outlined in Pathways to the Future (Ministry of Education, 2002);

- "2007 50 percent of regulated staff in every teacher-led service are required to be registered teachers

- 201080 percent of regulated staff in every teacher-led service are required to be registered teachers

- 2012 all regulated staff in every teacher-led service are required to be registered teachers" (p. 14).

The staged process was agreed to with the Minister amongst a smaller "technical working group". But Ross Boyd says it was a push from Government based on the following argument;

... that if you want a high-quality service, then you're going to have to have all the teachers qualified. All the teachers are interacting with the children, I mean, to some extent you can run an argument to say "why should you have only 60 per cent of early childhood teachers qualified, when we require 100 per cent of primary teachers to be qualified. What are you saying here? ... They're doing a job that is difficult - they might have to be better teachers, in fact, than primary teachers, so don't they need at least the same level of qualification?" (Interview 1, p.3, lines 102-108)

Following the release of Pathways to the Future (Ministry of Education, 2002), the Minister announced a compromise to the requirement for $100 \%$ qualified and registered teachers proposed in the Strategic Plan. The requirement for 2012 moved to $80 \%$ qualified with up to $30 \%$ 'in training'.

This last minute change was in recognition of the strong tradition of in-centre training for a lot of early childhood teachers (Ministry of Education, 2004). 
As noted by Ross Boyd, the requirement for $100 \%$ of the early childhood teaching workforce to be fully qualified by 2012 was a real risk to in-centre training;

Well, I think as it was initially set, with all teachers having to be qualified, registered teachers by 2012, there was quite a real risk to centre-based training - which has been mitigated to quite a large extent by allowing 20 per cent of those teachers to be in-training. Because what it would have meant is that all training would have to become pre-service. And ... if you couldn't employ people who weren't fully qualified, then you can't have students. And a large proportion of the training in early childhood does happen in centres. (Interview 1, p.8, lines 296-301)

\section{The Struggles to Meet the Requirement}

Within the Strategic Plan Working Group, a small group argued that the sector needed time to meet the target, and therefore, a staged plan was imperative. In addition, preliminary data prepared by the Ministry of Education, and presented to the Working Group, showed that, with the attrition and new graduate rates as they were at 2001, it would take 23 years to meet the goal of $100 \%$ qualified and registered staff by 2010 . Therefore, even at the time of setting the requirement, there was a very clear probability that the sector would struggle to meet it without significant interventions. It is therefore not surprising that all informants agreed the staged process was absolutely essential;

It was clearly impossible for the sector to meet the requirement to have all their teachers qualified any faster than that. In fact, there was quite a lot of discussion in the working group, that even that path that was set was too ambitious. You couldn't do it. And that was based on the reasonably slow uptake of qualified teachers in the years before that, ... And everybody could see ... and the Ministry was doing quite a lot of modelling, that there would have to be a huge increase in teacher supply, even to meet the sort of the staggered dates that were set out in the strategic plan. (Ross Boyd, Interview 1, p.3, lines 117-124)

It was impossible to do it without a staged process. (Nicola Chisnall, Interview 5, p.1, lines 11-12) 
Because they knew that they weren't going to get enough staff for centres if they had brought it in ... that it had to be brought in gradually, in order for people to be able to respond and upgrade their qualifications. (Ana Pickering, Interview 4, p.1, lines 9-11)

The supply side - to use economic terms - was not good enough to be able to just go for the ultimate goal in one go. It needed to be staged. (Anne Meade, Interview 3, p.1, lines 26-28)

Definitely a staged process. It was difficult enough for services to get to 2002, and having a staged process out to 2012, with a review of the numbers, that provides sufficient ways for us to actually [say] ... how is the sector doing? (Rose Cole, Interview 2, p.3, lines 94-96)

In recognition of these pressures, the Ministry of Education put in place various scholarships and initiatives to help centres and teachers meet the regulatory requirement (Mallard, 2005). These included incentive grants, more funding attached to qualified teachers, and support to tertiary institutions which put in place processes for recognition of prior learning. Ross Boyd identified some additional initiatives;

There were another lot of incentives put in place towards the end of last year [2004] - relocation grants, overseas inducements to get teachers to come back from overseas, all that sort of thing. (Interview 1, p.4, lines 137-139)

While the early childhood sector has been positive about the direction of the Strategic Plan (Ministry of Education, 2001), as a policy-objective, it is always desirable that the implementation has as few negative effects as possible. As McNeil and Coppola (2006) argue policies do not impact recipients equally, in fact they often affect some unfairly.

It is conceivable that a policy of this magnitude imposed incorrectly could leave experienced teachers without jobs, early childhood centres without teachers, and children and parents without the early childhood centres of their choice. For example, for one Montessori teacher to meet this requirement the only Montessori centre available in Whangarei had to close, because there were no other Montessori qualified teachers available to run the class while she trained. S. Balluet, (personal communication, July 26, 2004). 
For Montessori early childhood centres, the pressure to find a qualified teacher included the very real possibility of them closing. For one centre this was the main reason identified for discontinuation as a Montessori centre (see Chapter 7). This was also the case for centres within the mainstream one such centre; Kawhia Preschool took the Ministry of Education to court, arguing for exemption from the teacher qualification requirement. While the Preschool lost, the judgement (26 November 2004), suggested that probationary licenses be granted for 12 months, and that these should not be limited to the start-up of new centres, nor should they be only granted once (Young, 2004).

In response, on the 2 December 2004, only four weeks to the 1 January 2005 deadline, the Minister, Trevor Mallard changed the provisional licensing regulations, allowing for the granting of provisional licenses for up to 12 months to centres unable to meet the qualification licensing requirements (Mallard, 2004);

And the Ministry's response to the 2005 milestone was reviewing how ... how's this going to be met? ... you're keeping those goals of participation and quality. What you don't want to do is shut down 500 centres ... so there was a process that was set in whereby, there was a change in how provisional licensing was used. So that services who might just have got there, or they're nearly, nearly there ... the Ministry can work with them, to ... quality assure them through their licence, over a different timeframe ... it's usually three months, but some services need a longer timeframe. (Rose Cole, Interview 2, p.5, lines 189-195)

The Ministry was looking at all that data to see how many centres were at high risk. And those are the ones they concentrated on ... Although, to some extent, what also happened there was a regulatory change to allow a provisional licence to be put in place for longer. So that bought some time, if you like, for those centres. Provided that they looked like they were going to be able to meet the regulations and the new requirement within a year, then they could go on a yearlong provisional licence, to give them time to get their teacher qualified. (Ross Boyd, Interview 1, p.6, lines 224-230) 
Anne Meade was 'thankful' for the Strategic Plan's goal for an increase in participation and access.

It's fortunate that there is that increase in participation goal because otherwise there might not have been so much movement on government policy, or government implementation policy. The use of provisional licences is one step. The government is not too keen on centres closing, unless they are really poor quality. (Interview 3, p.3, lines 108-110)

For some Montessori centres the use of provisional licensing was helpful, as noted by Nicola Chisnall;

I mean there's been a lot of anguish. Last year (2005), people couldn't find people to fill the 'person responsible' role, and some centres had to close. Even though the Ministry was helpful, there was support, I guess that's something. People who had to have provisional licenses to keep going while they were getting through. (Interview 5, p.3, lines 101-104)

The Strategic Plan Working Group was well aware of the difficulties for centres in finding qualified teachers. The numbers given to the group showed the projected length of time it would take to meet the requirements (Meeting Notes, 2 May, 2001). Others have also stressed the shortage of teachers was making it extremely difficult for centres to employ qualified teachers with a DipTch (ECE) (Meade, 2002, Thorne, 2004). Since the 2002 policy requirement the Ministry has had to make a number of announcements to release the pressure on centres; for example, the exemption to teachers needing to be registered by 2007 , and the granting of 12 month provisional licences.

While these measures have been helpful, the shortage of teachers has meant difficulties for many centres - in particular those who need Diploma qualified teachers in addition to other training specific to the character of the centre, such as Montessori ${ }^{6}$. This raises the issue of whether the policy requirement has been implemented in a way that ensures all services in the early childhood sector are on equal footing when trying to meet this

\footnotetext{
${ }^{6}$ The NZCER national survey conducted in $2003 / 4$ stated $43 \%$ of centres had difficulties in finding teachers for any vacancies and $57 \%$ of Education and care services had a "Limited number of suitable applicants" (Mitchell \& Brooking, 2007)
} 
requirement. The diversity of provision in the early childhood sector will mean there will be diverse abilities in meeting the policy requirement.

The assumption that all within the educational sector will be affected by a policy in the same way has been identified by McNeil and Coppola (2006) they state one of four misconceptions about the nature of policy is that "policies can be written and implemented in ways that are technically universal and therefore culturally neutral" (p.686). I would argue that the experience for Montessori centres in meeting the qualification requirement has shown that policy implementation cannot be philosophically neutral either.

\section{Commitment to Diversity of the Sector - The Trade-offs}

The diverse nature of the early childhood sector in New Zealand is often celebrated and admired internationally (Meade, 1994; Meade \& Dalli, 1991; Keesing-Styles, 2003). In addition the Minister of Education (1999-2005), Hon Trevor Mallard (2000a) claimed the diversity of the sector is a strength - "Your sector is diverse. It is what makes it special. It is also what makes it one of the most complex areas of policy development" (Mallard, 2002). It was therefore a significant reason for his decision to create a large working group (31 people) who represented as many of the varied early childhood educational provision as possible, to create the sector's 10 year Strategic Plan.

Consequently the Strategic Plan Working Group were very committed to ensuring the Strategic plan protected the diversity of early childhood care and education service provision available to young children and their families and made clear statements of commitment to the provision of a diverse early childhood sector in New Zealand such as; "Families and communities have equity of access to a diverse range of quality EC services that meet their needs" (Early Childhood Education Strategic Plan Working Group, 2001, p. 9). 
Within Pathways to the Future (Ministry of Education, 2002) this commitment does not appear to be as clearly stated. While there are statements that acknowledge the diversity of the sector and the choice available to families accessing early childhood services ( $p .5$ ) there do not appear to be strong statements assuring the maintenance of those choices. In fact the "diverse sector" is identified as including Education and Care centres (who provide either sessional, all day or flexible hours, may be privately owned, community based or part of a larger organisation, and include Maori immersion and Pacific Island centres), Home-based services, Kindergarten, Kōhanga Reo, Licence-exempt playgroups, parent support programmes, playcentres and the Correspondence school (p.5) - there is no mention of Montessori or Steiner centres. This raises the question of whether Montessori centres were even considered in the formation of the policy. Accepting and acknowledging diversity of provision does in principle establish a strong argument for Montessori centres to participate as equals in the sector.

When asked whether during the formation of the policy for the qualification requirement there was any acknowledgement of how it might affect the diverse nature of the early childhood sector, the informants were divided.

For some of the key informants, their view of 'diversity' was of the difference between teacher-led centres and parent-led centres alone, and as the qualification requirement was for the teacher-led sector only, they felt the policy had therefore acknowledged the differences in the sector.

The government never intended to decrease diversity by pushing out those services that weren't based on teacher qualifications. (Ross Boyd, Interview 1, p.5, lines 173-174)

There was some recognition of diversity in that categorisation, which has been a mixed blessing ... the so-called teacher-led and parentled categories of services. (Anne Meade, Interview 3, p.2, lines 3940)

the intentions to retain diversity are there. (Rose Cole, Interview 2, p.5, line 167) 
Both Ross Boyd and Rose Cole felt diversity within the teacher-led services had been provided for within the qualification requirement. There was provision for an 'equivalent' qualification, and teachers could combine the DipTch ECE with any other qualification that was relevant for their centre.

The requirement is to have a Diploma of Teaching (ECE) or equivalent. And so that is meant to cater for the diversity as well. (Ross Boyd, Interview 1, p.5, lines 175-176)

By making broad targets, and not prescribing what that meant. By taking a view that this is where the benchmark ... this is an approved qualification. And provided that you have that approved qualification, you have whatever ... else you want ... so it wasn't prescriptive. (Rose Cole, Interview 2, p.3, lines 112-115)

However both respondents accepted that the qualification requirement, especially in the context of additional policy changes could affect the diverse nature of service provision in the sector in negative ways.

But there is no catering for diversity in saying that, okay, we're going to have a Diploma of Teaching (ECE) and a teacher-led service, and we're going to allow other things that are completely different, as well. ... Which was what was happening under the points system, but doesn't under this system. And that's, I suppose, one of the tradeoffs of having a clear benchmark in terms of quality through a qualification. What you're trading off are other things which may meet the same quality, but aren't recognised because they're not a credential. (Ross Boyd, Interview 1, p.5, lines 176-181)

One of the complexities of the strategic plan process that we were going through is retaining diversity. (Rose Cole, Interview 2, p. 2, line 66)

Commenting on the qualification requirement, Keesing-Styles (2003) raises her concerns that those deemed "qualified" may not "be truly equipped to teach effectively in diverse contexts"; and that the current definition of a "qualified teacher" is inadequate for the diverse early childhood sector in NZ (p. 236). Anne Meade, Ana Pickering and Nicola Chisnall agreed, clearly stating their view; the diversity of provision within the teacher-led sector had not been accommodated in the qualification requirement;

Possibly the only variation is home-based. But generally, it feels as if it's to make education and care centres, childcare centres, more like kindergartens. ... the model of [qualified] kindergarten teachers was adopted for all teacher-led services, without too much notice being 
given to diverse sub-sectors ... it has been problematic for Montessori, it's been problematic for Pasifika centres that it's a "one shoe fits all" policy for teacher-led services. (Anne Meade, Interview 3 , p.2, lines 58-63)

The Minister came to $\mathrm{ECAC}^{7}$, and he acknowledged the diversity of early childhood, and how wonderful it is. But I don't think that they thought through that that would be a result, that there would be less diversity... They were very intent as a sector on having a single qualification, and perhaps they thought with the AUT degrees, that those kinds of specialty things could be built within that structure of that single qualification. (Ana Pickering, Interview 4, p.1, lines 18-21)

Nicola Chisnall's view is that while the government and policy did not cater for diversity - the sector has been able to interpret the policy to meet the needs of the different types of provision.

I still see Montessori as distinct. But, because of the way in which we've developed the programme, at AUT, I think we have an integrated approach. And so in that sense, yes I think you can ... you can provide for the diversity together.

Okay. So did the policy do that? Or do you think AUT has done that?

We've interpreted the policy ... yes; it probably has not been the policy... I mean, there's not been a sympathy towards Montessori needs. (Interview 5, p.2, lines 47-52)

However Anne Meade believes this isn't enough;

I can remember us talking about the provision of training for both Pasifika services and for Montessori being concentrated in the Auckland scene, and that's unhelpful to Montessori and Pasifika services in other parts of the country. When government takes its hands off - which it did take its hands off - directing what tertiary courses would be provided where, it leaves the marketplace to work amongst the teacher education suppliers. It's been really unhelpful, because it leaves communities, such as the Montessori community, having to lobby and find somebody or somebodies to provide their teacher education course. The tertiary policy has got a weakness there, in that there isn't an interlocking tertiary policy to try and help on the supply side. Government is left with tools like scholarships and curriculum compliance and accelerated training for people who are already graduates.

Because there hasn't been any incentive for teachers colleges to diversify what they provide?

The only time the government has intervened is in putting up some money for doing the development phase for three teacher education providers to get primary teachers to upgrade to early childhood

\footnotetext{
${ }^{7}$ Early Childhood Advisory Committee (ECAC) represents all areas of the early childhood sector and is used by the Ministry of Education to consult the sector on early childhood issues.
} 
qualifications. But it's very rarely done that. It's making no moves, really, to interfere much in the market. It is leaving providers to make their own decisions. (Interview 3, p.2-3, lines 69-83)

This was the experience for the Montessori community in New Zealand. As part of a long term approach the national association (MANZ) approached possible tertiary providers to work alongside them in creating a specialised Diploma or Degree in Montessori that also met the requirements for a DipTch ECE. In 2000 MANZ went into partnership with the Auckland University of Technology (AUT) to provide a Bachelor degree in early childhood teaching with Montessori as a specialisation in the third year (Chisnall, 2002; Reid, 2004).

The BEd (Montessori Early Childhood Teaching) received final approval in 2001. This was worthy of celebration after the long and sometimes tortuous journey taken by the Montessori community through the qualification difficulties of the 80s and 90s (Chisnall, 2002).

\section{Summary}

This chapter has explored why the policy to have all early childhood teachers qualified was put in place. The main reason was linked to research showing the correlation between teachers' qualifications and quality practice in early childhood settings. This identification of the policy intention as being in the best interests of children raises an interesting dilemma.

McNeil and Coppola (2006) contend that when undertaking policy analysis one misunderstanding often revealed is that educational policies are "always constructed ... with the best interests of children in mind" (p.687), however because of the complex nature of the education landscape, there is often an unequal power relationship between those who design the policy and those who are impacted by it, and this can therefore influence whether the policy does, in fact, produce results that benefit children and, I would add, their families. 
This dilemma is explored through out the next three chapters: Has the qualification requirement impacted positively on the programme offered in Montessori centres in New Zealand? Or, has the policy had unintended consequences, not always in the best interests of children and their families?

It is argued that investigating the lived experience of those affected personally by a policy is vital (McNeil \& Coppola, 2006). In Chapter 5, I explore exactly this in the impact of the policy requirement on Montessori teachers who have needed to do additional training to meet the qualification requirement. Three focus groups revealed both similarities and disparities to the intentions identified by the interviewees.

Research has identified teachers' qualifications as one of the main structural components of quality provision and therefore able to be regulated (Smith et al, 2000). The Labour-Alliance Government's commitment to regulating for qualifications has been welcomed by the sector, after the numerous tries at raising the number of qualified teachers in the sector through quality funding initiatives and the licensing points system did not work. However while the push for $100 \%$ and the ideological drive for all to be qualified within a short time frame had the best of intentions - the pragmatics of the sector has meant a number of shifts or even 'back-downs' by Trevor Mallard over his five years as Minister of Education since the policy was announced in 2000. As Ball (1994) has said there is also "ad hocery [and] negotiation ... within the state, within the policy formation process" (p.16).

The shortage of qualified teachers has been the main hurdle and for many centres they needed time to train their current teachers to the new requirement. These two issues become even more apparent in Chapter 6 where the impact on Montessori centres is explored in more depth through the focus group data. 
Two of those interviewed, Ross Boyd and Rose Cole, had an in-depth knowledge of the policy formation, and I would therefore put into the category defined by Ozga and Gewirtz (1994) as the 'policy elite'. They also revealed their assumptions of how the policy would fit into the sector; identifying the view that the teacher-led part of the sector would somehow manage to fit into the defined required 'qualification', a good example of the misunderstanding identified by McNeil and Coppola (2006) that policies are written and implemented in "technically universal and therefore culturally (or philosophically) neutral" ways (p.686). This impact on the diversity in the sector is revealed in the struggle the Montessori community is experiencing in finding a way to meet both the qualification requirement and their desire to protect the authenticity of the Montessori approach. This is explored in more detail in both Chapters 7 and 8 . 


\section{Chapter Five: Getting Qualified - The Experience for Individual Teachers}

The policy requirement for early childhood teachers to be qualified with a DipTch (ECE) was developed with the intention to increase quality early childhood education experiences for young children. The policy was advocated for and welcomed by the sector when announced in 2002 (Dalli \& Te One, 2003; Ministry of Education, 2001). This Chapter will show that while many Montessori teachers were resistant, some welcomed the move towards a more professional sector. They saw the professionalisation of the sector as a chance to raise their pay and work conditions and also the profile of early childhood education as a whole. Once they began any additional training, they appreciated the chance to increase their skills and knowledge as early childhood practitioners. However the process of training was not without pain and frustrations.

In this study, the Montessori teachers involved in the focus groups held a Montessori qualification and had gained a DipTch (ECE). Many were veteran teachers holding positions of responsibility, owning or running a Montessori centre. Their experiences reveal the highs and lows of becoming 'qualified' - the resistance, frustrations, personal sacrifices and the positives of doing additional training.

In this chapter, the data from the three focus groups is discussed. These groups were held in Auckland, Wellington and Dunedin. They included Montessori teachers from a variety of backgrounds, with a range of experiences. They held similar or varying positions but they all shared the experience of having to implement this policy requirement in some way. They were all affected by the policy directly and as their stories show; the policy requirement raised both positive and negative consequences for them and their centres. This chapter and the next two explore the inequalities that often occur in the implementation of a policy - impacts on one part of the sector that were not predicted in the policy's formation. 
In fact this is one of the misunderstandings of educational policy; that policy will affect all recipients equally (McNeil \& Coppola, 2006). And to truly understand whether this is the case, policy impact studies must explore the "unofficial" version of the policy implementation from those directly affected by, in this case the teachers (McNeil \& Coppola, 2006, p.681).

As discussed in Chapter 2 many teachers rode the qualification roller coaster through the 1980s and 1990s, and gained equivalency through the 'grandparenting' system. If they entered the profession in the 1990s, they had the choice of the licensing points system, or to undertake an additional three years of training for the DipTch (ECE). Many chose the former option enrolling in short courses to collect 'licensing points' to enable them to continue as the 'person responsible' (Chisnall, 2002).

Consequently by 2000 there were still a large number of experienced Montessori teachers who would need additional training (over and above that already undertaken for licensing points) in order to meet the new requirement. With many having already worked hard over the previous years to gain enough licensing points to be the 'person responsible', the prospect of further training to get 'fully qualified' yet again was not received enthusiastically.

\section{Frustration - The Goalposts Move Again.}

Many Montessori trained early childhood teachers were frustrated to be once again asked to meet a new requirement.

Rachel - I did the three years and I have to say it was like "I really don't want to do this". I felt really forced into it - really resistant ... But it was that ... that feeling ... that the goalposts are continuously moving, and what's going to be next? ... And part of me just thinks, great, that's really good for Early Childhood and really good for us, as teachers. But the other part is going "enough's enough", ... And understanding that some people, just at this time of their life, really don't want to be doing that ... some people who ... were going to end up not having a job because they just couldn't face doing three years of a degree. (FG 2, lines 378-387) 
Judith - Well, I didn't want to ... I didn't see why ... I had primary, so I had all the child development, all that sort of what-have-you ... but I knew if I was going to stay working with children, it would be Montessori. So I did put it off, for years and years and years, until finally, I don't know really what pushed me ... or not pushed me, but made me say ... I suppose part of it was well, if I don't, I couldn't go anywhere else. (FG 2, lines 365-370)

Amelia - I was outraged. Because I think I've worked so hard ... I had a degree. I had a Montessori Diploma. l'd done my licensing points. And they came and said "no, no, we're going to change the rules". Take the rug from under you. And now you have to do this. And I felt that they wouldn't do that to a male profession. It's predominantly female. (FG 3, lines 427-432)

\section{Resistance}

These feelings are not surprising. Helen May (1996) argued 10 years previously, there was already a feeling of "weariness and mistrust" within the sector over any announcements on qualifications in early childhood (p.1).

The sector was feeling jaded and victims of the "mish mash chop change" policies of the 1990s (May, 1996, p.1). When the announcement came in 2000 for all 'persons responsible' to be qualified with a DipTch (ECE) or equivalent by 2005 , there were strong pockets of resistance amongst the Montessori sector.

Many felt defensive, believing that they already saw themselves as qualified. Nicola Chisnall identified the resistance as a product of the 'training' process in Montessori that leads Montessori teachers to believe their qualification is all they need.

I think there was certainly so much resistance in Montessori. I think they felt really challenged. .... and I guess that's part of the 'training' process in Montessori. I use that word advisedly. That people were told this is all you need, a (Montessori) diploma. You know what you need to know to teach in a Montessori sense, and certainly we were told to keep on studying, but in terms of preparation, this is what you need. I don't know, was that your experience? It certainly was mine! And so you felt a great affront that you were being told that you needed to do more study and you weren't 'sufficient'. I think that's been part of the resistance. (Interview 5, p.3, lines 87-92) 
This has been noted by Chattin-McNichols (1992, as cited by Goffin \& Wilson, 2001, p. 61), that many Montessorians feel that their training has provided them with everything they need to know about children and teaching and they have no need to know about other ideas or approaches.

All the teachers in the focus groups had Montessori qualifications originally; they have all either gained equivalency through the 'grandparenting clause' in the early 1990s or were required to go through a 'recognition of prior learning' (RPL) process. RPL was available to practitioners with licensing points wanting to gain a diploma by the 2005 deadline (Dalli \& Te One, 2003). The process involved preparing a portfolio of their qualifications and experience, this portfolio was then assessed by a tertiary provider and, in some cases, it was awarded credit towards some of the Diploma or Degree. For some Montessori trained teachers, this meant reduced requirements to achieve to graduate with a DipTch (ECE).

Elizabeth - I did about two-thirds of the course via Recognition of Prior learning. So I did that on my own. (FG 3, lines 68-69)

Sarah - I had to go and do my training but because I had my primary degree, I was lucky I only needed to do a year and a half but there was time off. And I didn't have to do practicums because I was already registered. I was fortunate in that way (FG 2, lines 99-101)

For many however their experience was the complete opposite, as this frustrated discussion from one of the focus groups clearly shows;

Robyn - If someone has been in Montessori for 15 years and has experience working with children and some qualification behind that that has got to be worth practicum RPL credit. It is quite crazy to have someone to go out for 24 weeks practicum over a 3 year period. Like for me for example, l've just had to - cause actually I have 2 degrees, a Montessori diploma and now l'm just doing a third degree, about to finish at AUT and there is no acknowledgement of previous skills gained in child development and in practical experience.

Annie - you probably would have a lot more people doing it - you know if I had got better RPL that would have changed the scenario for me. (She had to sell her school in the end)

Robyn - It's just bizarre. Because in some respects you're more qualified than the people that are assessing you in terms of your RPL! The Teacher Registration Board just sit there and go "Oh well this is this qualification that we require across the board - ... they are so rigid in that they are not looking at individuals. And I think that's 
where a lot of the practical experience could be acknowledged....... If you can provide references, and records of employment - why can't that be acknowledged?

$\underline{\text { Alice }}$ - It reflects even on those people who ... I totally agree with you because I went through exactly that myself - I had 15 years in Montessori pre-school and 10 years teaching special needs children and none of it was recognised. I had to do the whole 3 years. But even for those people who have been 'persons responsible' and then have to upgrade - if they had done a one year training catch-up for those people who had already spent huge amounts of time and money to get to 120 points it would have made a huge difference I think in the transition into getting qualified staff.

Lorraine - Because I had all the points to be the supervisor - but I couldn't ever claim - I mean l'd run the school for 4 years ... and yet none of that was acknowledged as even a part of my practicum - I still had to go and do every practicum because there was no one higher than me to oversee me but it was quite alright for me to run the school by myself! But there is no acknowledgment of what you've done $-\ldots$ (FG 1, lines 400-440)

The lack of recognition of experience was also acknowledged by Anne Meade. She said there was a weakness in the tertiary policy to support the early childhood sector in meeting the qualification requirement. In particular there was no incentive or obligation for tertiary providers to diversify what they provided or to be creative in their recognition of an individual's experience or qualifications. This difficulty in providing a fair and accessible teacher education system has also been noted by McLeod (2000).

It could be argued that it is not in the best interests of a tertiary provider to give significant 'recognition of prior learning' and thus reduce the amount of time a student needs to be enrolled. The less study a student is required to do, the less funding (income) the institution can obtain. For example the main source of funding for teacher education providers (during the early half of this decade) was attached to the number of 'Equivalent Full-Time Students' (EFTs) enrolled in each course. A. Godfree, (personal communication, July 6, 2007; Massey University, 2007).

This was suggested to Anne Meade;

Exactly. And the reality has been that RPL hasn't been all that helpful to the individual people wanting to complete their qualifications. There has been quite a bit of "preciousness", about what TEls [Tertiary Education Institutes] will accept, so recognition of 
people who've started ... Montessori overseas, and how much recognition they get, or RPL for that? People who've been through quite significant Playcentre training and experience, but they only get a small amount of recognition, and so on.

And from the individual's perspective it may mean that the jump into doing study is significant and perhaps it puts them off?

Yes, especially if they've spent a month solid putting their portfolio together. And probably from their own self-evaluation in their portfolio, they think they'll get far more.... Experience is not counting for enough from the individual's point of view. Teacher educators seem to be discounting that rather too much. (Interview 3, p.3, lines 88-99)

In relation to the recognition of Montessori qualifications, of which there are a large number from around the world, many tertiary providers were conservative and even AUT, the tertiary provider MANZ worked with in providing a more flexible avenue for RPL of Montessori qualifications, was not as sympathetic as many had hoped. The consequence was a large drop in the number of Montessori teachers doing additional training (Chisnall, 2002). But as Nicola Chisnall noted, this was perhaps just as well. She believes that a Montessori qualification alone is not enough to provide a breadth of understanding of the whole early childhood knowledge base.

Although in my agenda ... I always felt that there was a need for a three-year qualification. And that's why I was so much a part of organising .... the degree. We needed a three-year qualification.

And your reason for that?

Because I think people need that breadth of understanding. Montessori ... is a philosophy, and an approach. I prefer to call it an approach rather than a method. It is an open-ended idea, not fixed. And therefore one can appreciate other approaches, other philosophies. And we should, to deepen our understanding. (Interview 5, p.1, lines 29-35)

Nicola Chisnall is not alone within Montessori circles in this argument, Kahn (1981) has also questioned whether a Montessori training alone is enough, he suggests that in order to clarify what are the essential elements of Montessori there needs to be comparisons, by seeing Montessori from a different perspective the teacher begins self-analysis - vital for an effective Montessori practitioner. 


\section{A Realisation or Reluctant Acceptance?}

While Nicola Chisnall and others could see the need for additional training for those with just a Montessori qualification, for some teachers, they were reluctant to undertake further training. One agreed her Montessori qualification was not enough to prepare her as a teacher, but after 17 years of teaching she was reluctant to do what she was required to do and wanted what would be best for herself professionally and personally;

Charlotte - I did a one year Montessori qualification and that wasn't enough in reality... because ... in my case I came in very green and I would really have benefited not been in charge of a class, working under someone else or training at that time... (FG 2, lines 577-580)

... I had a bit of a crisis, a few years ago now, where I ... decided that l'd been teaching long enough and ... that I should go to university and get a degree. I should do the (ECE) degree [but]... what I should be doing is listening to myself and doing things that are going to enrich me as a person, so that I can use that in my teaching ... so I actually decided not to do a degree and decided that when I'm sick of my job I'm just going to leave. (FG 2, lines 427-439)

The reluctance to do further training meant some did not see the benefits of further training until they were forced to do it to meet the new policy requirement. They found it provided them with confidence as a teacher with a broader knowledge base, and they enjoyed learning new ideas.

Rachel - I felt really forced into it. Really resistant. In the end, I absolutely loved it. I'm a much better teacher for it. (FG 2, lines 378379)

Sarah - talk about professionalism, I think possibly that has lifted. Possibly a confidence as well - you know knowing more and doing more. (FG 2, lines 481-483)

Amelia - I'm glad that I have this knowledge and I think that Montessori is going to be better off for it. (FG 3, lines 602-603)

Jane - I did love the stimulation at the university. I loved the environment, not at Karori campus but at the Kelburn campus ... I just found that really stimulating ... I felt a lot more passionate about early childhood from being there. (FG 2, lines 441-443) 
Many teachers felt their Montessori qualification had prepared them well to teach in a Montessori early childhood setting, but had not provided an overview of the whole early childhood context in which Montessori sits. This was most likely the reason for the lack of recognition given to Montessori pre-service training when assessed for the 'Pathway Programme' developed in 1996; 40 points awarded for a one year face-to-face Montessori qualification (Chisnall, 2002). In addition others have specifically criticised the lack of current educational thinking and the isolation of the Montessori training from other educational ideas (Simons \& Simons, 1986). The teachers that did additional training appreciated gaining a deeper understanding of the wider early childhood landscape;

Elizabeth - I grew up as a Montessori child so I didn't really know any difference... and that's why the Diploma course was really interesting for me, because it gave me much more insight into NZ. (FG 3, lines 17-20)

Amelia - I'm glad I'm doing it. I really am enjoying the new thinking about the socio-cultural aspect. ... And it is very good ... for me to be thinking "is there another way?" ... And I think that if Montessori carried on the way it was going, I have the feeling we would have been surpassed by other ... programmes. (FG 3, 194-201)

Elizabeth - It gave an insight in different ways of operating and other things and that's probably the most I learned from it - just the fact that there's so much more out there. (FG 3, lines 207-210)

Leslie - I also think that one of the benefits is that you do learn more about different theorists ... we want to be able to find out about all other philosophies that are there. (FG 1, lines 547-550)

Most within the focus groups could see the association between Dr. Maria Montessori's ideas and current ideas in early childhood education. This will be discussed further in Chapter 8.

The additional training meant many were able to critically appraise the Montessori philosophy and approach through different ideas. For many, the additional knowledge strengthened their belief and commitment to the Montessori approach; 
Robyn - [The ece training] challenges you philosophically too, it makes you feel really strong. I look at all those other philosophies and say - "I just know why I am here". (FG 1, lines 552-554)

Jane - l've leant that I'm in the right environment and possibly more passionate about Montessori than I was. (FG 2, lines 498-499)

Sarah - For me personally the ECE [training] hasn't done anything to my Montessori but strengthened it. (FG 2, lines 590)

All participants enjoyed the new knowledge and in particular the ability to articulate the Montessori approach within the wider early childhood sector and how it fits into the New Zealand early childhood framework.

\section{The Benefits - Increasing Professionalism}

Both Ross Boyd and Nicola Chisnall agreed that the qualification requirement for all early childhood teachers to hold the DipTch (ECE) is part of a push to professionalise the sector.

Dalli \& Te One (2003) argued that to be called a "teacher" a person needs a teaching qualification, and for a professional service to exist, all teachers must be "trained to a benchmark level." (p.194). Focus group members would have regarded themselves a teacher without a DipTch (ECE), however they recognised that the drive for early childhood teachers to become qualified meant they felt valued as professionals;

Lorraine - I feel a lot more professional, I feel a lot more valued with the pay I'm getting now ... I'm basically being respected and the monetary value shows that. (FG 1, lines 542-545)

Rachel - [The qualification requirement has made the Montessori community] more professional and [opened] it up to more of the early childhood community. (FG 2, lines 549-550)

The move to professionalise the sector through the qualification requirement has been seen by some as the Government taking a more active role in ensuring quality early childhood education for young New Zealanders (Mitchell, 2001b). 
In addition, the Government's support of pay-parity for kindergarten teachers is a clear indication of the intention to professionalise the sector (Dalli \& Te One, 2003). For some commentators of early childhood policy this is a welcome and hoped for shift - an acceptance of greater state responsibility and involvement in early childhood education (Mitchell, 2001b).

In contrast Ozga (2000) has argued that to control or manage the teaching profession, a government uses either direct or indirect means - either through an ideology, encouraging their cooperation and modifying their behaviour or "regulated directly, through a system of direct specification of curriculum, career structure and professional formation" (p.10). She says that direct rule produces "disaffection and demoralisation" and "encourages militancy and alliances with other workers" (p. 10). The policy certainly motivated at least one Montessori teacher to join the union for early childhood teachers;

Amelia - I joined the union. And I don't think I would have joined the union if government hadn't in 2002 said "this is the way it's going to happen". And I felt that ... [if] they made policy changes again that affected my life so greatly ... and I had to make another career change, and l'm spending money left, right and centre to do this, [so] I joined the union... So I have become a member of the union so that I have a bigger voice. I'm part of a bigger group, so that if it ever happened again, with a group of other professional people who would try and use a little bit of muscle to affect policy. To affect it, rather than it affect me ... Whereas I don't think I would have been a union member, because I never was beforehand - until now. But I feel like I need to protect my livelihood, and my family's livelihood from these things happening again. (FG 3, lines 409-416, 432-442)

For this teacher the feeling of change happening to her, being controlled directly by the state, provided a strong reason to become part of a union seeing herself as part of a bigger group and as a safeguard. 


\section{Stresses and Strains of Training}

A sense of powerlessness emerged as a strong theme for many of the teachers. They did the additional training only because they had to. While they acknowledged the positive consequences for the early childhood sector as a whole, and for the Montessori movement in particular, personal and centre based struggles were evident in the focus group discussions: The word 'stress' came up regularly (whether financially or personally). All teachers, bar one (who took a year off), worked full-time, as well as doing the additional training for either a Diploma or Degree. All found managing study, work and family commitments, at times very stressful.

Jane - It's the impact it has on your life. I mean it takes over. When you have just one day at college a week - it doesn't sound much, but it's everything that's outside ... you just stop existing in your usual way ... I would love to be a full-time student! I would like to be able to do everything a hundred per cent, and not just fit it in to everything else. (FG 2, lines 389-390, 448-449)

Elizabeth - Oh, don't ask my family! We only had one-day weekends for years! (laughing) But ... it was really, really hard and ... I would have liked to have had a lot more time, because I ... enjoy studying. But it just was so much pressure (FG 3, lines 584-588)

Amelia - It feels impossible - overwhelming. It feels completely impossible. And ...you just go from one assignment to the next, to the next ... I only have one son, who's 13 , and a husband. But still! It's still a hundred per cent of my time, and he's started high-school and he was seriously ill last year so that's taken its toll. We're still reeling from that situation ... I find it actually almost impossible. And I keep thinking that my priorities are my family ... and as long as we're together at the end ... that's all that matters! (FG 3, lines 131-137, 142-148)

And the impact on relationships was costly, although it was looked at from a philosophical perspective in hindsight!

Sarah - For me personally doing the ECE [training] was an extremely positive thing - not at the time I nearly lost my relationship of nine years and I saw a friend's marriage breakdown that was a huge problem but in retrospect it was cause and effect. (FG 2, lines 584586) 
For one teacher, the impact on her job and other teaching colleagues was significant - she would not have done the training if she did not absolutely have to.

Elizabeth - I was Head Teacher in the Children's House, and that just goes on. And it fell apart at some stage ... what I found is that you're just not there anymore to help out colleagues, or to ... be part of the team. Because I was just constantly [divided] ... just trying to hold the team together ... I forgot. ... And that was hard. And it did fall apart. And we had to re-structure the classroom.

So would you have chosen to do the training?

l'd like to do it, but I would never, ever suggest to somebody to do it when they have a full-time job as well. It's just impossible. ... it's just ridiculous ... that's just too much. Because you need to have time to reflect on everything.

So if you didn't have to have done it, would you have done it?

No.

And in hindsight, are you glad you did it?

Yes. (FG 3, lines 155-157, 165-190)

Looking back she can see what went wrong;

Elizabeth - Because of my commitments to what I was doing, I probably didn't have that same ability or space to see it coming. Or work it out, or whatever ... but I am now much more able to see the bigger picture again. And to be able to notice what the rest of the school is doing ... And I think you get very narrow-minded like "I need to do this, because I just need to get through it". And that has its implications. And ... it was definitely not the cause of everything, but it would have contributed to it. (FG 3, lines 251-252, 262-269)

Others felt the pressure on their ability to do their job well and had difficulties managing the financial pressures;

Amelia - A Montessori teaching job is overwhelming in itself, because it seems you are ... constant working with the shelves - constantly trying to make it better. And that is a full-time job in itself. And to do anything else, something has to go. And usually ... ideas for shelves, observing children, and trying to get that spark is much, much harder to do when you've got this assignment due. (FG 3, lines 159-163)

Lorraine - When I did start studying it was evening classes and they changed them to day classes - and that caused extreme stress for me - because financially, I was a foreign student at the time so it might have been a bit different for me, but financially I had to have a 
full time job, and I was very lucky that my boss sponsored me through that. (FG 1, lines 676-680)

Alice - The stress on staff is definitely the biggest issue. Not only stress in terms of being able to maintain their position within the teaching environment but also financially. Huge, huge stresses put on staff when they have to go on practicums with no pay - paying mortgages and all those things that are involved - irrespective of the incentive grants, which some people get and some people don't (l've got a staff member who got it 1st year but hasn't got it 2nd year). (FG 1, lines 692-697)

For some the incentive grants were helpful;

Lorraine - It was good having the grant that came through to get those extra staff members [qualified], because at the time, 2002, we did have someone who was studying, it was a different staff member and it was helpful for her to have the extra financial incentive there and she also did it at night time which was an added benefit because she wasn't taking time out of her working day, which is quite disruptive. (FG 1, lines 135-139)

\section{The Training Provider - Patronising or Supportive}

The significance of which training provider added another element to the teachers' experience while doing their additional training. For some it meant enjoying the learning experience and feeling valued and challenged, for others it meant feeling frustrated and patronized. The latter saw little value in the additional qualification they gained. If the learning environment was not open to or even understood Montessori, the teachers found their background and experience was not valued. Others have noted this; the lack of recognition of Montessori within the university education community, often "from ignorance rather than considered study." (Bogart, 2004, p.22)

Jane - When you're constantly tutored by lecturers who aren't familiar with Montessori and who don't read Montessori ... it feels like you are having to justifying what you are doing and what you believe in (FG 2, lines 513-515) 
Sarah - It's quite a hard situation to be in. I was in a study group ... and I was the only one who had anything to do with Montessori and ... always had to defend Montessori because it's considered slightly foreign. (FG 2, lines 517-519)

Nicola Chisnall acknowledged that there is a lack of understanding of Montessori and that this would create a difficult learning experience for some

I think that it's been harder for people in other institutions where Montessori is still seen as a distinct philosophy and there's a lot of apprehension about it. (Interview 5, p.2, lines 45-46)

Some found the experience provided little new knowledge and was frustrating and patronising.

Jane - I think a lot of it does depend on where you do your training. Yes I did learn a lot of new things but a lot of what we learnt wasn't actually able to be brought back into [the] Montessori environment. (FG 2, lines 496-497)

Judith - [The training was] so frustrating ... some of the different courses ... some of it was so frustrating to sit through. And not just ... for somebody coming from a background experienced working with children ... we were all mature students and it was so patronising and it was like, such basic stuff ... yeah really hard to sit through.

Jane - I'm with you on that. [For example] sitting through a music session and you go around and say what our music background was and I said my bit and the lady looked at me and said "when you start teaching, you're going to find that really useful." And I had been teaching for ten years! And I just thought "this is insulting!" And I mean, I let it go ... I didn't bother saying anything but ... if you're teaching people, know who you're teaching. Don't treat them like they are just out of college. We're mature adults with a wealth of experience.

Judith - ...we had lecturers from varsity and yet the difference in what you were given was just incredible. The stuff from college could have been condensed into a lot less time with more quality, that's what I didn't really enjoy ... I could probably list some things I learned. And it wouldn't be a very long list. ... I just felt patronised. What are these people thinking? Being put through ...

Jane - An hour and a half at a woodwork table! Filling in the time! (FG 2, lines 393-415) 
And for Judith, she felt the impact of the training on her practice was minimal;

Judith - I brought back some lovely posters! ... No, I ... brought back ideas perhaps for the outside environment, that's probably helped us change a little bit there. (FG 2, lines 460, 466-467)

May (2001) noted that teachers colleges and universities were "reluctant to compromise academic standards for too much diversity of style and delivery" (p. 253). At times, the training providers' inflexibility failed to accommodate the Montessori trained teachers' previous experience. RPL was one thing, but the actual course content failed, in some instances, to acknowledge the potential contribution of these specialist teachers.

For some the experience was beneficial and they felt their Montessori background and experience was acknowledged and even embraced particularly those who did their additional training for a degree through AUT. In addition, having Nicola Chisnall as lecturer at AUT meant the environment was particularly supportive of Montessori teachers.

It is different at AUT ... where we have got the [Montessori] specialty incorporated nicely within the degree. And because people have become involved, they'd talk ... Montessori students (to other students and to lecturers), they (other lecturers) understand where we're coming from and they're sympathetic. (Interview 5, p.1, lines 42-45)

For Rachel and Sarah they found their experience doing the degree through AUT was very positive, and their Montessori knowledge and experience was recognised.

Rachel - I guess we were really lucky [being] in quite a unique group. Because we were all Montessori teachers, and it was well-known by all the lecturers that we were all teaching and that we had a vast variety of experience between us

Sarah - And they accredited people with that experience.

$\underline{\text { Rachel }}$ - And really allowed us to look at things ... from a Montessori perspective. And discuss that. Well you had to with the group that we were really! ... so that was quite nice to have a lecturer who knew our backgrounds. (FG 2, lines 417-425) 
Elizabeth found having a supportive environment helped her;

That was the advantage of being part of a group that are already practitioners, is one thing and where everybody comes from all places. So everybody was allowed to say what ever they want and it was really encouraged. (FG 3, lines 323-325)

\section{Becoming Registered}

Once qualified with a DipTch (ECE) or equivalent, teachers need to become registered. The registration process involves two years of advice and guidance under the supervision of a fully registered teacher in order to meet the 'satisfactory teacher' criteria laid down by the NZ Teachers Council ( http://www.teacherscouncil.govt.nz).

For Charlotte, a teacher of 17-18 years and Principal of a Montessori centre, the registration process was ridiculous and insulting. She commented:

Charlotte - I've got to get registered, and I just find that just a real, absolute pain in the bum, actually ... I find it really ... really silly. And, yes. It's alright ... we have a nice time together and Sarah has made it pretty stress-free which is really good. But I think ... the process of getting registered is really stupid ... When I'm in this situation where I'm the senior teacher, and they say "You need to get your senior teacher or your supervisor has to supervise you" ... well, I am the supervisor!

Jane - It's really insulting.

Charlotte - Oh, it's just silly. I think it's silly ... after 18 years of teaching, but anyway.

Sarah - Silly when I need to be your supervising teacher when I have 10 years less experience than you and I just happen to be registered! (FG 2, lines 69-82)

The difficulty in finding experienced registered teachers to provide advice and guidance to newly diploma qualified teachers was raised by other Montessori teachers who either had recently graduated with their new diploma or degree or had a newly graduated teacher in their centre (the impact of this is discussed in more detail in Chapter 7). 
As Anne Meade pointed out, the pressure on newly registered, and even recently graduated teachers, to provide support for someone's registration process is a significant concern;

those that are through registration have got a lot of pressure on them. And some of them might be fairly ... very recently registered. ... It's a very big ask, there's a lot of pressures ... on the people who are fully qualified and registered teachers, and there's a lot of pressure on those coming through. So they are going rather too fast, without that consolidation. (Anne Meade, Interview 3, p.6, lines 191-198)

Recently registered teachers need time to consolidate their own learning, and gain the experience needed to provide the depth and knowledge needed for a robust advice and guidance programme.

\section{Summary}

This chapter has explored the lived experiences of those directly affected by the policy requirement for early childhood teachers to be qualified, McNeil and Coppola (2006) argue that policy formulated by state agencies and then implemented through regulations or legislation means there is an unequal power relationship between those who formulate the policy, and those who are affected by it. In addition there is often an assumption made when policy is formed that it will have generalised affects for all recipients, and therefore will result in equitable outcomes. However, they argue this is not the case, and therefore, it is vital to explore the impact of policy at all levels especially its impact on children and classrooms, and teachers.

The experiences of the teachers captured in this chapter have shown how the policy requirement for DipTch (ECE) qualified teachers has affected Montessori teachers differently. The Montessori teachers involved in the

three focus groups provided rich data that described both positive and negative personal experiences of becoming qualified with a diploma or degree in early childhood teaching. All the teachers in the focus groups were supportive of strengthening the ece profession (excited by the prospect of a strong early childhood profession), based on their belief that complying with the regulatory requirements would result in higher professional status for 
Montessori teachers, and that their new qualification would be recognised and valued by the wider community.

While many (if not all) were reluctant to go on to do further training, they did see advantages in further education - although some said the additional knowledge would change only a small part of their teaching. This was often associated with their experience during training - whether they had felt supported and valued for their background and experience or whether they had felt patronised.

For all teachers interviewed, the further training did increase their commitment and passion for the Montessori philosophy and approach, providing more knowledge and skills that many, especially those who trained through AUT, found were complementary to their Montessori trainings. All felt their confidence as a Montessori teacher had grown.

At an individual level, they all expressed the huge workload and stresses involved in working full-time, running a family and doing additional training was at times overwhelming. And this stress was often in addition to managing the day to day running of a Montessori centre - as the teachers will highlight, the policy requirement for qualified teachers caused many disruptions and frustrations, which will be explored in more detail in the next chapter. 


\section{Chapter Six: Getting Qualified - The Experience for Centres}

This chapter will analyse the impact of meeting the requirement for DipTch (ECE) qualified teachers on the centres themselves. Assuming policy impacts on static organisations risks missing the "real story of that impact on the complex and messy organisations and on ... children." (McNeil \& Coppola, 2006, p.683) The focus group data provides the real story of how the Montessori centres in New Zealand responded to the policy requirement.

In the previous chapter, the teachers found working towards additional qualifications a struggle. Some participants held positions of responsibility (e.g. head teacher, manager, or owner of a Montessori centre). Managing the day to day realities of the policy requirement on their centres included:

- organising relievers to cover themselves or staff while on training,

- keeping on top of the administration of the centre,

- contend with conflict within the teaching team,

- lead and maintaining a rigorous Montessori programme,

- promote and be the public face of the centre,

- liaise and maintain relationships with parents and

- handle the financial pressures.

The policy requirement meant many centres were placed under pressure to make difficult and significant decisions about their teaching staff. Some centres had to prioritise - aim for more funding and employ non-Montessoritrained teachers with a DipTch (ECE) or, accept less funding, prioritise their Montessori character, and continue to employ Montessori qualified teachers first. 
However with the shortage of Montessori teachers there usually was not a choice. Therefore many centres supported existing staff to do additional training. For the centres this meant supporting the teacher financially either directly with their course fees or indirectly by covering their time away from the class with relievers. During the focus group all teachers reported that their centres were all accommodating and supportive of them in their training;

Rachel - There was a lot of support, I was able to take off time occasionally, in the third year I took the whole year off - I worked one day a week and I also got the grant from the MoE. (FG 2, lines 48-49)

Elizabeth - For the last five terms, l've had to do it face-to-face ... I was always away one day a week. And she (Centre Owner) organised the leave for that and the school paid half of my time, I paid the other half. And I got a grant on top of that. (FG 3, lines 73-76)

\section{Disruptions - Loss of Continuity for Children}

This support brought benefits for the centres through the increased confidence and renewed passion for Montessori in the teachers, as discussed in the previous chapter. However it also brought additional costs, frustrations and many changes. Nicola Chisnall noticed the changes in staff at centres;

It's been hard on centres. There's a lot of disruption with people going in and out ... it's been unsettling for them, and for the whole sector - a lot of movement around and in between centres. Now I'm talking generally. [It] doesn't seem settled at all. People ... have part-time jobs, and part-time study, so I think that's impacted on the profession. (Interview 5, p.3, lines 97-100)

Many centres found the constant changes in staff highly disruptive whether through staff going on practicum, to training or leaving to study or otherwise, there were ramifications for their programme, for other staff, for parents and especially for the children.

Leslie - But the other thing that ... is really disruptive, is, in all honesty, is the staff member I have that is training ... because she's out two days a week, she gets a lot of asthma, some weeks she might only be at work one day because she's had an asthma attack and you know obviously l'm very sympathetic to that, but if she's only 
working one day or two days a week it's really disruptive for the children. (FG 1, lines 226-230)

Lorraine - There are 4 of us now - and 2 of them are job sharing, ... So this term is very different, we are going to see how we all deal with four staff ... We'll just have to do more team building exercises and things like that! (FG 1, lines 70-81)

Jane - We've had staff out one day a week for the last three years, no four years, and that's going to continue. There has been at least two staff out each year. And it's had huge impacts on the programme, the staff and the children. (FG 2, lines 51-53)

The high number of staff changes in centres raised a real concern for the continuity of care for the children. There is evidence that high turnover impacts on quality outcomes for children (Barnett, 2003; Scarr, 1994; Smith et al, 2000; Whitebook, Howes, \& Phillips, 1989). Changes due to teachers leaving, involved in training or job share arrangements was identified in the focus groups as affecting the teachers' relationships with children;

Lorraine - [I am concerned that] spending a day and half with the children doesn't really cover a lot, I mean you've got to get to know these children, and you're only getting a certain perspective in those 2 days, plus they're trying to do observations ... so it's not ideal - but unfortunately to retain the other teacher that's what we thought would be beneficial at the time. (FG 1, lines 148-154)

Annie - That must be something everybody finds that going through so many changes of teachers, the continuity just isn't there any more is it? (FG 1, lines 156-157)

\section{The Importance of Leadership}

Many within the focus groups felt having a consistent leadership in the centre helped retain continuity for the children, providing a familiar face for the children and parents, providing consistent programme leadership and also their role in providing philosophical leadership for the centre; a continued commitment to the Montessori approach;

Lorraine - I think we are quite lucky in that... because I'm the main person that's been there for 7 years and I'm the one with the qualifications is that the leadership hasn't actually changed. (FG 1, lines 172-174) 
Leslie - That's what we've found is having the consistency is great, because I was "person responsible" prior to taking over ownership. ... So with me purchasing the centre ... I was able to maintain that consistency. (FG 1, lines 210-215)

However with the many staff changes some centres had experienced, those in positions of supervision found their methods of leadership needed to change; for some they found having to dictate within the team was not a comfortable place to be - this is not surprising when research indicates that the characteristics of leadership styles most common in early childhood education include, power sharing, relationship building, empowerment, democratic and participatory (Scrivens, 1998).

Robyn - I think [with] lots of different opinions and viewpoints, in terms of programme planning whether that changes how it's done. At I think it probably did change ... because it got to a point where instead of being more team like in terms of decisions, as Supervisor I had to actually make more decisions about them going to do it this way, which I would much rather have not done - would rather we came to a decision together. But because people were starting to go off on all these different tangents and other ece ideas - [I] had to come back and say well actually this is Montessori and this is how we are going to do it - which I found quite difficult, coming from always the Montessori [perspective] prior to having [a] more ece [perspective].

Lorraine - Because [if] you all [have] Montessori [you] would have the same sort of mindset, when you mention something it would get done, and now you have to explain - even dictate - which is not great. (FG 1, lines 598-610)

Ana Pickering identified the difficulty also, identifying the teacher's personalities as the deciding factor in whether the teaching team would work well together or not - strong leadership helped too.

It must always come down to the personalities of the people involved and how they fit in, and how strong their Montessori philosophy was in the first place, and whether you had a clear leadership at the top. (Interview 4, p.4, lines 118-120) 


\section{Tension within the Teaching Team}

Tensions arose from the sheer number of staff changes, incorporating teachers with differing trainings into the centre, the use of the term "person responsible" for licensing requirements (and what it actually meant in practice), and the working relationship between those experienced but "unqualified" and those "qualified" but inexperienced.

Anne Meade noted this as a significant issue within the mainstream sector of early childhood education and was concerned about the implications for quality practice

Another issue is people are in that in-between phase now - where there are inexperienced people being recruited into being the "person responsible". I think it's really quite a significant issue for quality. And it ends up with some quite difficult relationships inside. In that it's unfair on the person who's recruited, who really hasn't had enough experience yet to take on the leadership responsibilities that are being asked of them. And it sets up tensions between the more experienced people, often finding the young person making inappropriate decisions that, if they knew more about the complexities of being the person responsible, they wouldn't do. Some of the things they're doing, the more experienced people that are not qualified are more aware of the consequences. There is tension between those two that is hard on both sides, I think. It must be particularly difficult to be young, with less experience. But I empathise with the more experienced too. (Interview 3, p.5, 166-174)

This concern was echoed in all three focus groups - the struggles the centres had had with tensions amongst staff; between Montessori teachers and those with an ECE Diploma or Degree and no Montessori and especially where the centre had had to employ an ECE teacher with no Montessori (even new graduates) into the position of 'person responsible'. This had caused some significant tensions and conflicts within the teaching teams.

Robyn - The new owner ... is an administrator if you like and she's come in and seen the ECE qualification is what she needs but it is a Montessori school so she's employed people who are from AUT who have done the Montessori speciality, (which is quite different than a Montessori person who's then gone and done the ECE degree) and there are people who are in the centre who have been in the centre, I 
had it for 10 years, who have been there for most of that time and are excellent Montessorians but don't yet have the degree and then there are these other people that have come in that have very little Montessori experience but have the degree - and then they have this whole "ok so who's in charge" thing? And that has caused a huge amount of stress in the classroom.

Annie - l've been running some Montessori workshops just helping people who come out and don't have that experience with the equipment particularly and l've gone into schools to run some workshops. But actually from the owners that's what I'm getting, they're sort of telling me the ins and outs between the staff and then as soon as you sit down you can just feel that friction, from somebody who's got their ECE and no Montessori but they feel like ... I'm the supervisor and yet everything in the classroom well actually they don't know how to use it, so they've got a Montessorian telling them how to do that, and yet they're the ones telling the Montessori person how to run their classroom and the friction it causes just seems to be incredible and if you can manage that without it affecting the children that's pretty huge I think. (FG 1, lines 188-208)

Robyn - I think [the qualification] deadline ... has created that problem - the fact that you have to have these qualified staff which meet a specific criteria, centres are having to have these qualified 'people responsible' - so graduates and teachers with very little experience are being thrown into that ... position, being paid ridiculous amounts of money to do a job they can't do. And getting very stressed. (FG 1, lines 516-520)

Rachel - I'm in a constant struggle with ... my colleagues about implementing Montessori. I know the next person we are getting has much the same training which is really exciting. [It will be] really nice having another Montessori person actually on the teaching team. (FG 2, lines 486-489)

So having teachers with different philosophies .... Have you found they have meshed and have gelled or fireworks?

Rachel - All of those things! Yeah, it's quite interesting, actually. Probably most of the time it works really well ... we're coming from ... diverse backgrounds in a way, and that ... influences our programme but when ... I feel something is strained, then that's where it can be quite difficult to say well "It's coming back to the Montessori philosophy". And if somebody ... doesn't really agree with that, then that can be quite difficult. It's trying to find a way of working through that, so that everybody feels comfortable but still maintaining our integrity I suppose - because you can only compromise so far. (FG 2, lines 242-253)

Annie - People just come from so many different places it's just so hard for everybody to work as a team anymore. (FG 1, lines 447-449) 


\section{Concern for New Graduates}

The interviewed teachers were concerned at the number of new graduates being employed in positions of responsibility and the pressure that placed on them. Specifically the graduates of the BEd (MECT) from AUT, where their qualification means they meet the qualification requirement 'benchmark' for a DipTch ECE or equivalent and have specialised in Montessori in their third year - so they are in huge demand to fill places in Montessori centres desperate to employ a teacher with both qualifications.

The following teachers were particularly concerned for them;

Robyn - I have sat in lectures where these students who are just about to graduate think they can leave AUT and just whip in and supervise a centre - as Head teacher and they are being employed as the Head Teacher because there is such a need for "qualified staff" and the experience is somewhat different when they get there and they get really disillusioned and think "what have I done here?" Lorraine - Because also a supervisory position as opposed to just a teacher has a lot more going into it. Because I know trying to balance the supervising and the teaching is like juggling all the balls and waiting for them all to fall down sometimes. So these students are really going with not much experience and not much background in any kind of leadership. I don't think any of those courses are geared towards leadership - the subtle things that are learnt through experience. (FG 1, lines 491-503)

Jane - To put someone who's a new Montessori-trained teacher, such as an AUT graduate, anyone like that in charge of a classroom, I think is a particularly cruel thing to do, because let's face it there's a heck of a lot of learning on the job that you do, and even a degree is not going to, even a Montessori degree is not going to give you those classroom management skills, the skills needed to deal with parents and situations that arise with children. And so its wonderful these graduates are coming out and in time they'll be fantastic but they are certainly not ready to be Head Teachers. (FG 2, lines 595-600)

This focus group were also concerned with the lack of Montessori knowledge the AUT graduates had. This will be discussed in more detail in Chapter 7. 
However in relation to employing a new graduate in a position of responsibility Annie had this to say;

Can you imagine what that does to their self esteem? They've just done this three year course and paid all that money, they're probably paying off student loans, they get into a school and within a short time they realise that actually they're not efficient or effective and they need help from the other staff and everybody is working so hard nobody has time - it must shoot their self esteem. (FG 1, lines 247251)

Two of the interviewees felt the same; Nicola Chisnall clearly stated that she felt the AUT graduates were not ready to be in positions of responsibility;

The [AUT] graduates are not the people that we should be sending out to run centres. They need that mentoring process; they need that registration time to fully embed themselves into practice. (Interview 5, p.7, lines 222-223)

However, for many Montessori centres out of Auckland where they do not have AUT graduates to choose from, their predicament is even more frustrating; they have been forced to employ someone with the DipTch ECE or equivalent with maybe an interest in Montessori over someone with any Montessori training purely to meet the qualification requirement or because the centre had decided to go for the $100 \%$ funding rate. Many have commented that these decisions had a significant impact on the Montessori programme offered by their centres (see Chapter 7 ). The daily realities of accommodating a teacher with an ECE qualification and no Montessori knowledge in the teaching team were fraught with difficulties. Alongside the tensions discussed previously, the centres were finding themselves training these teachers during staff meetings and non-contact time - placing a significant demand on the experienced Montessori teachers in the centre.

Rachel - That's where staff training is really important as well and that's something that we have just started this term - making a Friday afternoon for staff training, because we've got one person who has no qualifications at all and is new to the Montessori environment so it's really a matter of showing "well this is what Montessori is". And that's good for me who's Montessori trained and for my other colleague who had started doing [Montessori] training but has stopped now. Partly to get some consistency but partly for me ... to help them understand that Montessori was the foundation and everything should be built on that. Where as I think that's quite difficult when people haven't got Montessori training and they are 
working in a Montessori school and they are picking up almost all the superficial rules but not actually what's really underpinning it all which are the most important things. (FG 2, lines 270-278)

Some found training in the centre was not enough - they had difficulty in providing training with the specific Montessori equipment but also how to provide the breadth and depth of knowledge of the philosophical approach training not just the "what" but also the "why". And the time available to do either (or both) well was the main hurdle, as the following discussions show;

Sarah - To maintain 100\% [teachers qualified] - that took precedence. There's an issue with it, relying on in house training because there's a limit to how much non-contact and training time we have. Again, that's a problem with a small team. If you've only got one person who can perhaps offer a role in the training.

Judith - But don't you find that so much of the training is not just presenting the material? All the philosophy and all the reading and all the work that people do, who have been lucky enough to do full-time training .... it's so hard to give them time or you time to try and help them with that ... like we do with staff every second Friday [is] presenting the materials. But ... you ... walk away thinking "well, that's great. They now know how to present the pink tower," but I don't know if that was really giving them the understanding of why, or what it's all about, or where it will come from. And I think that's really difficult [to do] ... you can give them books, of course, but ... they need [a] group .... to get together so that they can talk and discuss the philosophy around it all.

Charlotte - We tried to do that at our Centre because we felt that quite often ... where issues come up with parents, if parents have raised concerns ... one of the things that we thought was really important was about how staff responded ... And we assure them, from a Montessori perspective, and if people are not confident to do that, then that reassurance wasn't taking place. So we started trying to ... take a chapter from a Montessori book and ... debate the philosophy. Forget about all the materials, and debate the philosophy. And we had nearly three good sessions. But actually, the reality is there's no time! Because we're also supposed to be self-reviewing and we're also supposed to be goal-setting, and actually there is just no time. (FG 2, lines 294-320)

\footnotetext{
${ }^{8}$ The Pink Tower is a piece of Montessori equipment from the Sensorial curriculum for 3-6 year olds. It is ten graduated cubes from $10 \mathrm{~cm} 3$ to $1 \mathrm{~cm} 3$ which is built into a tower and introduces seriating; weight and size.
} 
The call for more time was unanimous. The pressure on non-contact time came in a number of ways; staff meetings, staff trainings, time with students, time with graduates, study leave, professional development leave, preparing portfolios, administration work, or covering staff on practicum. And for most centres the main concern was the impact on their funding;

Rachel - We are very small - there is just 4 of us it's a lot harder to take time off to do professional development. We only have 5 discretional days where a trained teacher can be away [without a qualified replacement] and still retain the same funding. This means that we either lose funding or not do as much professional development as we would wish (FG 2, lines 338-341)

\section{Benefits}

However the new rates of funding were identified as being the major benefit of the qualification requirement;

Charlotte - The money's been great! (laughing) The money is fantastic! The money ... it's a large amount of money ... the funding is amazing. And that's had a huge impact, positive impact, I think.

So the incentive is certainly there.

Charlotte - The incentive is there. The rewards are mighty ... we've been able to employ a staff member where before we wouldn't have employed [someone] to cover one part of our day, ... And also we could give staff additional funding for all their efforts on profile books ... And we could reduce our fees by $10 \%$ as well, so actually the impact of the funding has been huge for us. So that's been really great. (FG 2, lines 135-147)

For some the financial incentive was significant. For example, one centre made a conscious decision to employ all teachers with a DipTch (ECE) to meet the requirement and that meant losing staff who were unable or unwilling to do their ece training.

Sarah - We had a teacher who wouldn't do her training, and ... we needed to replace her ... purely because of the qualification issue. And in terms of employing new staff they always need to be ece qualified. (FG 2, lines 102-106)

For Robyn, while she had sold her Montessori centre she was watching the staff changes with concern;

I need to say I have sold my school but I do know where they are at. Provided they keep their staff, they will have over $50 \%$ "qualified" 
staff, as in the ECE degree, but not necessarily to the benefit of the Montessori aspect. And other than that they are going to lose one of their unqualified staff at the end of this term, and that has really been forced upon her by the fact that they want more qualified staff, so her hours have just been reduced and reduced to a point where it is not viable for her to work there. So in terms of the deadline they will meet it but at what cost I wonder. (FG 1, lines 109-115)

She therefore felt very strongly about the loss of experienced Montessori teachers from centres

From a personal point of view it's made me quite angry in terms of the lack of recognition of people that do have experience and do have the [Montessori] qualification. In terms of the centre - there are some people that won't be able to work past 2012 in an early childhood centre, that have years of experience, that are at a point in their lives where they can't financially afford to go and study fulltime or it's just too intimidating for them to do it. And they are really quality people that we are will lose out of early childhood. (FG 1, lines 712717)

Elizabeth was also concerned at the loss of experienced teachers from the Montessori community

We're going to lose some very valuable people in the process, and it's going to [mean less] to choose from. Whereas people who have genuinely wanted to do Montessori, ... a large number are now no longer able to ... they've made decisions not to teach anymore, and gone on to do something else a bit different. So we've had a smaller pool of people to choose from. (FG 3, lines 542-547)

\section{Summary}

The three focus groups of Montessori teachers, revealed their concerns, frustrations and struggles in implementing the policy for qualified teachers within their centres. In particular they identified the difficulties in managing the day to day needs of the centre, the costs, and practical realities (eg. finding relievers) of providing support to their teachers to do additional training. Centres felt forced into making a decision about whether to aim for $100 \%$ funding and have all teaching staff with a Diploma or degree (often at the cost of Montessori qualified staff), or maintain their commitment to Montessori and forgo the additional funding. Consequently some centres made significant decisions about their teaching staff. 
They all emphasised the frustration they felt with the lack of continuity for children and their families due to the number of staff changes occurring within the school. The shortage of qualified teachers, either with Montessori or with a Diploma or Degree meant many centres were struggling to find the right teacher for the job - often settling for the candidate with the qualification rather than the one who would be the best fit for their centre. This issue is discussed in more detail in the chapter 7.

The teachers in the focus groups identified the tensions experienced by their centre's teaching teams; the difficulties in bringing teachers together who may have quite incompatible philosophical approaches to their teaching of children, the difficulties for teachers working together who had differing levels of experience especially if their position within the team did not reflect this, and the struggle for new graduates.

The concern for new graduates was high. Many of the teachers worried about the new graduate teachers being placed in positions they were not ready for - in particular the AUT graduates with the BEd (MECT) degree moving straight into positions of responsibility when experienced Montessori teachers felt very strongly that their level of Montessori knowledge was not enough to run a Montessori programme confidently or effectively.

Others noted the effort required to support any new teacher without Montessori training within the centre - the pressure on the experienced Montessori teachers was considerable. The consequences for the larger Montessori community of these concerns are discussed further in the next chapter.

The value of experienced Montessori teachers was evident in those centres who felt they were managing to cope with the qualification requirement. To enable the centres to maintain continuity, a committed Montessori programme, a harmonious teaching team, and a committed parent body, required strong leadership from experienced teachers. 
The ability to be resourceful and to find solutions to the problems posed by policy implementation must be solved in the context of the recipients, and this will often be messy and require "productive thought, invention and adaptation" (Ball, 1994, p.19). This messiness in dealing with the teacher shortage is discussed further in chapter 7 .

While all saw the additional funding coming into the sector as a huge benefit, others felt the policy requirement would have a detrimental impact on the Montessori community in New Zealand. 


\section{Chapter Seven: Getting Qualified - The Consequences for the Montessori Community of}

New Zealand

In this chapter the focus group and interview data helps reveal the impact and unintended consequences, of the policy requirement for all early childhood teachers to be qualified, on the wider Montessori community of New Zealand. This community encompasses the owner operators/administrators, the teachers, the academics, the centres, the families, and the children involved in Montessori education.

For the Montessori community there has been "real struggles over the interpretation and enactment" of the policy (Ball, 1994, p.19). There tends to be an assumption that teachers and contexts will adjust to policy rather than policy adjusting to the context (Ball, 1994). This chapter will show just how messy and complex these policy-forced adjustments can be. It will show their consequences reach even further - in this case deeply into the Montessori community and its reason for being.

McNeil and Coppola (2006) argue that it is a mistake to "accept the truism that policy is an imposition of rationality on what can be a chaotic or at least complex institution: the public school" or in this case the early childhood sector (p.685).

And as Anne Meade observed;

Human behaviour never follows the rational policy decisions that are put in place! (Interview 3, p.1, lines 34-35)

The struggle to find experienced Montessori teachers, or Montessori teachers with a DipTch ECE, or even a DipTch ECE alone was a recurring theme for all three focus groups. For a Montessori centre to provide a strong and authentic Montessori programme it needs experienced Montessori qualified teachers - therefore a number of the consequences identified in 
this chapter, due to the qualification requirement, for the Montessori movement of New Zealand looped back to this issue - a shortage of Montessori teachers.

\section{Teacher Supply - Ministry Initiatives}

As Ross Boyd noted, the shortage of ECE teachers nationwide had been identified by Ministry of Education during the formation of the policy and the requirement was thought to be too ambitious. (See Chapter 4) In addition, the policy has been implemented during a time when the whole New Zealand labour market has been tight, with a significant difficulty finding both skilled and unskilled labour being reported (Department of Labour, 2007).

Therefore, throughout the implementation of the policy the main area of support to centres to meet the requirement has been focussed on teacher supply.

RB - That's why, there was more poured into incentive grants, scholarships have all been re-hung. A whole lot more work in terms of promotion of early childhood education. ... the new funding system itself, meant that as soon as you got extra teachers, you got the money for them, ... And everything that [has] happened since the strategic plan, around qualified teachers, was to try and reach those targets which are actually still quite ambitious. (Interview 1, p.2-3, lines 124-130)

The Ministry have also worked to identify the areas and centres most 'at risk' to achieving the targets, while ERO had managed to categorise the 'at risk' centres into types eg: Montessori, Pacifika or Steiner (Education Review Office, 2004), the Ministry has only managed to work at a regional level identifying Auckland and Tauranga as areas of need, putting in place recruitment brokers and a relief pool of teachers. They are also looking at relocation grants;

RB - There was a lot of work done by the Ministry to identify those centres that were going to struggle to achieve that, and then working with them. ... the question was asked "is it just Auckland, or should the relocation grants be applicable to other parts of the country as well? Or should there be other incentives in those other parts of the 
country. So all of that is monitored all the time (Interview 1, p.5,6, lines 185-188, 236-240)

Anne Meade also identified the teacher supply issue and the initiatives put in place by Ministry, and those they have not made.

The moves have been there ... not to change that policy (other than that shift back from 100 per cent to 80 per cent); rather the moves are to try to boost the supply. So scholarships, recruitment drives, that sort of thing. ... There are regional differences that are really quite challenging to try and address ... the teacher education system is primarily for the 'mainstream', not minority groups and the diversity of childcare services. The two very visible ones missed out are Montessori and the Pasifika. What do they do? ... So the regional issues really have not been addressed adequately.

... It's really hard to recruit professionals into some places in New Zealand, as people do tend to stay close to where they graduate on the whole. It's a well-known pattern of behaviour. (Interview 3, p.2,4, lines 67-69, 113-116)

Another pattern identified by the Ministry was the tendency for teachers to want to work with other teachers - to be part of a professional community.

$\mathrm{RC}$ - What we know about teacher behaviour is that they like to go where other teachers are. So you are more likely to get those services who've got lots of teachers ... are likely to be a far more attractive proposition than getting paid 25 bucks an hour to work at a place where you're going to [be on your own] ... money is not everything. So what we know is that recruitment retention for services where there are one or two teachers is often a harder thing to manage, than when you've got that critical mass - because you're having professional conversations ... I think there are definitely shortages in some areas. (Interview 2, p.7, lines 268-281)

This was also observed by focus group members who noted the isolation that could occur in Montessori centres if only one teacher was Montessori qualified - a not uncommon situation due to the small size of most centres, a lack of Montessori teachers or to the centre's choice to employ a Diploma qualified teacher instead (this is discussed in more detail later in the chapter). The result is a feeling among the teachers that the Montessori professional community is stretched. 


\section{Significant Shortage of Montessori Teachers}

In particular, the significant shortage of Montessori qualified teachers especially those with an ece qualification. Montessori teachers are identified as a shortage by the Ministry of Immigration and Department of Labour (Department of Labour, 2007). Both Nicola Chisnall and Ana Pickering have noted this shortage and its impact on Montessori centres.

NC - There are centres who are struggling. Some are okay, in Auckland. And I counted them up - there are about 25, 26 of them ... and those who have not been able to get Montessori plus qualifications, are definitely floundering around. (Interview 5, p.5, lines 155-157)

Ana Pickering found Auckland was the area in most need;

[l get] a lot of feedback from centres who've been, particularly ... from Auckland ... not only can they not find anybody with a Montessori training, they can't even find anybody with early childhood training to apply for their jobs! Because there isn't anybody, because there's such a shortage of early childhood people, and the expectations of the graduates coming into the sort of salary they were commanding, it's huge, because they can. And they're getting offered jobs in their first year of training. (Interview 4, p.4, lines 122-127)

Anne Meade had also noted the aggressive recruitment;

It didn't used to be much of an issue, but it certainly is now, so there is a "churn" rate. There is aggressive recruiting going on ... And so the churn rate has gone up, and a higher salary does count. People are moving on. (Interview 3, p.5, lines 157-165)

The teacher supply issue was discussed often in the focus groups with many centres struggling to find teachers.

Charlotte - I think where [the qualification requirement has] impacted is just in terms of employing staff. You just don't have the options anymore that you had before. (FG 2, lines 88-89)

Judith - We have interviewed people with all sorts of qualifications, but none of them Montessori. (In the end they employed someone who seemed to fit with no qualifications) .... and luckily it's worked out ok. (FG 2, lines 203-207) 
Lorraine - Because there didn't seem to be anyone out there with both (Montessori and ece) when we were looking. (FG 1, lines 123124)

The lack of qualified teachers has been noted by Mitchell and Brooking (2007) in the First NZCER national survey of early childhood education services 2003-2004; $43 \%$ of managers had difficulty finding suitable and qualified teachers for their vacancies (p.70). In addition they noted there were a number of comments relating to a "lack of applicants with the values and philosophy of the service" (p.71).

\section{Unintended Consequence - Loss of Centre}

For one centre owner, Annie, the struggle to find a Montessori teacher led to her selling her Montessori centre after 10 years.

It was a small school ... it had 3 teachers. Basically finding the staff was the hardest thing - because the one person that had Montessori and diploma ... decided that she didn't want to teach, so the one person who could have pulled it through for me at the time was no longer around. So then I really needed someone to replace her - it changed the dynamics completely - trying to find people; and the parents got restless with the changes. Getting in an ECE teacher with no Montessori ... And I felt the level of Montessori that I had at my school slipping away from me - and I didn't like it.

And probably the crunch for me ... I got a Montessori teacher who said she was willing to do the diploma [but did not work out] ... It was probably the end for me really - it was a battle to continually try and keep everything else on track and this person had made it so difficult and I really just hated the whole scenario. And I had always loved what I did, but I didn't anymore. ...

And it was that qualification thing because you would advertise and advertise and advertise and ... then anyone who knocked on the door you'd just drag them in and do what you could with them. Knowing that this wasn't what you were doing before, knowing that the children weren't getting what they were entitled to and that just ate at me. I did have younger staff who were willing to do some training, but you know with the time out - needing to release them to go and do some training I only had Montessori I didn't have the diploma so I even at one point thought well if I can find the right person, they could help me along this while I go and do my training, and that just never happened. I just never got the right person, and it never happened for me ... so selling my school started to be quite a nice option - so that's what I did. (FG 1, lines 16-45) 
And after the centre was sold it no longer remained a Montessori centre;

I did sell it to someone who made me think that she wouldn't change. I think it took 6 months to get rid of all of my staff but 1 . But I do understand why that happened because I was having difficulty anyway, but she was coming from a completely other place and she needed to earn money ... Probably took about 6 months as far as I know - that's about when I stopped driving by!... (FG 1, lines 743747)

Annie is not alone, this story and others which are very similar have occurred elsewhere in New Zealand. Another focus group member had just sold her centre and wondered about the new owner's commitment to Montessori. As she saw it, the teacher changes occurring within the centre were leading it away from providing a strong Montessori programme. While the Ministry is assessing the impact by looking at the number of centres who are closing - which as Rose Cole noted is just one ("Only one centre closed recently, because of it." Interview 2, p.5, line 188), the pressure is there, as Ana Pickering has noted

The Ministry is just looking at numbers, so if we ask them ... how many centres have had to close because they couldn't meet their person's responsible requirements; well there've been very few. ... How many haven't been re-licensed; well there have been very few. So they look at those numbers and say we don't feel ... that you've got a problem. And yet, we know that there are, not just Montessori, but early childhood in general, that there are centres that are absolutely thin on the ground, and are struggling to continue to stay open ... (Interview 4, p.2, lines 45-50)

While the Ministry of Education does record the closures of centres, they are not monitoring whether they remain a Montessori centre or not. Therefore it is crucial to capture both stories; the 'unofficial story' from the recipients of the policy versus the 'official story' of the policymakers (McNeil \& Coppola, 2006).

Montessori centres which have closed since 2003 have been in Whangarei, Christchurch, Auckland and Canterbury. In addition there have been three Montessori centres which have been sold and no longer offer a Montessori programme. A Pickering, (personal communication, November 13, 2007) 


\section{$100 \%$ Funding or Strong Montessori Programme}

For all centres, the difficulty of finding a teacher meant making significant choices; whether to aim for $100 \%$ funding and employ an ece teacher with no Montessori and hope they would go on to train in Montessori, or to employ a Montessori teacher and have them go on to train in an ece qualification, and miss out on the additional funding.

For one centre the priority was to employ Diploma qualified teachers or teachers in training for the Diploma, with the intention that they would go on to do further training in Montessori, all with the aim for the $100 \%$ funding rate;

Sarah - Our thinking at the moment is that it is better to get somebody who's maybe not Montessori trained but just new to Montessori. Train them ourselves. [The owner] will always take a centre-based student and have them four or three days a week for their 3 years training until they are qualified. But we're a small team we've got one full-timer and one part-timer ... and one of them has worked very well. For the other there is only so much we can do [with] her, in the end we got her with the ECE because we desperately need it. To maintain $100 \%$ that took precedence. (FG 2, lines 289294)

Data provided by the Ministry of Education, showed there were only a small number of Montessori centres who had $80 \%$ and above ECE qualified and registered teachers. In $200513 \%$ of Montessori centres could claim additional funding for employing $80-100 \%$ Diploma qualified teachers, in 2006 this dropped to $12.5 \%$. Although the number of Montessori centres able to claim additional funding for $100 \%$ ECE qualified and registered staff rose from $8 \%$ in 2005 to $11 \%$ in 2006 . (Ministry Data, see Appendix 13).

Centres choosing to employ a Montessori teacher and have them go on to train in an ece qualification maintained the Montessori philosophy but missed out on additional funding. This approach relied on the centre already having qualified and registered teachers and a Montessori teacher prepared to train. The huge cost to acquire a Montessori qualified teacher from overseas is the biggest hurdle to this plan; 


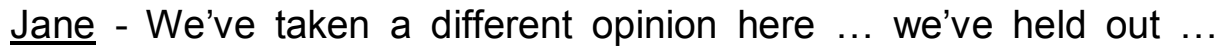
we've had [one of] our Head Teacher's position vacant ... and [the Principal] has being filling it because we've been wanting the right person and we have waited about 18 months and we're employing someone from [overseas] who is Montessori qualified but they're going to have to do the State [ECE] training. Because this is a Montessori school, we would rather have someone with Montessori training ... we just cannot put someone in ... a Head Teacher position that's not Montessori trained. ... And while it has been hugely difficult for everyone concerned I believe it's the right decision.

And therefore the choice not to go for the top funding rate too.

Jane - That's right. And that has made a huge impact on ... the whole junior school. But I still believe it's the right decision to make- if we are going to make this as purely a Montessori School as possible.

Charlotte - You can't ... I don't think you can employ people in the senior roles if they're not Montessori trained.

Jane - No. How can you expect parents to pay if they are not getting a Montessori trained Head Teacher. (FG 2, lines 115-131)

However for some centres there was no choice.

Alice - For me it meant that I actually had to employ a diploma trained person to come into the centre and be the 'person responsible' over staff who had been there for a long period of time and the only people you could get were just ECE trained with no Montessori experience, and it caused a huge amount of conflict within the classroom. We were fortunate we had the same person every week, [when] I had to leave to go and do my course, but they had very different ideas from what we have in terms of the Montessori philosophy ... in terms of maintaining the philosophy within the class [it] just didn't work - it was very difficult. (FG 1, lines 161-170)

Leslie - I think there's a number of Montessori centres, due to the changes (qualification requirement), [who] are advertising for staff with an early childhood qualification as opposed to either both or [just] Montessori ... and having to make those compromises [when] you are employing early childhood trained staff as apposed to having your Montessori philosophy remain intact by employing Montessori trained people. (FG 1, lines 670-674)

Ana Pickering has noted this trend amongst a number of Montessori centres;

I think the other [impact for] Montessori centres has been staffing their centres ... and so many of them have acknowledged "yes, I had employed early childhood people ahead of Montessori people because I needed to stay open." (Interview 4, p.4, lines 114-116) 
This movement is echoed in the data supplied by the Ministry of Education from 2005 to 2006; there was a shift from the majority of Montessori centres having unqualified (without a DipTch ECE) teachers (223 to 183) to the majority having Diploma qualified teachers (207 to199). The difference between the two groups however is minimal. (Ministry Data, see Appendix 13)

In addition, the desperate situation often meant not employing the right person for the job;

Rachel - Having to take the person who has the qualifications rather than the person who is right for the job. And then the person who has both (ECE and Montessori qualifications) which is so rare, that no matter who they are you might want to just take them anyway. (FG 2, lines 111-113)

Kathryn - We are having to do this ... more and more - appoint the qualified registered person over other applicants irrespective of whether they are the best person for the job. (FG 3b, lines 61-64)

This issue has not been experienced by Montessori centres alone. Mitchell and Brooking (2007) noted that over half (57\%) of education and care centres had difficulties finding 'suitable applicants' either because they had no suitable qualification, insufficient experience or did not share the centre's philosophy (p.71).

\section{Montessori Teachers From Overseas}

Traditionally, Montessori centres have employed experienced Montessori teachers from overseas - this is happening less often, and the consequences have meant not only fewer Montessori teachers to choose from, but for some this has meant losing the cultural richness that the teachers brought to the Montessori centres.

AP - That's been [an impact] the fact that they can't employ experienced Montessorians from overseas as we had so traditionally relied on those people ... there's been a huge falling off of people being employed from overseas. (Interview 4, pp.4\&8 lines 121-122, 291-292) 
Elizabeth - The overseas people that won't be able to be hired like we did in the past - which is a shame, because there is a lot to learn and a lot to gain from people from other cultures ... especially Montessori qualified people from other places. (FG 3, lines 453-455)

Charlottte - And ... I think partly what [the qualification requirement] brings is ... where Montessori schools traditionally have been very rich in a kind of cultural exchange... Cultural diversity in staff, it's not as rich anymore I find ... because ... someone who is trained from [overseas] and you go - "no thank you!" You don't even want to see them anymore! (FG 2, lines 90-95)

The difficulties for centres employing teachers from overseas is the lack of recognition gained for their qualifications through NZQA - for many centres the hassles of dealing with NZQA (and other agencies) are just too frustrating;

Kathryn - overseas qualified Montessori teachers have an impossible job getting work permits renewed, RPLs for doing Dip ECEs etc. The whole thing is a mess at present. NZ Immigration Service recognises Montessori as a long term occupational shortage category, yet [other agencies] won't recognise their qualifications. (FG 3b, lines 38-43)

Jane - It's a shame that NZQA haven't got it together in recognising overseas qualifications, I think it's had and will have a huge detrimental impact to us as a Montessori community. (FG 2, lines 565-567)

For most Montessori teachers coming into New Zealand, even with some sort of generic qualification, it is very difficult to receive equivalency to the DipTch (ECE) from NZQA. The lack of movement by NZQA in recognising qualifications from overseas has also been noticed by Anne Meade;

I think there's some quite closed shop feel about what NZQA does in recognising overseas qualifications, which will be experienced ... I'm sure, in the Montessori movement. I think it's probably experienced by services that are multicultural, say in Auckland. [For example] I stumbled across an Indian Centre. How do they get on? They would ideally like to have Gujarati speaking staff or whatever, wouldn't they? What are we doing to help maintain those sorts of diversities and recognising .... for goodness sake, Te Whāriki recognises cultural values and says it is about learning and affirming families' own cultures. Are we doing enough on that? No, I don't think so. I think one of our agencies is really unhelpful to diverse sectors - whether it's philosophy-related diversity, or whether it's cultural diversity. (Interview 3, p.9, lines 322-329) 
When asked about whether the Ministry of Education has worked with other agencies such as NZQA on the teacher supply issue, Ross Boyd answered that there had only been a move to recruit New Zealand qualified teachers from overseas and his reason was due to the curriculum, Te Whāriki, being too specialised.

No, what there has been is [a] focus on overseas recruitment, but it is for people with a New Zealand-based qualification. And I guess what the government is really saying through that, is that the early childhood curriculum is too specialised for teachers that are trained in other areas, to have confidence in teachers trained outside of that curriculum, would actually be able to deliver it ... (Interview 1, p.5, lines 201-206)

The contrast here is interesting. It highlights what McNeil and Coppola (2006) argue is often a difference in expert knowledge between the policy makers and the recipients of the policy. They say the recipients of policy "may have insights unavailable to the formal policy process" (p.683). In this situation the 'policy elite' have made an assumption that Te Whāriki, the New Zealand curriculum for the early childhood sector is "too specialised" for overseas teachers to work with. However the expectations are different within the sector itself. In fact Helen May (2001), one of the main authors of the curriculum, writes that Te Whāriki "allows for different programme perspectives" and there are "many possible 'patterns', depending on ... the cultural, structural or philosophical context of the particular service" (p.245). There would therefore seem to be room for teachers from overseas with specific expertise to fit within the curriculum framework of Te Whāriki and meet the critical needs of some centres for teachers, at least until 2012, when all teachers will need a Diploma or Degree. 


\section{Desperate Need for Montessori Mentors}

The expertise Montessori centres need is experienced teachers in the Montessori curriculum. Traditionally the teachers from overseas have provided support, encouragement and inspiration to New Zealand Montessori centres, mentored new graduates or those in training and met the desperate need many centres have - a Montessori teacher able to run a Montessori programme - a teacher who is able to help the children use the equipment or engage in activities in line with the Montessori curriculum; essentially maintaining a strong Montessori programme.

As Ana Pickering points out the qualification requirement has meant a higher percentage of teachers without Montessori qualifications in centres and that has implications.

I think that the increasing number of early childhood people who are now in Montessori Centres, which has been a direct consequence of having to employ them in order to meet the requirement and to get the funding rate, means that we've got less and less Montessori people in centres who can mentor new Montessori graduates or even new early childhood graduates in those classes. (Interview 4, p.8, lines 286-289)

Nicola Chisnall has also observed the implication on Montessori practice

If [centres have] had difficulty in getting sufficient Montessori staff, they've had to bring in early childhood staff and there is a dilution [in Montessori practice. (Interview 5, p.5, lines 164-165)

Annie argued - working alongside someone with experience and additional knowledge is how a new teacher can consolidate and extend their knowledge.

If you've got an ECE person coming in with just maybe a year of Montessori, they still need somebody to show them the more difficult pieces ... they need people with experience to nurture them - that's how you learn. (FG 1, lines 303-306) 
In addition Anne Meade noted;

Such people would be extremely helpful for your newer graduates, etc. Because I get a sense that there's some funny melding going on at times, between the typical ways that early childhood services have been run in New Zealand and Montessori ... Your overseas people could bring you in-depth understanding of Montessori, without the contamination that often happens here ... You just miss the boat on those gems. (Interview 3, p.10, lines 339-343)

Further implications are the lack of mentors available for advice and guidance through the registration process, as Nicola Chisnall has identified.

That's a problem that we need [fixed] as a Montessori movement we need ... a mentoring system ... People do it through cluster groups. Help each other. But I think there's a bit of a dearth. So ... I think there needs to be some sort of provisional development programme for graduates - to help them through the registration process. ...

And that's why we need a mentoring programme ... developing that across a cluster of centres, would be a possibility. Even within a centre, you still need teachers who are, experienced. And so previously our mentoring programme was overseas teachers ... we can't dismiss that completely, right now (Interview 5, p.4,5,7, lines $137-138,143-145,235-238)$

Leslie agreed;

Because that's a challenge, trying to find advice and guidance people for people with provisional registration, especially people with sympathy for Montessori. (FG 1, lines 799-800)

\section{Montessori Teachers Under Pressure}

The result of this lack of experienced Montessori teachers has meant more pressure on the current experienced Montessori teachers with ece qualifications who are being called on to provide advice and support - the worry is that they may burn out and leave the profession.

Robyn - And it's the Supervisors that are having to constantly ... work longer hours and do the admin at home and stuff so that they are able to mentor the younger staff members, so what's going to end up happening is that these supervisors are all going to burn out and they are going to go "yep that's enough" "out of here" and all your experience will be gone. (FG 1, lines 789-793) 
As most Montessori centres are small, the pressure is most likely on the one teacher with Montessori and ece qualifications who might also happen to be the manager/owner/administrator and teacher, as identified by Ana Pickering and Sarah.

AP - I think [it] has been stressful on people ... especially in small centres where there's ... one person and so many of our centres are small. They don't have echelons of people above running the whole show. So they are teaching, they are doing the [admin] (Interview 4, p.3, lines 91-94)

Sarah - For a small team if there is two full-timers and one part-timer and one with a Montessori qualification that means $1 / 3$ of the team has Montessori. One third is a small amount and I think that puts a lot of pressure on you personally - where's your support and someone to help carry the load. (FG 2, lines 590-593)

Anne Meade had noticed this pressure also;

It was something that we predicted in the strategic plan working group. And l've heard that it is happening, too. There is an overload on people who are fully qualified and registered. They are asked to be associate teachers, and they are also the advice and support people for provisionally registered teachers. So there is huge responsibility on them, and they've got a full-on job anyway and maybe other things in their lives ... (Interview 3, p.5-6, lines 184-187)

In their survey of the early childhood sector during 2003-2004, Mitchell and Brooking (2007) noted that $21 \%$ of teachers described their workload as "excessive". In addition, Mitchell and Brooking (2007) argue that as the survey was done prior to a number of new policy initiatives set to be released over the following years it would be reasonable to expect this number to rise - the focus groups of this study occurred during 2006 . They also commented on the association between excessive workload and low morale. This raises the concern that with the pressure currently on experienced Montessori teachers, there is the risk of low morale within the Montessori profession and the possibility of these teachers leaving altogether. 


\section{A New Hope - AUT Graduates?}

Is there a light at the end of the tunnel - some relief for these teachers? As outlined in Chapter 2, MANZ hoped to rectify the teacher supply difficulty by negotiating a means that would produce teachers with a qualification that meet both Montessori and the DipTch (ECE) requirements - the first 9 graduates of the BEd (MECT) from the Auckland University of Technology (AUT) were in 2004, with a further 17 in June 2005 (Pickering, 2005). At the end of 2005 there were 6 more graduates, and an additional 22 graduates in 2006. N.Chisnall, (personal communication, November 12, 2007)

According to MANZ, as at mid 2005, there were 17 Montessori centres employing AUT graduates (including the 9 experienced Montessori teachers who gained a BEd (ECT) via the flexi-course offered through AUT) (Pickering, 2005). Since the end of 2005 there have been 19 graduates, (out of 28) employed in Montessori centres. N.Chisnall, (personal communication, November 12, 2007)

So has this solution been successful? Ana Pickering does not think so;

I think in terms of it meeting our teacher supply problem, and the rest of the country ... I don't think it's been a great success. (Interview 4, p.4, lines 143-144)

The members of the Auckland focus group, who have had the most experience with the graduates of AUT, also did not think it had been successful so far. They had particular concerns that the graduates were not given enough preparation in the Montessori curriculum and were coming into centres without a robust and thorough knowledge of Montessori. They felt strongly that the graduates needed experienced mentors alongside them.

Annie - But there are a lot of people who aren't there anymore to nurture these students who must be so lost when they come out of AUT. (FG 1, lines 444-446) 
Lorraine - I also find that the students that are coming from AUT you are getting a really high calibre of student but ... I'm teaching them [how to use] the equipment! (FG 1, lines 232-234)

Robyn - [lt should be] a Montessori degree [from] year one ... not just specialising in year three and it really is plonking it on the end. It's very minimal in my opinion....

When I trained in Montessori there was a long period of time working with the equipment. I have been involved in presenting materials to the students at AUT - I took a class on Sensorial equipment and within a period of 3 hours I presented most of the Sensorial equipment to the students. They [could] practise and use the equipment in a free period they had ... but in terms of their demonstration - that was it! Sensorial - three hours - that just blew me away! But that's the time allocation that they're been given for the Montessori part of the ECE. ... It takes time and practice to be a proficient practitioner. (FG 1, lines 253-256, 277-286)

\section{A 'watered-down' Version of Montessori Education}

Without the experienced Montessori teachers, the implication is, as the focus group members believe, a 'watered down' version of Montessori

Robyn - I think what's happening is, I see the old Montessori teachers (those that qualified with a Montessori diploma) having to constantly nurture the watered down version of Montessori that's coming out of AUT. ... They are going into it because they want ECE - and they've made a decision to do a speciality bit on the end that's Montessori - an add on. And it is a watered down version - very much so. So they don't have that groundwork, that whole way of thinking - that passion for Montessori. It is certainly better than no Montessori but it would be a lot more beneficial to the centres and the individuals training if it were a Montessori degree from Day 1. (FG 1, lines 471-479)

Ana Pickering agrees. She is concerned that the depth of knowledge of

Montessori that the AUT graduates have, alongside the requirement for teachers with ece qualifications, will bring a weaker version of the Montessori approach;

And then ... when you have the training that we do have in New Zealand, ... if what they've been modelled during their training, and what they come out into in schools, is a very watered down; lets do a bit of Reggio, let's do a bit of Montessori, let's do this, that and the other thing. ... Then that just perpetuates ... And then there would be some people would be saying "well, that's fine." That surely doing a 
bit of Montessori is better than not doing it at all. [So is it ok for an AUT student] who have done their Montessori Special Ed papers are going off and working at [a] kindergarten and bringing a bit of Montessori into the kindergarten. But I don't feel that that was our intention, as an Association, to slightly Montessori-ify the rest of early childhood. I thought that our intention was to make sure that we could maintain a strong Montessori movement in New Zealand so that parents could have a real choice. (Interview 4, p.6, lines 216-226)

Others raised the same concern. They were deeply worried about the ability of centres to maintain an authentic Montessori approach with the influence of other philosophies and approaches. They believed there was a risk that alternative approaches would become a thing of the past.

When the majority of teachers in Montessori centres have a Diploma or Degree in early childhood education based on theorists suggesting a curriculum different to that proposed by Dr. Montessori, then the programmes of all early childhood centres could become essentially the same $^{9}$.

Lorraine - The biggest thing for Montessori is going to be to maintain the Montessori philosophy when they are getting staff with the [ECE] qualifications because if you don't have someone who doesn't believe in Montessori then they can actually change the whole character of what Montessori is all about, they can change the whole centre and ... then you don't have a Montessori school anymore ... And there's no standard to say "Yes that's Montessori". (FG 1, lines 681-687)

Alice - I think that if we're not very, very careful about standing strong about what we believe in terms of Montessori [then] Montessori is going to disappear. Because the expectations are that everybody will be ECE trained and alternatives will become a thing of the past and Montessori is going to disappear along with it if we are not strong. (FG 1, lines 697-701)

Robyn - My concern is that [Montessori] is going to get watered down to a point where it's just maybe got a pink tower and we can call ourselves a Montessori school, I think there's enough of that now without it getting worse. (FG 1, lines 726-729)

\footnotetext{
${ }^{9}$ See Bodrova (2003) for a comparison of Vygotsky and Montessori, who argues there are more differences between the two theorists than similarities.
} 
Overall these concerns raise the question; can centres continue to provide an authentic Montessori practice? Both Nicola Chisnall and Ana Pickering are not so sure;

$\mathrm{AP}$ - I think it (the qualification requirement) has made it a lot more difficult for Montessori Centres to be Montessori Centres. And to offer a really strong Montessori philosophy and practice in the schools, because they don't have enough people who know what [that] is. (Interview 4, p.2, lines 38-40)

NC -Another example would be in ( $x$ centre) ... they lost their Montessori-qualified, mentoring people, at the top. And they've only got one now. And now they've got all these younger people and they're kind of re-inventing things, and it's not very settled anymore. (Interview 5, p.4, lines 122-124)

It is difficult to know what exactly is changing for Montessori centres in the delivery of their programmes, an area that requires further research. However as Ana Pickering observes; certainly a lack of knowledge of the curriculum and how to present the materials would make an impact;

Because that's your teaching resource - to me, it's my technical skill those are my teaching tricks up my sleeve, that when I walk into the room, and Chris [is] standing there and I'm wondering what to do with him, and I know ... I can look around my classroom and think, "oh, maybe he's ready for extensions on such and such" ... and I know enough about what's in my classroom that I can ... meet his needs. And if you don't know that, you don't know how to meet their needs. (Interview 4, p.10, lines 356-360)

But as Mary Jane Shuker (2005) has argued, there has been ongoing debate on the "correctness of [Montessori] practice" (p.230) and she goes on to argue that "although the integration of Montessori education within any country results in a culturally specific Montessori education, the paradigm is culture sensitive and highly adaptable" (p.286).

In addition, Nicola Chisnall would argue that, in particular, the graduates of AUT are part of a more open Montessori approach which is situated within the wider context of early childhood education, incorporating the broader range of educational theorists that are covered in the degree - these ideas will be discussed further in Chapter 8. 


\section{Part of the Wider Early Childhood Profession}

For some teachers in the focus groups they could see benefits for the Montessori community - in particular feeling a part of the larger community of early childhood education

Rachel - I think one of the things that I've seen about having other people who have done other trainings coming in is that Montessori has now opened the doors a lot more. I think it used to be quite closed. With other people coming in even for a short time and us going and doing training in other places has really helped people understand what Montessori is a lot more rather than thinking it's a strange thing on the other side of early childhood. (FG 2, lines 489493)

Elizabeth - I think it's a good thing, because we're a part of New Zealand. So it's good ... to acknowledge ... the bigger world. But you have to also stay true to Montessori ... And then you're also part of the wider early childhood sector, doing a good job there as well. (FG 3 , lines 574-580)

For Ana Pickering, being part of the move towards a qualified, professional early childhood sector had been good for the Montessori community - it had meant being acknowledged and considered a small but important part of early childhood education in New Zealand.

I have felt very much at ECAC (Early Childhood Advisory Committee)

${ }^{10}$ that there's great acknowledgement around the table [for diverse services] ... they often say, "to incorporate the special character of the Kohanga Reo, Steiner and Montessori". ... I think that [discussion] about, whether we should have tried to stand outside of this process and ... insisted that a Montessori diploma on its own was adequate .... [But] I think that the view ... that we needed to meet this requirement just like everybody else. I think that was a good thing to do....

[And] I think in terms of the kind of involvement that l've had with the Ministry, I think if we weren't sitting at that table, talking ... about Montessori. We would have been forgotten a long time ago ... [to] have that acknowledgement, is really important for us as a movement ... And that they do see us as an important part of teacher-led services ... to have the opportunity to have people on the working parties. (Interview 4, p.9-11, lines 324-332, 375-388, 400-402)

\footnotetext{
${ }^{10} \mathrm{ECAC}$ is a group of representatives from the early childhood sector of New Zealand brought together by the Ministry of Education. The group meets regularly with the Ministry to share, discuss ideas and concerns, and to hear and consult on the latest policy initiatives occurring with in the sector.
} 


\section{Summary}

This chapter has explored the impact of the policy requirement on the wider community of Montessori in New Zealand. The overwhelming impact has been the severe shortage of Montessori qualified teachers with a Diploma or Degree. Also a shortage of Montessori qualified teachers alone and a nationwide shortage of teachers with a DipTch (ECE) or equivalent (Thorne, 2004).

This shortage of experienced Montessori teachers has meant a number of consequences identified by the focus groups and the interviewees. Namely: significant pressures on the experienced Montessori teachers currently working within the sector, the loss of experienced Montessori teachers to run programmes and to guide and support new teachers and the loss of Montessori centres - either through closure or by being sold and no longer remaining a Montessori centre.

Many centres felt frustrated at not being able to employ the right person for their centre, either due to a lack of candidates or because they needed to employ someone with an ece qualification to meet the requirement. This was sometimes linked to the centres' decision to aim for better funding by having all teachers with a Diploma or Degree. However the data provided by the Ministry of Education suggests that, as the majority of centres had less than $80 \%$ ece qualified, the centres were either unable to employ any qualified teachers or were prioritising their employment decisions to teachers with Montessori qualifications.

The traditional source of experienced Montessori qualified teachers is from overseas. A few centres had continued to do this - however others found the efforts required and the lack of recognition from NZQA of their qualifications (and therefore no additional funding attached to their employment in the centre), meant it was no longer a viable option. Many of the focus group teachers mentioned their sorrow at the loss of cultural richness that these teachers had brought to their centres. 
All were greatly concerned however at the loss of their expertise as mentors for new Montessori teachers, and their influence on Montessori programmes.

The issue of overseas teachers raised a conflict in views between the 'policy elite' (in this instance Ross Boyd) and the expert observer (Anne Meade). Ross Boyd argued that the Ministry did not consider bringing in overseas teachers to help meet the teacher supply crisis, as they felt the curriculum, Te Whāriki, was too specialised. However, Anne Meade argued that Te Whāriki recognises cultural and philosophical diversity and therefore specialist teachers from overseas should be able to join centres that need them. Here is an example of the recipients of policy providing insights that are not seen by the policy makers (McNeil \& Coppola, 2006).

The AUT BEd (MECT) degree, instigated by MANZ in the late 1990s has not met with the success the Association had hoped. All focus group members in Auckland were concerned at the lack of Montessori knowledge displayed by the AUT graduates and alongside the larger number of teachers without Montessori training working in Montessori centres, they were anxious with, what they saw, as a move towards a 'watered-down' version of Montessori education. They saw a risk that Montessori centres would be much the same as other early childhood education centres. There is a tendency to assume homogeneity in the recipients of policy (Angus, 1993, as cited in Ozga, 2000, p. 23). The question could then be asked, if this is the case could the result of this policy implementation be a homogenisation of the recipients?

So will the overall consequence for Montessori in New Zealand of the policy requirement, be a move towards a new Montessori approach? Or will there be a 'watered-down version' of Montessori that essentially means very little distinction between a Montessori centre and any other centre (other than perhaps the equipment)? 
Or will the Montessori community find a balance and be able to incorporate the knowledge from the wider early childhood sector and continue to maintain the authentic Montessori approach currently available in New Zealand, therefore protecting the choice and diversity of the sector? These questions have been explored in more detail by the focus group and interview participants and are covered in the next chapter. 


\section{Chapter Eight: A New Montessori Approach in New Zealand?}

In this chapter the focus group participants and the two Montessori observers; Ana Pickering and Nicola Chisnall, explore the notion of a new Montessori approach, an unintended consequence of the qualification requirement.

They discuss their thoughts on where Montessori education is going in New Zealand - in particular;

- How will the qualification requirement affect the educational programmes provided in Montessori centres?

- Will the Montessori method in New Zealand become a 'watered down' version of what is currently available here or overseas?

- Or will it grow into the more creative, responsive and flexible programme?

As many have argued (Ball, 1994; Goertz, 2006; Halpin, 1994; McNeil \& Coppola, 2006; Ozga, 2000; Ozga \& Gewirtz, 1994), policy analysis must explore the impacts and consequences of policy on the recipients of policy.

This study has shown that one of the most significant impacts of the qualification requirement, and possibly one with the most far reaching consequences, is on the teaching of Montessori in the Montessori early childhood centres of New Zealand.

This chapter will attempt to predict what that impact could be: What will the Montessori approach in New Zealand look like in 2012 - the final date of this staged policy requirement? 


\section{Blending Montessori with Other Approaches}

Due to the qualification requirement, as we have heard in the previous chapters, centres have had to either employ teachers with a Diploma or Degree with no Montessori knowledge or experience, often in the 'position of responsibility', alongside experienced Montessori teachers. This raises tensions amongst staff and, for some, difficulties in accommodating the knowledge and skills of the teacher with the Diploma into the Montessori centre;

Leslie - Our teachers that are training are going out into ... mainstream environments for $3,4,7$ weeks at a time and then they come back with all these buzzing ideas and you think how are we going to keep them happy, allow them to be able to integrate their knowledge but still maintain [the] Montessori philosophy. (FG 1, lines 370-373)

Some centres have been able to employ a graduate of the specialised AUT Montessori degree - BEd (MECT). However the concern raised by Ana Pickering and the focus group teachers is if these graduates are the only Montessori qualified teacher in the centre, the Montessori programme will suffer due to their lack of the Montessori curriculum knowledge - leading to a 'watering down' of the approach.

While many of the focus group participants were concerned for centres and their ability to meet the requirement and maintain a strong Montessori programme, those that had gained their early childhood qualifications could see the advantages of that knowledge in their practice. For Sarah, a teacher who had a Montessori qualification first then did her ece degree through AUT, bringing the two together has enriched her practice;

I think I was very lucky in the way round I did it. In the AUT course we did get a lot of questions about how much has your Montessori been watered down because you've done an ECE ...[but I think] you take what you want from the ECE, it doesn't have to water it down, it can add to it, or increase your knowledge base. ... Maybe that's why ECE didn't change what I thought. It gave me some other ideas and added to my knowledge base but it convinced me very strongly that yes Montessori was where I wanted to be, and ECE can be part of 
Montessori - its not Montessori and ECE as two very separate things. (FG 2, lines 169-173, 190-192)

Nicola Chisnall had also observed this in those who had strong Montessori backgrounds and experience and had gone on to gain an ece qualification through AUT.

In other centres, they've taken on new graduates. And they've had people who've upgraded and that's really good, because they are the people who have ... the wisdom, the Montessori experience, but they've also got the Diploma or Degree and often these centres are great. They'll take on new graduates and welcome their input and, they're bubbly places. (Interview 5, p.4, lines 129-132)

She explains how the broader theoretical knowledge and the current approach to early childhood education are very much in keeping with $\mathrm{Dr}$ Montessori's ideas.

... people are hanging on to Montessori practice without taking on the bigger socio-cultural perspective which Montessori can accommodate, if you've thought about it carefully. That's what has happened with those people who did our upgrade programme. They've gone back and have that knowledge now ... they have wonderful [ERO] reports because they know how to do it. They know how to connect with what's needed but they've also got a wonderful depth of Montessori. (Interview 5, p.5, lines 165-169)

Chisnall is keen to see the end of the "mechanistic" approach that arises from some Montessori trainings. Ana Pickering agrees and is also hopeful that bringing Montessori and other theories together will have a positive impact on Montessori practice.

I would hope that in the schools where there have been early childhood people and Montessori people working alongside ... by sharing their different understandings ... they have enthused each other and broadened each other's views of things. And I would hope that with the AUT graduates, too, that they've seen Montessori in a wider context. And Nicky's (Chisnall) view that moving it away from, what she would say, that very mechanistic approach, which I know is there in our centres, so maybe [for] some people there has [been a] shift from that. (Interview 4, p.6, lines 229-234) 
However Pickering is cautious. She has observed the more practical change to the way Montessori centres are run through the qualification requirement - the increase in qualified teachers has meant giving all adults in the class teaching roles. Traditionally a Montessori classroom had one qualified Montessori 'Directress' who guided the children and presented the materials, with an assistant who maintained the environment and oversaw the whole classroom - now there seems to be more co-teacher situations.

I think the way we teach in our classes has probably changed since this qualification has come in ... going away from that directress/assistant model. Which, I think, has advantages - it must have advantages being in a co-teacher situation with someone. (Interview 4, p.8, lines 306-309)

Pickering can also see the disadvantages from a philosophical view point

But it's changed our ratio ... changed the way we teach in the classroom ... You've probably got more people interfering with what the children are doing, instead of less. Because ... it used to be more clearly defined, the role of the assistant was to keep the overview and to help maintain the environment ... and now I think if you've ... got two teachers or three teachers co-teaching in a classroom, you've got three people who are actively engaged with children so ... from a Montessori viewpoint, you've probably got too many adults in there. (Interview 4, p.8-9, lines 309-315)

$\mathrm{Dr}$ Montessori states that the child has an innate drive towards independence and the adult is often the obstacle to their pursuit - doing too much for them is a hindrance to their natural development, their desire to perform activities for themselves (Montessori, 1962/1993).

\section{A New Montessori Approach?}

Could the blending of other educational theorists, such as Lev Vygotsky, and the Montessori approach bring about a 'new Montessori' approach in New Zealand? Nicola Chisnall believes so. When asked what it was that she thought was missing from some Montessori practice, she described a lack of parental involvement and what she saw as 'rigid practice' - going from one presentation to another without really responding to the child's needs, a 
teacher that was too controlling and following the method rather than the child;

Parent participation and partnership has been a huge one. I think for some, there's a big issue in terms of teacher control. That's my main issue. I believe Montessori teacher preparation up to now, has contributed to rigid practice - where the teacher tells the children. ... And misunderstanding the child-centered nature of Montessori because we're so keen to get through those presentations! So people are being controlling, not understanding the emergent curriculum which Montessori understood so beautifully ... she listened to the children, and heard their needs, and adapted her approach accordingly, built up ideas and met what they wanted in terms of language, in terms of maths. I mean, it was all in response to the children. They showed her what to do. So it's that responsive reciprocal teaching partnership with children. (Interview 5, p.5-6, lines 171-180)

Lakshivi A. Kripalani (1981), an AMI trainer ${ }^{11}$, agrees, she contends the emphasis is often on the presentation of the materials, therefore missing the principals underlying the equipment, with the result "that the child is lost in the shuffle" (p.30).

So what is Nicola Chisnall's vision for Montessori practice in New Zealand?

I want to see people ... who are ... post-modern Montessori, basically. That can see Montessori, not as the "one way to God" ...there's only one way to Montessori! But that they are thinking, creative Montessori centres. That they are responsive to the children - ... that the materials are there, as a resource. A wonderful resource.... but the philosophy is the key, and that you've got a group of teachers who have got that community of practice, that are working together ... it's not a hierarchical system. ... a creative system that still goes back to the insights that Montessori had, in terms of the 'absorbent mind', the 'sensitive periods' and ... research is backing up all her ideas. And so we can hold onto those, and all those intuitive insights that she had that are now being verified. So there's no reason for us to chuck out Montessori, at all. I think there's fully a reason to strengthen what she discovered. And I want teachers who are discovering, for themselves, new things about children. Not a static approach. ... Curriculum knowledge, content knowledge [knowing] how to use the golden beads for example. How to get the best out of them, to understand their links ... [to] the concepts that children can develop early on. ... knowing how to support the strategies that children are developing ... [able] to be aware, and how to look for them, and how to ask the right questions and give the right

\footnotetext{
${ }^{11}$ The American Montessori Internationale (AMI) was founded by Dr Maria Montessori in 1929. It maintains that it is the only organisation providing an authorised Montessori training.
} 
experiences to children, to foster those. ... [able] to understand what's underlying the materials. What is it teaching? What concept is this one developing? (Interview 5, p.6,8, lines 202-212,258-264)

Ana Pickering agrees and sees the Montessori approach and the theoretical framework of Te Whāriki (Ministry of Education, 1996), as complementary;

I'm sure that we could have just kept running quite nice Montessori classes without having to know anything about Te Whāriki ... But I think having that kind of knowledge; I think it gives us another framework to understand children. I mean, if you're looking at your vision for children as being capable and confident learners, I think that fits perfectly with Montessori and ... it helps give another framework. (Interview 4, p.11, lines 407-411)

Others have also argued that the Montessori approach is able to fit within the current approach to early childhood education within New Zealand such as co-constructivism as defined by New Zealand researchers Joy Cullen (1998) and Stuart McNaughton (1995) (as cited by Farquhar, 2003, p. 8).

Elkind (2003) has argued "Both Montessorians and constructivists put the child at the center (sic) of the educational program and emphasize the opportunity to explore, manipulate, and operate upon materials at the child's own time and rhythm" (p.28). Bodrova (2003) agrees, stating "Both Montessori and Vygotsky can be described as constructivists: they believed that children construct their own knowledge and do not simply mirror what is being taught to them" (p.31). Bodrova (2003) says that they do differ.

While Dr Montessori believed the construction occurred primary within the child, Vygotsky believed the construction of knowledge occurred within a shared cultural space - hence the term co-construction. Dobozy (1999) agrees, she contends that while $\mathrm{Dr}$ Montessori is a constructivist, she ignored the personal and cultural background of the child "completely" (p.1).

Here Nicola Chisnall disagrees; she argues Dr Montessori did not view the child in isolation, that during her early work setting up the first Casa dei Bambini, she responded directly to the children, their backgrounds and their families - in addition she was also able to see beyond their illiterate families 
and provided the opportunity for the children to learn to read and write (Chisnall, 2004). Kahn (1981) has also argued that the Montessori teacher is a "co-participant with the parents in assisting the child's growth and development" (p.8).

As Chisnall has said there is room for Montessori centres to accommodate more socio-cultural approaches into their programme, for one centre in New Zealand this was their experience. Leonie Kelly (an experienced Montessori teacher) reflected on the inequitable learning opportunities happening for toddlers in her centre. She and her staff collaborated with the centre's parents and explored the toddlers' prior knowledge and experiences therefore creating a socio-cultural context from which to observe the toddlers, build on their interests and meet their development needs. After changes, such as additional materials and rearranging the prepared environment, the result was "the toddlers [showed an] obvious enjoyment and engagement in the programme" (Visser \& Kelly, 2006, p.24).

Does incorporating other ideas mean, as some have predicted, a watered down version of Montessori - or Montessori centres becoming just like everyone else? Nicola Chisnall does not believe so;

Definitely not! (laughs) No.... it's interesting. I've got a bunch of students out on practicum at the moment and those that have gone to Montessori centres that are running well ... they said "Oh, now we can see what you were talking about - it's wonderful! It's so different $\ldots$ this is the best practicum l've ever been on ... this is ... my fifth practicum and it's just fantastic! And the children are concentrating, it's so different to childcare and ... people are wonderful. (Interview 5, p.6, lines 183-187)

\section{Montessori First}

However, Ana Pickering's hesitation with the move towards a 'new' Montessori approach is that Montessori centres need experienced teachers with a strong foundation and understanding of the Montessori philosophy and curriculum before they are able to take on new ideas and other theoretical approaches. 
She believes it is possible to critique the Montessori approach, and that this is a life long journey, but teachers need to firstly be able to know how to put the philosophy into practice - be able to use the Montessori materials, to teach the curriculum.

For me it's a balance between understanding the depth of your Montessori philosophy - which I think is a lifetime's work. And understanding how that translates into your actual classroom practice. Or ... your general life practice within your community ... And I think ... that Montessori isn't just something that you "do" to children in classrooms, but actually it's a philosophy for living life. [But the concern is] you could end up with someone who has some understanding of Montessori philosophy, and its relevancy to the rest of education in the universe ... But they don't actually know how to deliver the curriculum in the classroom. And I don't think that's very helpful, either. [But] I think there has to be a balance between the two - of understanding why you do the things that you do, with the Montessori materials, but knowing actually you could run a Montessori classroom without them. (Interview 4, p.7, lines 234-254)

Chisnall had also observed the change in practice of some Montessori centres who were struggling without experienced Montessori teachers, for some centres it has resulted in providing programmes that do not sit within the Montessori philosophy.

Some of them have gone off on tangents ... they do a literacy focus ... or a school readiness-type programme, and you think ... this is not Montessori at all. You're just using the name. Others ... may have Montessori rooms within a primarily 'childcare' programme. So yes, it is a problem. (Interview 5, p.5, lines 161-163)

Both Chisnall and Pickering would therefore argue that this deeper understanding and ability to incorporate other approaches, without impacting the core elements of the Montessori programme ${ }^{12}$, comes from a strong foundation and understanding of the Montessori philosophy and the curriculum - therefore before the New Zealand Montessori community can get to Nicola's vision of a 'new' Montessori it needs experienced Montessori practitioners which, according to Chisnall, will come in time.

\footnotetext{
${ }^{12}$ The core or essential elements of a Montessori programme have been identified by Dr Nancy McCormack Rambush, American Montessori Society (AMS), as a guide to prospective parents (See Appendix 14). Currently MANZ is collating the essential elements of Montessori within the New Zealand context in consultation with the wider Montessori community of New Zealand. These are expected to be available in 2008.
} 
In Montessori, I don't think it's been going long enough, and there are not sufficient qualified people out there to really challenge current practice. Because the people who are coming in are new, and there's still very much that hierarchical system in Montessori. And so there are difficulties in the system... from those who decided not to go through and do the qualification and so their thinking has not been challenged. When ... a younger person comes in, they may just be wanting to soak up the experience of being in the field ... but because of their qualification, they also see problems in the practice. So until the current practitioners engage with the new people in discussion and reflection....or retire, we won't see the full benefit of the new qualifications.... (Interview 5, p.4, lines 113-120)

For Pickering, centres just do not have the time; they are struggling right now and are in desperate need of qualified and registered teachers. And while she sees the worth of the graduates bringing a broad philosophical view of Montessori in the long term, she believes the AUT degree could (and should) be producing graduates with both a wider view of Montessori and the practical knowledge and skills to deliver the Montessori curriculum in the classroom. As she says Montessori centres are telling her they need teachers who can walk into their classes and teach the curriculum. Without them they are not able to maintain a strong Montessori programme;

If ... the AUT qualification, if it had answered the needs, if there had been a big enough uptake, if it had provided teachers that Montessori Centres felt were useful when they walked into the classroom. ... they don't know the scope and sequence of the curriculum. That's what we're hearing back anecdotally. They don't know how to present material ... So it's that ... practical teacher resource thing, like how do I know how to deliver my philosophy through my practice? That's what they don't seem to be understanding. But maybe ... this is a new kind of Montessori graduate that, as time goes by, and these people become leaders within our community, because they've got a different view, maybe there's a strength that will come from that. Whereas I think it could have been both ... it could be a degree where yes, they have a depth of philosophy and they have a width of view of early childhood, but they also have the practical aspect of knowing how they do this with children on a daily basis in the classroom. (Interview 4, p.9-10, lines 332-335, 343-356)

This concern was held by the focus group participants (see Chapter 7), their immediate solution was for experienced Montessori teachers to mentor and support the new graduates. Give them that curriculum knowledge, a deeper understanding of how the philosophy works in practice and then incorporate 
other approaches to develop and accommodate the Montessori approach to fit the socio-cultural approach of New Zealand's early childhood sector.

\section{A 'Creative' Solution?}

As mentioned previously Montessori centres traditionally employed experienced Montessori teachers from overseas to provide support and programme leadership and would again if they could.

One teacher, Amelia, wondered if it was possible to have these Montessori teachers from overseas come into the centres on a limited authority to teach' (LAT) as is the case in the primary system

I got a limited authority to teach. And if you can't get what you want in your centre, you can apply for someone like me - I wasn't a registered primary teacher - but I could work ... why can't you do the same in ECE? (FG 3, lines 474-476)

This was discussed further by the group with the following suggested - a temporary arrangement for overseas Montessori teachers to be granted provisional registration (therefore bring extra funding to the school) for their two year working visa. It is attached to the one centre offering them a job, they lose it if they move to another centre and if they choose to stay longer in New Zealand they must go on to do a Diploma or Degree. This is an example of what Ball (1994) describes as localised solutions - where the problems posed by policies, such as the inability to employ overseas Montessori teachers to meet the teacher supply issue, because they do not meet the qualification requirement, must be solved in context; a solution or creative "invention or adaptation" explored by the teachers, to meet the policy requirement (Ball, 1994). 
When this possible solution was mentioned to Nicola Chisnall she was positive in her response;

We used to bring people in from overseas, and ... you've mentioned the possibility of getting a limited license to practice .... and I think that might be a good way around it. ... So, in the short term, that might be a solution. (Interview 5, p.7, lines 223-239)

Anne Meade was also receptive to the idea;

That sounds like a pretty smart solution to me. (Interview 3, p.10, line 361)

When raised in another focus group, the teachers were very open to the idea and would look to employ from overseas under those conditions

Lorraine - Yes, I think it would maintain the character then - they would bring a huge amount of experience.

Leslie - Yes, because then if you have got someone like that in your centre as a mentor it would help over come the watering down that we are all concerned about. (FG 1, lines 783-787)

As Ana Pickering argues it will be very difficult to maintain a strong Montessori approach in New Zealand without experienced Montessori teachers

People have said things to me like, "I don't think there will be anything such as a Montessori centre in New Zealand in a few years. I think ... the future of Montessori in New Zealand is ... we're just going to become just like the rest of early childhood." [So] how can we manage to maintain our special character ... how do we maintain that philosophy, when we don't have enough people with Montessori skills and training in our classrooms, delivering the goods to the children? (Interview 4, p.6, lines 210-215)

The consequence of this would be fewer Montessori centres, which provide a strong Montessori programme; with competent and effective Montessori qualified teachers. For Annie, who sold her school, that was one of her biggest concerns, she wanted there to remain a distinct choice for parents.

The biggest thing (and I got a lot of letters from my parents) one of the big fears that they had was the government in doing this was taking their choice away ... But the watering down of Montessori, in the end if it does go, means that parents do not have a choice anymore ... (FG 1, lines 704-708) 


\section{Summary}

This chapter has explored the wider unintended consequences, of the policy requirement for qualified teachers, on the Montessori approach in New Zealand. All participants saw an amalgamation of the current theories and approaches, gained through a Diploma or Degree in early childhood, with the Montessori approach. The chapter then explored whether this was going to mean a 'watering down' of the Montessori approach or the beginning of a new Montessori approach in New Zealand.

For Nicola Chisnall she can see the benefits of a new Montessori approach and believes the original writings of Dr. Montessori can easily accommodate the socio-cultural and co-constructivist approach of Te Whāriki, which is influenced by theorists such as Lev Vygotsky, Urie Bronfenbrenner and Jerome Bruner (May, 2001).

Both Ana Pickering and many focus group teachers agreed and felt there were certainly advantages to the knowledge the AUT graduates brought to centres; however their lack of curriculum knowledge and skills in presenting materials meant they were not up to the expectations of the sector.

As Pickering argued the AUT BEd (MECT) degree intended to, and still could, produce graduates with the knowledge of Montessori alongside the other early childhood theorists, as well as, the ability to put that philosophy into practice - the scope and sequence of the materials.

However for all participants, looking at the predicament of centres in the immediate and short term, the shortage of experienced Montessori teachers who also had qualifications that could meet the requirement was of great concern. For those centres with experienced Montessori teachers, the view of the Montessori observers was they were able to incorporate Te Whāriki well and accommodate other approaches, without impacting on the essential elements that make up a Montessori classroom. 
For those centres without an experienced Montessori teacher, or even with a higher proportion of teachers without Montessori, there is still the risk of the centre providing a watered down Montessori approach - such as a programme that focused on a 'school readiness' programme or had a 'Montessori' room which the children attended during one part of the day..

To avoid this risk and meet the need for experienced Montessori teachers, the participants explored a possible solution - a short term measure which gave experienced Montessori teachers from overseas a 'provisional registration' or LAT (or something similar), attached to the centre they were to work in for their two year working visa. This would enable centres to obtain valuable funding for that teacher, maintain their Montessori curriculum and provide support and mentoring to the other teachers in their centre.

This localised solution (Ball, 1994) could mean maintaining a robust Montessori community in the short term which can nurture, support and encourage the new Montessori teachers, whether AUT graduates or otherwise, joining centres throughout New Zealand. So helping to produce a strong foundation of Montessori knowledge and skills, providing a fertile bed in which other ideas and approaches can grow. 


\section{Chapter Nine: Conclusion}

This thesis set out to investigate the impact of the early childhood teacher qualification policy requirements (2002) on the Montessori community of New Zealand. The study used interviews and focus groups to explore the views and experiences of the 'policy elite', expert observers, and Montessori teachers themselves.

In 2007, New Zealand, along with the rest of the world, celebrated 100 years of the Montessori Method of education. At the time, her ideas were revolutionary and although challenged over those 100 years, many argue their relevance to current research on education and early childhood curriculum approaches today (Chisnall, 2004; Elkind, 2003; Kramer, 1976; Lillard, 2005).

This study revealed how one of many minority early childhood options within the early childhood sector of New Zealand was forced to make significant changes to their centres. These changes challenged the Montessori sector in New Zealand to question whether it could accommodate the current theoretical approaches to early childhood education, and, still maintain the fundamental tenets of the Montessori Method approach.

The policy changes had both direct and unintended consequences. For example the direct impact has been:

- Four Montessori centres have closed since 2003, an additional three have been sold and are no longer offering a Montessori programme,

- A severe shortage of Montessori teachers, causing significant recruitment and retention issues for many centres.

- Individual teachers endured significant personal and financial pressures to undertake additional training to meet the qualification requirements,

- Centres struggled to maintain continuity of care for children and parents while juggling staff changes, 
○ Tensions within teaching teams have created difficult working environments and placed additional pressure on the supervisors in centres.

The unintended consequences are:

- Experienced Montessori teachers leaving the profession, or are not employed from overseas, therefore leaving a lack of mentors - guides for Montessori programmes and new teachers.

- The concern for new graduates, in particular those from AUT, placed in a position of responsibility without the knowledge, skills and experience required for the position.

The unintended consequences raised the following question: What influence has the addition of generic early childhood qualifications had on Montessori teaching practice and programmes?

Some participants predicted that, as a result of the policy, the Montessori approach would become watered down, and that the Montessori approach would no longer exist in New Zealand. Others believed the original writings of Dr. Maria Montessori were very much aligned with the currently accepted theories of early childhood education, and that the current Montessori practice has become too rigid. Still others believe that the qualification requirements will result in a new, open, and creative Montessori approach. 


\section{The Challenges}

Goertz (2006) asserts that policy analysis serves several functions such as identifying policy problems; considering the design of the policy; exploring how policy is implemented; how do localities adopt polices; and, what are the effects? This study considered the intention of the policy requirement for qualified teachers in early childhood centres; the assumptions made during the policy formation process; the implementation of the policy; and, the effects on the Montessori teachers and centres. The findings reveal unintended consequences that created numerous challenges for the teachers and their centres, and for the wider Montessori community in New Zealand.

The research used a critical theory framework to expose and explore perceived injustices within the Montessori early childhood sector resulting from the policy implementation requiring qualified teachers. Critical research can be the "first step toward forms of political action that can redress the injustices found in the field" (Kincheloe \& McLaren, 1994, p.264). Findings demonstrated the struggles Montessori centres experienced to remain viable and authentic Montessori centres. This research argues that these experiences could support policy changes to rectify the injustices uncovered in the data. Kincheloe and McLaren (1994) suggest exploring the challenges that occur during the policy implementation process is the start - the next is to identify the challenges for change that must occur from this study. The challenges emerging from the research are described next.

\section{For the Ministry of Education}

The problem of teacher supply was identified during the policy formation phase, however consideration of the diverse landscape of the New Zealand early childhood education sector, was limited. While the Ministry of Education provides initiatives to address the teacher supply issue (see Chapter 4 ), these were restricted to regional disparities that did not meet the 
specific needs of the non-mainstream early childhood services available in New Zealand. While the context for this study was Montessori, the research focus and design has relevance to other philosophical or cultural approaches, such as Steiner or Pasifika education.

As discovered, the assumption, as shown by the 'policy elite', is that this policy requirement would impact on a homogenous sector. I contend therefore that this policy could be unfairly affecting other parts of the early childhood sector, not just the Montessori community alone.

Therefore the challenge to the Ministry of Education is to be both creative and responsive to the struggles and needs of teachers and their centres, and not to see their problems as 'resistance' (Ball, 1994).

For example there is room for the Ministry of Education to consider the solution suggested by the participants in this study which is to allow Montessori centres to employ experienced overseas Montessori teachers with Limited Authority to Teacher status, or as 'provisionally registered' in specific centres. While this is a short term measure, it would acknowledge the complexities and difficulties experienced by Montessori centres, provide a resolution to the teacher shortage, and address the need for Montessori mentors for new graduates.

\section{For teacher training providers}

This study identified the significant role of teacher training providers in the implementation of this policy requirement. First, the learning environment encountered by some Montessori teachers who did additional training, the experience was frustrating and they felt patronised. The challenge to teacher training providers is to a) acknowledge the existing skills and experience in the Montessori sector, and b) incorporate this in the training programmes. 
Second, a challenge for those training providers who made significant moves to respond to the diverse needs of the early childhood sector, such as AUT. The introduction of the BEd (MECT) is important for the Montessori community nationally, and internationally, and also for the early childhood sector in general. The initiative to encompass a Montessori qualification within a generic teacher training programme is to be applauded. However there is room for improvement - the challenge now is to ensure the graduates are able to run a robust Montessori programme - something the findings of this study have identified as not occurring now.

\section{For the Montessori community}

The findings identified a further challenge - to the Montessori teachers and centres in New Zealand: how to accept the qualification requirement as an opportunity to improve the experiences offered to children in their programmes? It is important for the Montessori community to explore how other early childhood approaches might enhance the Montessori approach to weave their own New Zealand Montessori "whāriki". This includes exploring the Montessori contribution to the wider early childhood sector.

\section{A Moment in Time}

This thesis has captured a moment in time - the intention of the policy requirement for DipTch (ECE) qualified teachers and the response of the Montessori teachers, centres and community to its implementation. It has not provided a critique of how the response and unintended consequences have impacted on Montessori educational practice. That is for further research.

It has however identified the unfairness of a one size fits all policy; it has documented the significant short term and long term consequences for the Montessori community in New Zealand; and, identified the challenges that still exist. 
It is now time to look at creative strategies to lessen the impact of this policy, and ensure that the diverse early childhood landscape of New Zealand is retained, supported, and celebrated for the next 100 years.

As I write this conclusion, the early childhood sector is in the process of two more significant policy changes; new regulations governing the licensing of centres and the policy of " 20 hours free for 3 and 4 year olds". Both are threatening the way Montessori centres currently offer their programme. These policies are being introduced into an environment that all policymakers praise for its diversity. But the policies are not only applied as if the sector is not diverse, their formation and implementation runs the risk of making it less diverse.

If diversity and choice is valued, the whole early childhood sector, including the Ministry of Education, need to do more than hope and talk. They must actively protect diversity, through providing quality experiences for children that also meet their philosophical and cultural needs.

In fact, I take a step further. High quality early education has long-term benefits for children (Podmore et al, 2000). However this study has found the effort to impose a structural "quality" measure can detrimentally impact diverse early childhood approaches. Rigorously applying "quality" without allowing for differences, risks killing the vitality brought by differences vitality that is essential for continued improvement. 


\section{References}

Altheide, D. L., \& Johnson, J. M. (1998). Criteria for assessing interpretive validity in qualitative research. In N. K. Denzin \& Y. S. Lincoln (Eds.), Collecting and interpreting qualitative materials (pp. 283-311). Thousand Oaks: Sage Publishers.

Ball, S. J. (1994). Education reform: A critical and post-structural approach. Buckingham: Open University Press.

Barnett, W. S. (2003). Low wages = Low quality: Solving the real preschool teacher crisis. Retrieved 24 July, 2004, from http://nieer.org/ resources/policybriefs/3.pdf

Barnett, W. S. (2004). Better teachers, better preschools: Student achievement linked to teacher qualifications (No. 2). New Brunswick, $\mathrm{NJ}$ : National Institute for Early Education Research.

Barrington, J. (1998). Central and local control in education. New Zealand Annual Review of Education, 7, 79-93.

Bloor, M., Frankland, J., Thomas, M., \& Robson, K. (2001). Focus groups in social research. London: Sage.

Bodrova, E. (2003). Vygotsky and Montessori: One dream, two visions. Montessori Life, 15(1), 30-33.

Bogart, L. (2004). The role of University-based teacher education programs as part of the whole. Montessori Life, 16(1), 22-23.

Bruce, L. (2004). NZEl supports early childhood qualification move. Retrieved 27 January, 2004, from http://www.nzei.org.nz/get/502

Chisnall, N. (2002). On spinning, weaving and darning: Changing perspectives on Montessori in Aotearoa-New Zealand 1975-2000. Unpublished Master's thesis, Victoria University, Wellington.

Chisnall, N. (2003). Weaving the Montessori Whariki. Wellington: IECS.

Chisnall, N. (2004). Changing perspectives on Montessori in early childhood education. Early Education, 34(Autumn), 15-21.

Codd, J. A. (1994). Educational reform and the contradictory discourses of evaluation. Evaluation and Research in Education, 8(1\&2), 41-54.

Connelly, F. M., \& Clandinin, D. J. (1990). Stories of experience and narrative inquiry. Retrieved 19 May, 2007, from http://links.jstor.org/ sici+0013-189X\%28199006\%2F07\%2919\%3A5\%3C2\%ASOEANI\% 3E2.0.CO\%3B2-V

Creswell, J. W. (2003). Research design: Qualitative, quantitative and mixed methods aproaches (2nd Edition). Thousand Oaks, C.A: Sage. 
Creswell, J. W., \& Miller, D. L. (2000). Determining validity in qualitative inquiry. Retrieved 26 April, 2007, from http://proquest.umi.com. helicon.vuw.ac.nz/pqdweb?index $=0 \&$ did $=57818398 \&$ SrchMode $=1 \&$ si $\mathrm{d}=4 \& F m t=6 \& V I n s t=P R O D \& V T y p e=P Q D \& R Q T=309 \& V N a m e=P Q D \&$ TS=1177556885\&clientld=7511

Creswell, J. W., Hanson, W. E., Plano Clark, V. L., \& Morales, A. (2007). Qualitative research designs: Selection and implementation. Retrieved $17 \quad$ May, 2007, from http://tcp.sagepub.com/cgi/content/abstract/35/2/236

Dahlberg, G., Moss, P., \& Pence, A. (1999). Beyond quality in early childhood education and care: Postmodern perspectives. London: Falmer Press.

Dalli, C. (1993). Is Cinderella back among the cinders? A review of early childhood education in the early 1990s. New Zealand Annual Review of Education, 3, 223-252.

Dalli, C., \& Te One, S. (2003). Early childhood education in 2002: Pathways to the future. New Zealand Annual Review of Education, 12, 177-202.

Denscombe, M. (1998). The good research guide for small-scale social research projects. Buckingham: Open University Press.

Denzin, N. K., \& Lincoln, Y. S. (1994). Introduction: Entering the field of qualitative research. In N. K. Denzin \& Y. S. Lincoln (Eds.), Handbook of qualitative research (pp. 1-34). Thousand Oaks, CA: Sage.

Department of Education. (1988). Before Five: Early childhood care and education in New Zealand. Wellington: Department of Education.

Department of Labour. (2007, 30 July). Immediate Skill Shortage List. Retrieved 30 October, 2007, from http://www.immigration.govt.nz/NR/ rdonlyres/89185A40-27D3-41F4-84BE-30129920411D/0/ISSL.pdf

Department of Labour. (2007, November). Skills in the labour market at a glance. Retrieved 14 December, 2007, from http://www.dol.govt.nzl PDFs/lmr-skills-sep2007.pdf

Dobozy, E. (1999). Constructivist and Montessorian perspectives on student autonomy and freedom. Retrieved 6 July, 2007, from http://www.waier.org.au/forums/1999/dobozy.html

Early Childhood Education Project. (1996). Future Directions: Early childhood education in New Zealand. Final report (revised edition). Wellington: NZEI.

Early Childhood Education Strategic Plan Working Group. (2001). Final Report of the Strategic Plan Working Group to the Minister of Education.

Early Childhood Group. (1994). Early childhood qualifications and training: A summary of key developments. Wellington.

Education Review Office. (2000). What counts as quality in early childhood centres. (No. 4). Wellington: Education Review Office. 
Education Review Office. (2004). Early childhood: Readiness to implement the 2005 qualification requirements. Wellington: Education Review Office.

Edwards, A. (2001). Qualitative designs and analysis. In G. MacNaughton, S. Rolfe \& I. Siraj-Blatchford (Eds.), Doing early childhood research: International perspectives on theory and practice. (pp. 117-135). Sydney: Allen \& Unwin.

Elkind, D. (2003). Montessori and constructivism. Montessori Life, 15(1), 2629.

Farquhar, S. E. (2003). Quality teaching early foundations. Wellington: Ministry of Education.

Fiske, E., \& Ladd, H. (2000). When schools compete: A cautionary tale. Washington DC: Brookings Institute Press.

Goertz, M. E. (2006). Policy analysis: Studying policy implementation. In J. L. Green, G. Camilli \& P. B. Elmore (Eds.), Handbook of complementary methods in education research (pp. 701-710). New Jersey: Lawrence Erlbaum Associates.

Goffin, S. G., \& Wilson, C. S. (2001). Curriculum models and early childhood education: Appraising the relationship (2nd ed.). New Jersey: Merrill Prentice Hall.

Golafshani, N. (2003). Understanding reliability and validity in qualitative research. The Qualitative Report, 8(4), 597-606.

Halpin, D. (1994). Practice and prospects in education policy research. In D. Halpin \& B. Troyna (Eds.), Researching education policy: Ethical and methodological issues (pp. 198-206). London: Falmer Press.

Harrison, J., MacGibbon, L., \& Morton, M. (2001). Regimes of trustworthiness in qualitative research: The rigors of reciprocity. Qualitative Inquiry, 7, 323-345.

Holstein, J. A., \& Gubrium, J. F. (1994). Phenomenology, ethnomethodology, and interpretive practice. In N. K. Denzin \& Y. S. Lincoln (Eds.), Handbook of qualitative research. Thousand Oaks, C.A: Sage.

Hughes, P. (2001). Paradigms, methods and knowledge. In G. MacNaughton, S. Rolfe \& I. Siraj-Blatchford (Eds.), Doing early childhood research: International perspectives on theory and practice (pp. 31-55). Australia: Allen \& Unwin.

Kahn, D. (1981). Training, the teacher, and praxis. The N.A.M.T.A Quarterly, $6(3), 1-4$.

Keesing-Styles, L. (2003). Re-thinking the notion of qualified teachers in early childhood education. New Zealand Journal of Educational Studies, 38(2), 235-244.

Kincheloe, J. L., \& McLaren, P. L. (1994). Rethinking critical theory and qualitative research. In N. K. Denzin \& Y. S. Lincoln (Eds.), Handbook of qualitative research. Thousand Oaks, C.A: Sage. 
Kramer, R. (1976). Maria Montessori: A biography. United Kingdom: Montessori International Publishing.

Kripalani, L. A. (1981). A continuing exploration in Montessori teacher training. The N.A.M.T.A Quarterly, 6(3), 24-31.

Kvale, S. (1996). InterViews: an introduction to qualitative research interviewing. Thousand Oaks, C.A: Sage.

Ladd, H. F., \& Fiske, E. B. (2003). Does competition improve teaching and learning? Evidence from New Zealand. Educational Evaluation and Policy Analysis, 25(1), 97-112.

Lauder, H., \& Hughes, D. (1999). Trading in futures: Why markets in education don't work. Buckingham: Open University Press.

Lawler, S. (2002). Narrative in social research. In T. May (Ed.), Qualitative research in action (pp. 242-258). London: Sage.

Libertarianz Party. (2000). 'Forced Retraining' removes parents' choice. Retrieved 9 November, 2007, from http://www.scoop.co.nz/stories/ Po0005/S00092.htm

Lillard, A.S. (2005). Montessori: The science behind the genius. New York: Oxford University Press.

MacNaughton, G., \& Rolfe, S. (2001). The research process. In G. MacNaughton, S. Rolfe \& I. Siraj-Blatchford (Eds.), Doing early childhood research: International perspectives on theory and practice. (pp. 12-30). Sydney: Allen \& Unwin.

Mallard, T. (2000a). Early childhood education meeting. Retrieved 1 April, 2005, from http://www.executive.govt.nz/speech.cfm?speechralph $=32074 \& \mathrm{SR}=1$

Mallard, T. (2000b, 30 November). Teaching qualifications for early childhood education licensing. Retrieved 3 July, 2007, from http://www.beehive.govt.nz/ViewDocument.aspx?Document/D=9247

Mallard, T. (2002). Early Childhood Symposium. Retrieved 3 July, 2007, from

http://www.beehive.govt.nz/Print/PrintDocument.aspx?Document|D=1 $\underline{4923}$

Mallard, T. (2004). Change to provisional licence system. Retrieved 27 January, 2005, from www.beehive.govt.nz/ViewDocument.cfm? Document|D=21684

Mallard, T. (2005). Scholarships for early childhood teacher training. Retrieved 4 July, 2007, from http://www.scoop.co.nz/stories/ PA0505/S00301.htm

MANZ Qualification Committee. (2000). Minutes of Meeting 1 \& 2 April.

Massey University. (2007). University Funding. Retrieved 6 July, 2007, from http://sfp.massey.ac.nz/massey/depart/admin/sfp/universityfunding.cfm 
May, H. (1990a). From a floor to a drawer - A story of administrative upheaval. A post Meade reflection on early childhood policy. Access, 9(2), 41-48.

May, H. (1990b). Growth and change in the early childhood services: A story of political conservatism, growth and constraint. In S. Middleton, J. Codd \& A. Jones (Eds.), New Zealand education policy today: Critical perspectives. Wellington: Allen \& Unwin.

May, H. (1992). After 'Before Five': the politics of early childhood care and education in the nineties. Women's Studies Journal, 8(2), 83-100.

May, H. (1996, 15-16 May). Training, qualifications and quality: The costs of compromise. Paper presented at the Assessing and improving quality in early childhood centres - A national seminar, Childrens Issues Centre, Wellington.

May, H. (1997, 13 June). Childcare workers, carers, teachers: The changing context of childcare work and training. Paper presented at the Closing the Gap: a Forum on Equal Pay, Wellington.

May, H. (1999). The price of partnership: the Before Five decade. In M. Thrupp (Ed.), A decade of reform in New Zealand education: Where to now? (pp. 18-27). Waikato: School of Education, University of Waikato.

May, H. (2000). ece@2000.aotearoa.nz: Mapping the landscape of the "century of the child". New Zealand Annual Review of Education, 9, 117-132.

May, H. (2001). Politics in the playground: the world of early childhood in postwar New Zealand. Wellington: Bridget Williams Books.

May, H. (2002). Early childhood care and education in Aotearoa - New Zealand: An overview of history, policy and curriculum. McGill Journal of Education, 37(1), 1-20.

McLeod, L. (2000). Early childhood practitioner research in New Zealand: Why? How? Where? And with whom? International Journal of Early Childhood, 32(1), 20-25.

McNeil, L., \& Coppola, E. M. (2006). Official and unofficial stories: Getting at the impact of policy on educational practice. In J. L. Green, G. Camilli \& P. B. Elmore (Eds.), Handbook of complementary methods in education research (pp. 681-699). New Jersey: Lawrence Erlbaum Associates.

Meade, A. (1988). Education to be more: Report of the Early Childhood Care and Education Working Group. Wellington: Department of Education.

Meade, A. (1990). Women and young children gain a foot in the door. Women's Studies Journal, 6(1/2), 96-110.

Meade, A. (1994a). Before Five - 5 years on. Paper presented at the Special NZARE Seminar, 13 \& 14 August, Auckland. 
Meade, A. (1994b). World leaders in early childhood education. In $\mathrm{H}$. McQueen (Ed.), Education is change: Twenty viewpoints. (pp. 48-59). Wellington: Bridget Williams Books Ltd.

Meade, A. (1999). The early childhood landscape in New Zealand. In J. Hayden (Ed.), Landscapes in early childhood education. Crossnational perspectives on empowerment - a guide for the new millennium. (pp. 83-92). New York: Peter Lang.

Meade, A. (2000). The early childhood landscape in New Zealand. In J. Hayden (Ed.), Landscapes in early childhood education. Crossnational perspectives on empowerment - a guide for the new millennium. (pp. 83-92). New York: Peter Lang.

Meade, A. (2002, 19 September). Teacher quality vital to early education scheme. The New Zealand Herald.

Meade, A., \& Dalli, C. (1991). Review of the early childhood sector. New Zealand Annual Review of Education, 1, 113-132.

Ministry of Education. (1990). Early childhood qualifications and training: $A$ blueprint for the future. Wellington: Author.

Ministry of Education. (1996). Te Whariki. Wellington: Learning Media.

Ministry of Education. (2001, 28 May 2007). Analysis of submissions received on the Consultation Document for the Development of the Strategic Plan for Early Childhood Education, August 2001. Retrieved 23 November, 2007, from http://www.minedu.govt.nz/index.cfm? layout=document\&documentid=6524\&indexid=7689\&indexparentid=1 $\underline{0943}$

Ministry of Education. (2002). Pathways to the Future: Nga Huarahi Arataki. Wellington: Author.

Ministry of Education. (2004). Early childhood exemption. Retrieved 3 July, 2007, from http://www.edgazette.govt.nz/articles.php/?id=6646

Mitchell, L. (1995). Crossroads - early childhood education in the mid 1990s. New Zealand Annual Review of Education, 5, 75-92.

Mitchell, L. (1999). Before Five: The price of partnership. Paper presented at the Conference "A decade of reform in New Zealand: Where to now?" 10-11 June, University of Waikato, Hamilton.

Mitchell, L. (2001a). Bulk Funding of New Zealand's early childhood services: An analysis of the impact. Wellington: NZCER.

Mitchell, L. (2001b). Currents of change: Early childhood education in 2001. New Zealand Annual Review of Education, 11, 123-143.

Mitchell, L. (2002). Notes for presentation to OECD country seminar, 14 October.

Mitchell, L., \& Brooking, K. (2007). First NZCER national survey of early childhood education seervices. 2003-2004. Wellington: NZCER.

Montessori, M. (1962/1993). The discovery of the child. Oxford: Clio Press. 
Montessori Association of New Zealand. (2000, December). Annual Report: Expanding horizons gains acceptability for Montessori. Montessori NewZ, 20, 17.

Moss, P. (1994). Defining quality: Values, stakeholders and processes. In P. Moss \& A. Pence (Eds.), Valuing quality in early childhood services. London: Paul Chapman.

Organisation for Economic Co-operation and Development. (2001). Starting strong: Early childhood education and care. Retrieved 16 October, 2004, from http://www1.oecd.org/publications/e-book/9101011E.PDF

Ozga, J. (2000). Policy research in educational settings: Contested terrain. Buckingham: Open University Press.

Ozga, J., \& Gewirtz, S. (1994). Sex, lies and audiotape: Interviewing the education policy elite. In D. Halpin \& B. Troyna (Eds.), Researching education policy: Ethical and methodological issues. London: Falmer Press.

Perigo, L. (1999, 16 July). Politically Incorrect Show. Retrieved 15 May, 2005, from http://www.freeradical.co.nz/content/pishow/pi990716.php

Phillipsen, L. C., Burchinal, M. R., Howes, C., \& Cryer, D. (1997). The prediction of process quality from structural features of child care. Early Childhood Research Quarterly, 12, 281-303.

Pickering, A. (2005). Graduates boost teacher numbers. Montessori Newz, 38(June), 1-2.

Podmore, V. N., Meade, A., \& Kerslake Hendricks, A. (2000). Aspects of Quality in Early Childhood Education. Wellington: NZCER.

Reid, J. (2004). AUT Update. Montessori Newz, December, 20.

Riessman, C. K. (2002). Narrative analysis. In A. M. Huberman \& M. B. Miles (Eds.), The qualitative researchers companion (pp. 217-270). Thousand Oaks, C.A: Sage.

Rist, R. C. (2000). Influencing the policy process with qualitative research. In N. K. Denzin \& Y. S. Lincoln (Eds.), Handbook of qualitative research. (2nd ed.). London: Sage Publications Inc.

Ritchie, J., \& Spencer, L. (2002). Qualitative data analysis for applied policy research. In A. M. Huberman \& M. B. Miles (Eds.), The qualitative reseracher's companion (pp. 305-329). Thousand Oaks: Sage.

Scarr, S. (1994). Child care quality, and cost: Research, values, and public policy. In A. Borge, E. Hartman \& S. Strom (Eds.), Day care centres: Quality and provision. Oslo: National Institute of Public Health.

Scott, D., \& Morrison, M. (2005). Key ideas in educational research. London: Continuum International.

Scott, D., \& Usher, R. (1999). Researching education: data, methods and theory in educational enquiry. London: Continuum.

Scrivens, C. (1998). Leadership in early childhood: The Kindergarten experience. New Zealand Journal of Educational Administration, 13, 36-43. 
Shuker, M. J. (2005). The historical evolution and contemporary status of Montessori schooling in New Zealand, as an example of the adaptation of an alternative educational ideal to a particular national context. Unpublished PhD thesis, Massey University, Palmerston North.

Silverman, D. (2000). Doing qualitative research: A practical handbook. London: Sage.

Simons, J. A., \& Simons, F. A. (1986). Montessori and regular preschools: A comparison. In L. Katz (Ed.), Current topics in early childhood education (Vol. VI, pp. 195-223). New Jersey: Ablex Publishing Corporation.

Smith, A. (1996a). The quality of childcare centres for infants in New Zealand. NZARE Monograph, 4.

Smith, A. (1996b). Quality programs that care and educate. Childhood Education, 72(6), 330-336.

Smith, A. B., \& Farquhar, S. E. (1994). The New Zealand experience of charter development in early childhood services. In P. Moss \& A. Pence (Eds.), Valuing quality in early childhood services. (pp. 123139). London: Paul Chapman.

Smith, A. B., Grima, G., Gaffney, M., Powell, K., Masse, L., \& Barnett, S. (2000). Strategic Research Initiative Literature Review Early Childhood Education. Report to the Ministry of Education. Dunedin: Children's Issues Centre.

Smith, N. (1999). New standards in early childhood education. Retrieved 15 May, 2005, from http://www.executive.govt.nz/speech.cfm? speechralph $=29021 \& S R=0$

Standing, E. M. (1957/1998). Maria Montessori: Her life and work. New York: Plume.

Stott, D. (2001). Strategic Plan out for comment. Montessori Newz, 23, 3.

Suzuki, L. A., Ahluwalia, M. K., Kwong Arora, A., \& Mattis, J. S. (2007). The pond you fish in determines the fish you catch: Exploring strategies for qualitative data collection. Retrieved 17 May, 2007, from http://tcp.sagepub.com/cgi/content/abstract/35/2/295

Te One, S. (1996). On the road again: The pathways programme in context. Unpublished EDUC 502 Assignment.

Te One, S. (2003). The context for Te Whariki: Contemporary issues of influence. In J. Nuttall (Ed.), Weaving Te Whariki: Aotearoa New Zealand's early childhood curriculum document in theory and practice (pp. 17-49). Wellington: NZCER.

Thorne, S. (2004). New incentives acknowledge teacher crisis. Retrieved 17 October, 2004, from http://www.ecc.org.nz/mediareleases/ index. php?rt=20\&rid $=487$

Toma, J. D. (Ed.). (2006). Approaching rigor in applied qualitative research. Thousand Oaks: Sage Publications. 
Visser, J., \& Kelly, L. (2006). Of painting and washing windows, and butter, jam and marmite sandwiches: Towards a more toddler inclusive Montessori setting. The First Years: Nga Tau Tuatahi. New Zealand Journal of Infant and Toddler Education, 8(2), 21-24.

Wellington, J. (2000). Educational research: Contemporary issues and practical approaches. London: Continuum.

Wells, C. (1991). The impact of change - against the odds. Paper presented at the Fifth Early Childhood Convention, September, Dunedin.

Whitebook, M. (2003a). Bachelor's degrees are best: Higher qualifications for pre-kindergarten teachers lead to better learning environments for children. Retrieved 24 July, 2004, from http://www.trustforearlyed.org/docs/WhitebookFinal.pdf

Whitebook, M. (2003b). Early education quality: Higher teacher qualifications for better learning environments - A review of the literature. Berkeley, CA: Center for the study of Child Care Employment. Retrieved 24 July, 2004, from http://www.iir.berkeley.edu//cscce/pdf/teacher.pdf

Whitebook, M., Howes, C., \& Phillips, D. (1989). Who cares? Child care teachers and the quality of care in America. Executive Summary. National Child Care Staffing Study. California: Child Care Employee Project.

Wylie, C. (1998). Five years old \& competent. Wellington: New Zealand Council for Educational Research.

Wylie, C. (2001, 6-7 April). Competent children: Findings and issues from the first 7 years. Paper presented at the Ministry of Social Policy Seminar, The long road to knowledge: Longitudinal research and social policy., Wellington.

Wylie, C. (2004). Twelve years old \& competent. Wellington: New Zealand Council for Educational Research.

Young, J. R. (2004). Kawhia Preschool decision. Retrieved 3 July, 2007, from http://www.ecc.org.nz/mediareleases/index.php?rt=20\&rid=517 


\section{Appendix 1:}

TE WHARE WĀNANGA O TE ŪPOKO O TE IKA A MĀUI

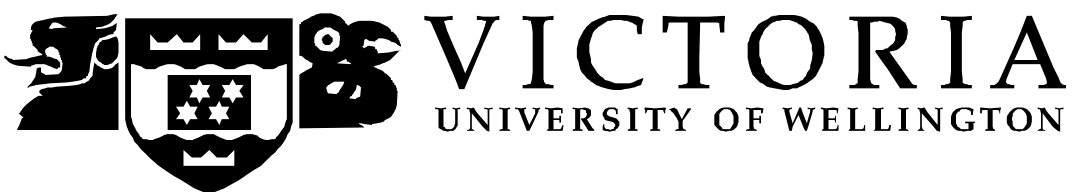

INSTITUTE FOR EARLY CITILDITOOD STUTIES

Te Pimangw a Ringilhau Köhungahwng,

Research for Masters Thesis

(Through Victoria University of Wellington)

June 2005

Researcher: Sola Freeman

Supervisor: Sarah Te One / Dr. Carmen Dalli

Background:

In 2002, the Labour/Progressive Coalition Government outlined its vision of having all adults working in teacher-led services to be qualified (with the Diploma of Teaching ECE or equivalent) by 2012, in the document Pathways to the Future (Ministry of Education, 2002). This vision was created collaboratively and after much consultation with the early childhood sector. This requirement will occur via a staged plan.

I am interested in the impact of this policy requirement on the Montessori sector of New Zealand.

I am undertaking this study for my thesis in part fulfilment of a Master of Education degree at Victoria University of Wellington. The working title is "The 2002 qualification policy requirement implementation and its impact on Montessori in New Zealand".

This research is to be a qualitative case study to:

- investigate the intentions of the New Zealand Governments' 2002 policy requirement for all early childhood teachers to be qualified with a Diploma of Teaching (ECE) or equivalent by 2012

- analyse the impact and consequences of the policy implementation.

- explore the impact of this policy in practice, using the Montessori early childhood sector of New Zealand as a case study.

There will be two broad questions: 
- What have been the consequences of the SPECE policy implementation for Montessori teachers and their centres - both positive and negative?

- To what extent has the SPECE policy for qualified teachers been able to incorporate the special character of Montessori centres?

\section{Rationale:}

This research is therefore twofold in its focus:

1. analysing the current early childhood education policy context generally,

2. taking a particular focus on the New Zealand Montessori sector.

I have been actively involved in both of these two contexts; as a member of the Early Childhood Education Strategic Plan Working Group, and as a parent of children in Montessori early childhood education, a Montessori teacher, early childhood education researcher and Board member of a Montessori school.

\section{Methodology:}

I plan to interview key policy people to identify the intentions of the policy. This will include people such as Ministry of Education officials; others from agencies involved in the policy implementation and those involved in the provision of teacher education to Montessori teachers.

In addition I will conduct three focus groups in Auckland, Wellington and Dunedin with the principals/managers of Montessori centres and Montessori teachers; exploring the experience and consequences for the centres and for the teachers themselves of "upgrading" their qualifications to the Diploma or Degree in Early Childhood Teaching, and the impacts on their centre and the Montessori programme they offer.

The involvement of all those interviewed will help analyse the story of education policy implementation and in particular the consequences for one part of the diverse early childhood landscape in New Zealand.

I intend to finish this research project by 2007/8, with the research; interviews and three focus groups, being conducted throughout 2005, and follow-up interviews in mid 2006. The analysis and writing will take place over 2006/7.

\section{Reference:}

Ministry of Education. (2002). Pathways to the Future: Nga Huarahi Arataki. Wellington: Author 


\section{Appendix 2:}

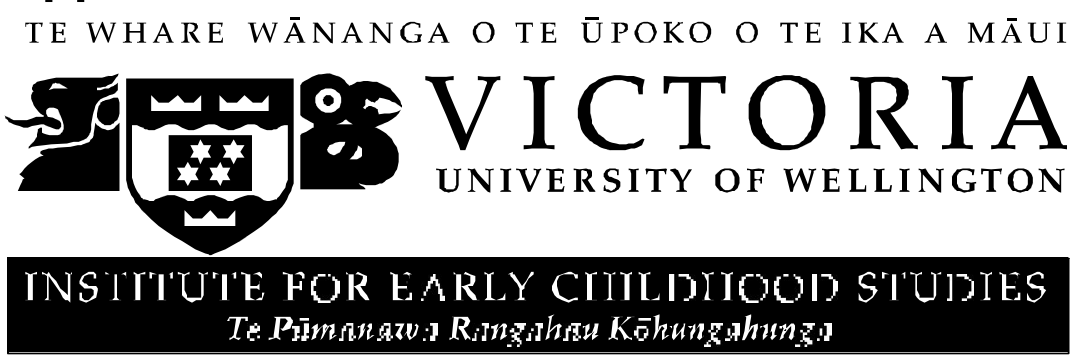

[Date]

[Name and address]

Dear [name],

I am writing to you to seek your participation in a research project on an aspect of policy of the Strategic Plan for Early Childhood Education in New Zealand Pathways to the Future.

I am undertaking this study for my thesis with the working title of "The 2002 qualification policy requirement implementation and its impact on Montessori in New Zealand". The thesis is in part fulfilment of requirements for a Master of Education degree at Victoria University of Wellington.

I have been actively involved in both of these contexts. I was a member of the Early Childhood Education Strategic Plan Working Group (2000-2002) and remain a parent of children in Montessori early childhood education, a Montessori teacher, early childhood education researcher and Board member of a Montessori school.

I am interested in the impact of this policy requirement of having all teachers qualified with a Diploma of Teaching ECE or equivalent in early childhood education and care centres by 2012 on the Montessori sector of New Zealand.

My study is a qualitative case study to:

- investigate the intentions of the New Zealand Governments' 2002 policy requirement for all early childhood teachers to be qualified with a Diploma of Teaching (ECE) or equivalent by 2012

- analyse the impact and consequences of the policy implementation.

- explore the impact of this policy in practice, using the Montessori early childhood sector of New Zealand as a case study.

As part of my research I am seeking to interview key policy people to identify the intentions of the policy. This includes people such as Ministry of Education officials; others from agencies involved in the policy implementation and those involved in the provision of teacher education to Montessori teachers.

I would appreciate the opportunity to interview you in regard to your part as the Convenor of the Strategic Plan Working Group, in the preparation and/or implementation of the policy and your understanding of its intentions and how it may affect the Montessori early childhood sector of New Zealand. 
I would be grateful if you were able to spare about an hour of your time for an interview. If you are willing to participate in this research I have included a consent form for you to sign and either return via mail or to me when we meet, also the proposed questions which will guide our time together.

I will contact you via phone to arrange a time convenient for you and we can then discuss the questions further before we meet. In the meantime you are welcome to contact me if you have any concerns or questions on (04) 9341266 (email:

Sola.Freeman@vuw.ac.nz) or you may wish to contact my supervisor: Dr. Carmen Dalli at Victoria University on (04) 4635168 (email: Carmen.Dalli@vuw.ac.nz ). I look forward to talking with you further and thank you in advance for your involvement.

Yours sincerely,

Sola Freeman 


\section{Appendix 3:}

TE WHARE WĀNANGA O TE ŪPOKO O TE IKA A MĀUI

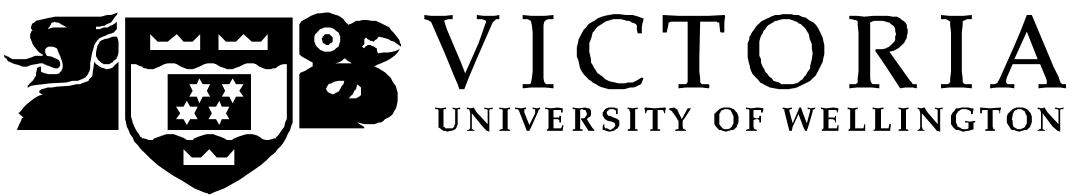

\section{INSTITUT'E FOR EARLY CTITLITOOD S'TUIJIES}

Te Pimanaw i Ringisha Köhungshung,

\section{CONSENT FORM}

Please read the following and place a tick in each box if you agree with it.

I agree to be a participant in this research.

I have read and understood the purpose of the research, and the commitment I will be making.

I agree to a tape recording of my discussion being made. A written transcript will be available for information to be withdrawn and/or corrected by myself.

I agree to my responses during my discussion being written down.

I understand the findings of this research project may be published at some future date, in scholarly and professional journals, conference presentations and in the thesis.

I understand that all tapes and/or written notes will be stored securely.

I understand that my name may be published in the research report and the information and opinions I provide will be identified as coming from me, unless I request otherwise on the form below.

I understand that following the completion of this project the taped and written data will be securely stored in the Montessori Association of New Zealand (MANZ) archives, to add to its historical collections and for the use of future researchers. The computer disk with edited interview transcript and the original tape and notes will be stored only if consent is given below. The consent process for releasing data to future researchers is detailed below and requires a separate signature.

I understand that my participation is voluntary and I may withdraw at any time before the writing of the thesis is completed. 
Signature:

Date:

\section{Consent for storage and future use of data from Interviewee}

(Please tick for yes)

$\square$ I agree that the completed and edited transcript from the interview (saved in CD format) may be stored securely in the MANZ archives for the future use of researchers approved by MANZ and the current researcher (or duly appointed agent).

$\square$ I agree that the original notes and tapes of the interview may be stored as above for the use of researchers for reference purposes only.

$\square \quad$ I do not agree to my name being published in the research report or for information and opinions I provide to be identified as coming from me.

Name:

Signature:

Please return this form in the attached envelope or to me at the interview. 


\section{Appendix 4:}

\section{Interview Questions:}

Should you agree to being interviewed, the following questions will be used as a guide. I expect the interview to take about one hour.

My study is a qualitative case study to:

- investigate the intentions of the New Zealand Governments' 2002 policy requirement for all early childhood teachers to be qualified with a Diploma of Teaching (ECE) or equivalent by 2012

- analyse the impact and consequences of the policy implementation.

- explore the impact of this policy in practice, using the Montessori early childhood sector of New Zealand as a case study.

I am therefore seeking to explore two broad questions:

- What have been the consequences of the SPECE policy implementation for Montessori teachers and their centres both positive and negative?

- To what extent has the SPECE policy for qualified teachers been able to incorporate the special character of Montessori centres? 


\section{Appendix 5:}

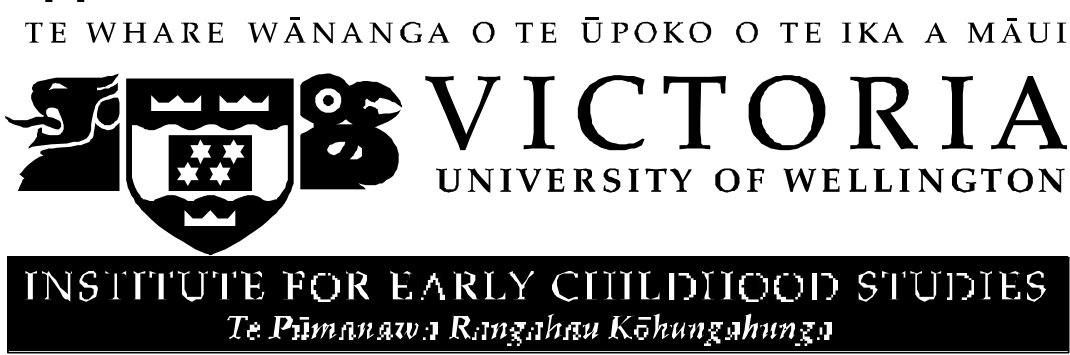

[Date]

[Name and address]

Dear [name],

As discussed on the phone today I am writing to you to seek your participation in a research project on an aspect of policy of the Strategic Plan for Early Childhood Education in New Zealand - Pathways to the Future.

I am undertaking this study for my thesis, with the working title; "The 2002 qualification policy requirement implementation and its impact on Montessori in New Zealand", in fulfilment of requirements for a Master of Education degree at Victoria University of Wellington.

I have been actively involved in both of these contexts. I was a member of the Early Childhood Education Strategic Plan Working Group (2000-2002) and remain a parent of children in Montessori early childhood education, a Montessori teacher, early childhood education researcher and Board member of a Montessori school.

I am interested in the impact on the Montessori sector of New Zealand of the 2002 policy requirement of having all teachers qualified with a Diploma of Teaching ECE or equivalent in early childhood education and care centres by 2012 .

This research is to be a qualitative case study to:

- investigate the intentions of the New Zealand Governments' 2002 policy requirement for all early childhood teachers to be qualified with a Diploma of Teaching (ECE) or equivalent by 2012

- $\quad$ analyse the impact and consequences of the policy implementation.

- $\quad$ explore the impact of this policy in practice, using the Montessori early childhood sector of New Zealand as a case study.

As part of my research I plan to hold three focus groups in Wellington, Dunedin and Auckland, involving managers/ principals of Montessori early childhood centres and/or Montessori teachers involved in study towards, or 
who have just completed, additional qualifications to meet the qualification policy requirement.

I would appreciate the opportunity to discuss with you the consequences of the implementation of the 2002 policy, your understanding of its intentions, and how it may affect the Montessori early childhood sector of New Zealand. The specific issues we will discuss will be how your centre has meet the qualification requirements and the consequences from the implementation of the 2002 policy and/or your involvement in completing additional qualifications to meet the qualification policy requirement and the impact of this.

I would be grateful if you were able to spare no longer than $60-90$ minutes of your time for a focus group meeting. If you are willing to participate I have attached a consent form for you to sign and either return via mail or to me when we meet.

In addition I hope to conduct a short follow -up telephone call with you later in the year to determine whether your centre will meet the 2007 requirement or to discuss any other issues. A separate letter and consent form giving further details on this will be sent at a later time.

At this stage I am hoping to arrange a time on the 17 or 25 June 2006, please let me know which day and time would suit and I will contact you via phone to confirm the time convenient for you and others in your area and will send further information and the likely questions we will discuss before we meet. In the meantime you are welcome to contact me if you have any concerns or questions on (04) 628846 or email sola@freeman.gen.nz or you may wish to contact my supervisor: Dr. Carmen Dalli at Victoria University on (04) 4635168 . I look forward to talking with you further and thank you in advance for your involvement.

Yours sincerely,

\section{Sola Freeman}




\section{Appendix 6:}

TE WHARE WĀNANGA O TE ŪPOKO O TE IKA A MĀUI

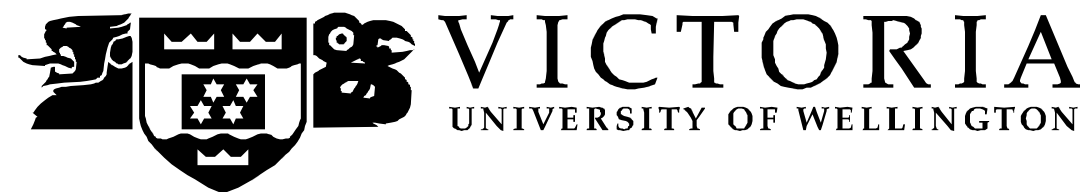

INSTITUT'TE FOR EARLY CITILIIOOD S'IUIJIES

Te Pimsnaw d Ringisha Kohungahung.1

\section{CONSENT FORM}

Please read the following and place a tick in each box if you agree with it.

I agree to participation in this focus group to discuss;

$\square$ how my centre has meet the qualification requirements and the consequences from the implementation of the 2002 policy and/or

$\square$ my involvement in completing additional qualifications to meet the qualification policy requirement,

I have read and understood the purpose of the research project, and the commitment I will be making.

I agree to a tape recording of the focus group discussion being made. A written transcript of the group interview will be available for information to be withdrawn and/or corrected by myself.

I agree to my responses during my discussion being written down.

I understand the findings of this research project may be published at some future date, in scholarly and professional journals, conference presentations and in the thesis.

I understand that all tapes and/or written notes will be stored securely.

I understand that the name of the centres and of individuals participating in focus groups will remain confidential to the researcher. (Please indicate below how you would prefer to be identified in the report)

I understand that following the completion of this project the data will be securely stored in the Montessori Association of New Zealand (MANZ) archives, to add to its historical collections, with the group's permission. The computer disk with the edited group interview transcript, with identifying details deleted for confidentiality, will be stored for use by future researchers only if consent is given below. The consent process for releasing data to future researchers is detailed below and requires a separate signature.

I understand that my participation is voluntary and I may withdraw at any time before the writing of the thesis is completed. 
Signature:

Date:

I would like to be identified in the report by the name of:

\section{Consent for storage and future use of data from Interviewee}

(Please tick for yes)

$\square$ I agree that the completed and edited transcript from the group interview, with identifying details deleted for confidentiality, (saved in CD format) may be stored securely in the MANZ archives for the future use of researchers approved by MANZ and the current researcher (or duly appointed agent).

Name:

Signature:

Please return this form in the attached envelope or to me when we meet. 


\title{
Appendix 7:
}

\section{Focus Group questions:}

\author{
Introduction:
}

Thank- you for coming today - I have given you all a copy of my thesis flyer for your information.

Has anyone been in a focus group before? The idea is for me to ask questions that begin a discussion around the areas we are focusing on. I want to capture the informal chat of those at the "coal face" who have to implement the qualification policy. The idea is for you to spark each others memory and ideas. Remember to try not to speak over each other. My role is as facilitator so I will be trying to be neutral and I am not to lead you!

In my research I am seeking to explore two broad questions:

- What have been the consequences of the Qualification policy implementation for Montessori teachers and their centres - both positive and negative?

- To what extent has the Qualifications policy for qualified teachers impacted on the special character of Montessori centres? If at all.

$\Rightarrow$ What is the qualification level of your staff right now?

$\Rightarrow$ Where do you expect to be in 2007 in terms of meeting the $2007(50 \%)$ requirement?

\section{- So will you meet the 2007 requirement?}

$\Rightarrow$ Can you think back to 2002 when the policy was introduced and recall what measures your centre has had to undertake to meet this requirement?

$\Rightarrow$ What have been the consequences of this - for yourself and for your centre?

\section{- Can you elaborate further?}

5. Can you describe the impact (if any) that the implementation of the qualification requirement has had on the Montessori programme in your centre? 


\section{Appendix 8:}

VICTORIA UNIVERSITY OF WELLINGTON

Te Whare Wananga o te Upoko o te Ika a Maui

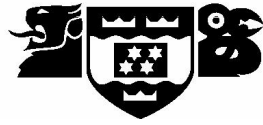

\section{HUMAN ETHICS COMMITTEE}

\section{Application for Approval of Research Projects}

Please write legibly or type if possible. Applications must be signed by supervisor (for student projects) and Head of School

Note: The Human Ethics Committee attempts to have all applications approved within three weeks but a longer period may be necessary if applications require substantial revision.

1 NATURE OF PROPOSED RESEARCH:

(a) Staff Research/ Student Research (delete one)

(b) If Student Research Degree ...MEd...Course Code EDUC 592...

(c) Project Title: The 2002 qualification policy requirement implementation and its impact on Montessori in New Zealand

\section{INVESTIGATORS:}

(a) Principal Investigator

Name ...Sola Freeman

e-mail ...markandsola@paradise.net.nz.....

School/Dept/Group

(b) Other Researchers

Name

Position

(c) Supervisor (in the case of student research projects)

...Dr. Carmen Dalli....

\section{DURATION OF RESEARCH}

(a) Proposed starting date for data collection ..11 July 2005 (proposed trip to Dunedin) 
(Note: that NO part of the research requiring ethical approval may commence prior to approval being given)

(b) Proposed date of completion of project as a whole December 2006

4 PROPOSED SOURCE/S OF FUNDING AND OTHER ETHICAL CONSIDERATIONS

(a) Sources of funding for the project

Please indicate any ethical issues or conflicts of interest that may arise because of sources of funding e.g. restrictions on publication of results

$N / A$

(b) Is any professional code of ethics to be followed $Y \square \quad \mathbf{N} \bullet$

If yes,

name NZARE

(c) Is ethical approval required from any other body $\mathbf{Y} \bullet \mathbf{N} \square$ If yes, name and indicate when/if approval will be given

\section{DETAILS OF PROJECT}

Briefly Outline:

(a) The objectives of the project

A qualitative case study to:

- investigate the intentions of the New Zealand Governments' 2002 policy requirement for all early childhood teachers to be qualified with a Diploma of Teaching (ECE) or equivalent by 2012

- analyse the impact and consequences of the policy implementation.

- explore the impact of this policy in practice, using the Montessori early childhood sector of New Zealand as a case study.

(b) Method of data collection

- Interview key policy people, such as Ministry of Education officials; others involved in the policy implementation and those involved in the provision of teacher education to Montessori teachers, to identify the intentions of the policy.

- Three focus groups in Auckland, Wellington and Dunedin with the principals/managers of Montessori centres and Montessori teachers.

- And conduct short telephone interviews with focus group members mid year 2006 to identify any changes or further impacts closer to the 2007 implementation date. 
(c) The benefits and scientific value of the project

This research is two fold in its focus; analysing the current early childhood education policy context, and with a particular focus on the New Zealand Montessori sector. In addition it will explore the impact of the Government's recent early childhood policy initiative through those actually experiencing its implementation.

The links between the intentions and policy rationale (that qualified teachers are linked to quality educational experiences for children) and the actual consequences for practice will be explored.

The involvement of all those interviewed will help analyse the story of education policy implementation and in particular the consequences for one part of the diverse early childhood landscape in New Zealand.

(d) Characteristics of the participants

Key policy people, such as Ministry of Education officials including Manager of Strategic Plan Implementation and Manager of Teacher Supply, others involved in the policy preparation or implementation such as the Executive Officer of the Montessori Association of New Zealand and Coordinator of the Strategic Plan Working Group, and those involved in the provision of teacher education to Montessori teachers.

Principals/managers of Montessori centres and Montessori teachers "upgrading" their qualifications to the Diploma or Degree in Early Childhood Teaching.

(e) Method of recruitment

.....By approach

(f) Payments that are to be made/expenses to be reimbursed to participants $N / A$

(g) Other assistance (e.g. meals, transport) that is to be given to participants

...Tea and coffee supplied to focus group participants.......

(h) Any special hazards and/or inconvenience (including deception) that participants will encounter N/A.

(i) State whether consent is for (delete where not applicable):

(i) the collection of data

(ii) attribution of opinions or information

(iii) release of data to others(as identified in Answer to Question I)

(iv) use for a conference report or a publication

(v) use for some particular purpose (specify) 
Attach a copy of any questionnaire or interview schedule to the application

(j) How is informed consent to be obtained (see sections 4.1, 4.5(d) and 4.8(g) of the Human Ethics Policy)

(i) the research is strictly anonymous, an information sheet is supplied and informed consent is implied by voluntary participation in filling out a questionnaire for example (include a copy of the information sheet)

$\mathbf{Y} \cdot \mathbf{N} \square$

(ii) the research is not anonymous but is confidential and informed consent will be obtained through a signed consent form (include a copy of the consent form and information sheet)

$\mathbf{Y}$ 曰 N • (please see attached consent form for focus group participants)

(iii) the research is neither anonymous or confidential and informed consent will be obtained through a signed consent form (include a copy of the consent form and information sheet)

$\mathbf{Y} \nabla \mathbf{N} \bullet$ (please see attached consent form for interviewees)

(iv)informed consent will be obtained by some other method (please specify and provide details)

$\mathbf{Y} \bullet \mathbf{N}$ V

With the exception of anonymous research as in (i), if it is proposed that written consent will not be obtained, please explain why

N/A

(k) If the research will not be conducted on a strictly anonymous basis state how issues of confidentiality of participants are to be ensured if this is intended. (See section 4..1(e) of the Human Ethics Policy). (e.g. who will listen to tapes, see questionnaires or have access to data). Please ensure that you distinguish clearly between anonymity and confidentiality. Indicate which of these are applicable.

(i)access to the research data will be restricted to the investigator

(ii) access to the research data will be restricted to the investigator and their supervisor (student research)

$\mathbf{Y} \bullet \mathbf{N}$ V

(iii) all opinions and data will be reported in aggregated form in such a way that individual persons or organisations are not identifiable

$\mathbf{Y} \mathbf{\nabla}$ •

(for Focus Group participants only, as identified in Question I)

(iv) Other (please specify)

- all opinions and data will be reported in such a way that some persons will be identifiable (for interviewees only, as identified in Question I)) 
(I) Procedure for the storage of, access to and disposal of data, both during and at the conclusion of the research. (see section 4.12 of the Human Ethics Policy). Indicate which are applicable:

(i) all written material (questionnaires, interview notes, etc) will be kept in a locked file and access is restricted to the investigator

(ii) all electronic information will be kept in a password-protected file and access will be restricted to the investigator $\quad \mathbf{Y} \nabla \mathbf{N} \bullet$

(iii) all questionnaires, interview notes and similar materials will be destroyed:

(a) at the conclusion of the research

$\mathbf{Y} \cdot \mathbf{N} \nabla$

(as identified below)

(b) $\stackrel{\text { or }}{\underline{1}}$ years after the conclusion of the research

(as identified below)

\section{$\mathbf{Y} \cdot \mathbf{N} \nabla$}

(iv) any audio or video recordings will be returned to participants and/or electronically wiped

(v) other procedures (please specify):

(as identified below)

$\mathbf{Y} \bullet \mathbf{N} \nabla$

- Notes, tapes and edited transcripts of interviews will be stored securely in the MANZ (Montessori Association of New Zealand) Archives.

- Edited transcripts of Focus Group interviews (with identifying details deleted) will be stored securely in MANZ archives).

If data and material are not to be destroyed please indicate why and the procedures envisaged for ongoing storage and security

Data will be stored securely with the archives of the Montessori Association of New Zealand - available for future researchers. This research will form a significant part of the history of Montessori in New Zealand. There is very little research on Montessori in New Zealand, this research will join other data in the archives collected for another thesis on Montessori in New Zealand from 1975 to 2000, and will continue that story.

(m) Feedback procedures (See section 7 of Appendix 1 of the Human Ethics Policy). You should indicate whether feedback will be provided to 
participants and in what form. If feedback will not be given, indicate the reasons why.

Participants will receive a transcript of their interview for them to withdraw and/or correct information.

(n) Reporting and publication of results. Please indicate which of the following are appropriate. The proposed form of publications should be indicated on the information sheet and/or consent form.

(i) publication in academic or professional journals $\quad \mathbf{Y} \square \mathbf{N} \bullet$

(ii) dissemination at academic or professional conferences $\mathbf{Y} \square \mathbf{N} \bullet$

(iii) deposit of the research paper or thesis in the University Library (student research)

$\mathbf{Y}$ V $\mathbf{N}$

(iv) other (please specify)

Signature of investigators as listed on page 1 (including supervisors) and Head of School.

NB: All investigators and the Head of School must sign before an application is submitted for approval

Head of School:

Date...

Date

APPLICATIONS FOR HUMAN ETHICS APPROVAL

\section{CHECKLIST}

- Have you read the Human Ethics Policy?

- Is ethical approval required for your project?

- Have you established whether informed consent needs to be obtained for your project?

- In the case of student projects, have you consulted your supervisor about any human ethics implications of your research?

- Has your supervisor read and signed the application?

- Have you included an information sheet for participants which explains the nature and purpose of your research, the proposed use of the material collected, who will have access to it, whether the data will be kept confidential to you, how anonymity or confidentiality is to be guaranteed?

- Have you included a written consent form? 
- If not, have you explained on the application form why you do not need to get written consent?

- Are you asking participants to give consent to:

- collect data from them

- attribute information to them

- release that information to others

- use the data for particular purposes

- Have you indicated clearly to participants on the information sheet or consent form how they will be able to get feedback on the research from you (e.g. they may tick a box on the consent form indicating that they would like to be sent a summary), and how the data will be stored or disposed of at the conclusion of the research?

- Have you included a copy of any questionnaire or interview checklist you propose using?

- Has your application been seen by the head of your school or department (or the person given responsibility to consider applications on behalf of the head (see section 4.5(b) of the Human Ethics Policy).

PLEASE FORWARD YOUR COMPLETED APPLICATION FORM TO THE SECRETARY, HUMAN ETHICS COMMITTEE OR, IN THE CASE OF APPLICATIONS FROM SCHOOLS OR DEPARTMENTS WITH AN APPROVED ETHICS SUB-COMMITTEE, TO THE CONVENER OF THAT SUB-COMMITTEE 


\section{Appendix 9:}

TE WHAKE WXNANGA O TE OPOKO O TE IKA A MAUS

S9 兽

School of Education Studies

Te Kura Akoranga Matauranga

2 August 2005

Sola Freeman

21 Everest Street

Khandallah

Wellington

Dear Sola

RE: Your ethics application AARP/SOES/2005/14, 4 July 2005

I am pleased to advise you that your application received on 4 July has been approved.

Best wishes for the completion of your research.

Yours Sincerely

Le

Dr Lex MeDonald

Convenor, School of Education Studies Human Ethics Committee

Cc Carmen Dalli

School of Edacwoon Soudies. Te Kura Akocangn Masuranga, PO Bro 600 , Wellingtan, Actoruch. New Zealand, Telephoee $+64-4-4635070$ of 4635345 


\section{Appendix 10:}

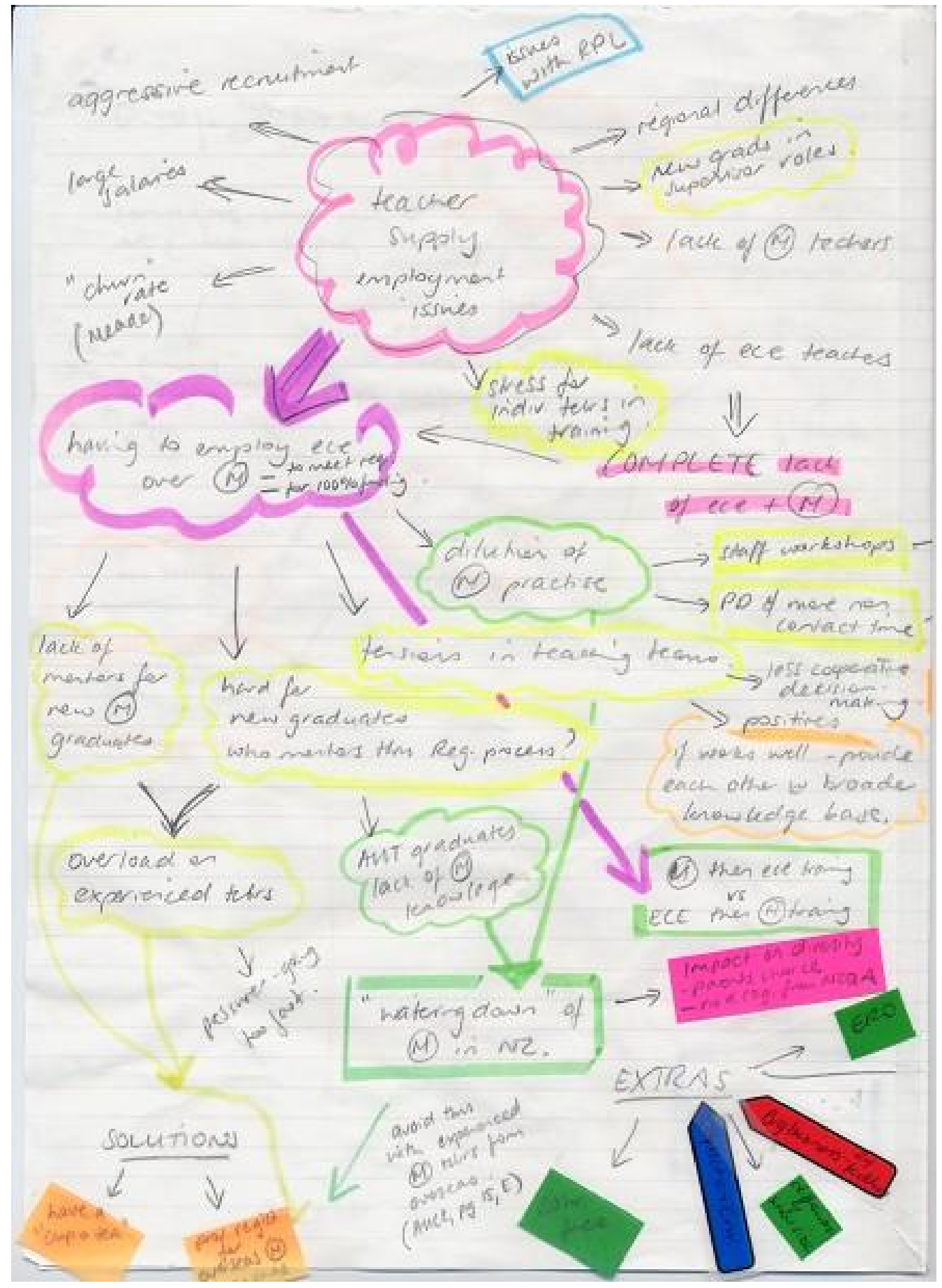




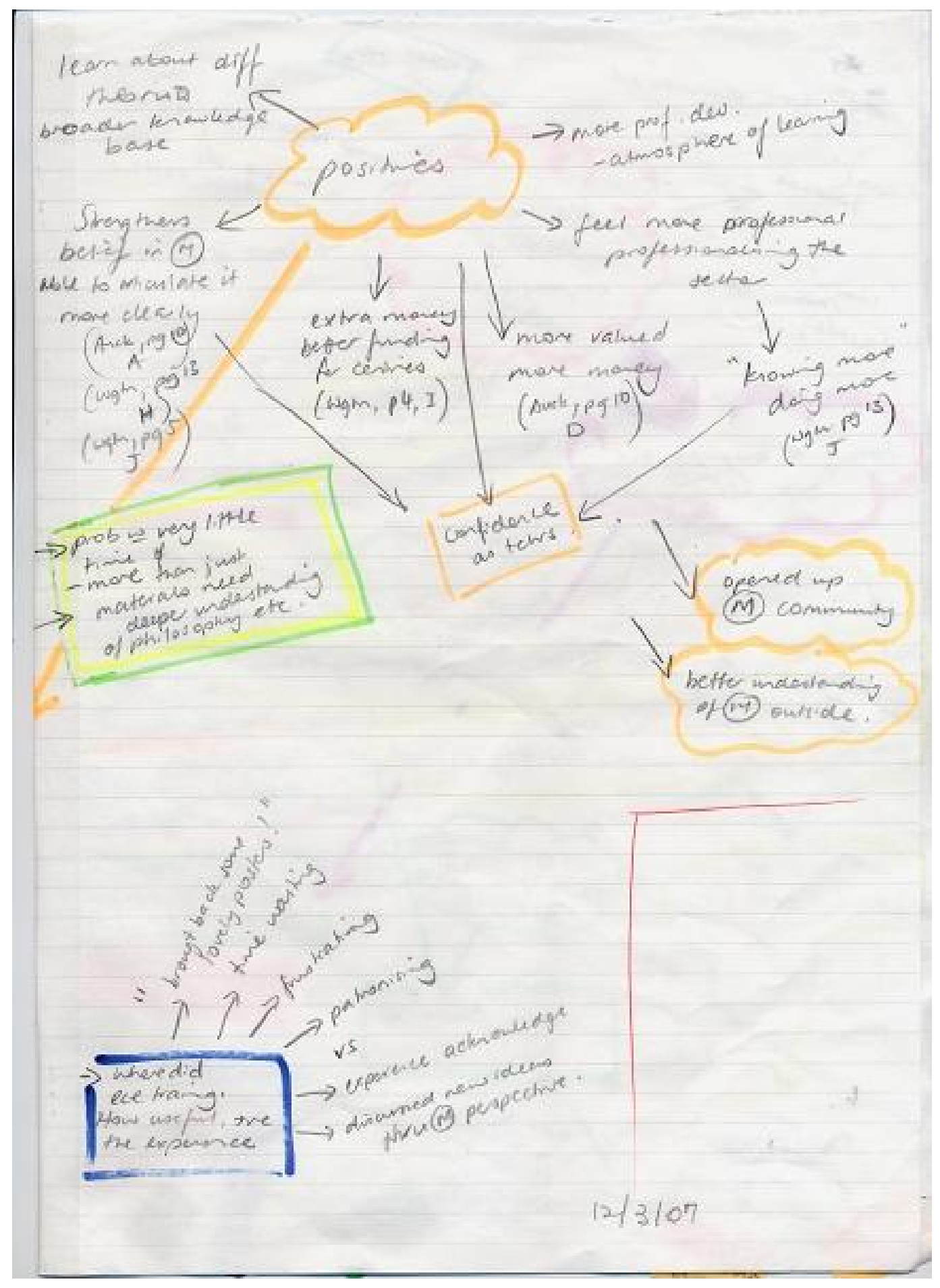




\section{Appendix 11:}

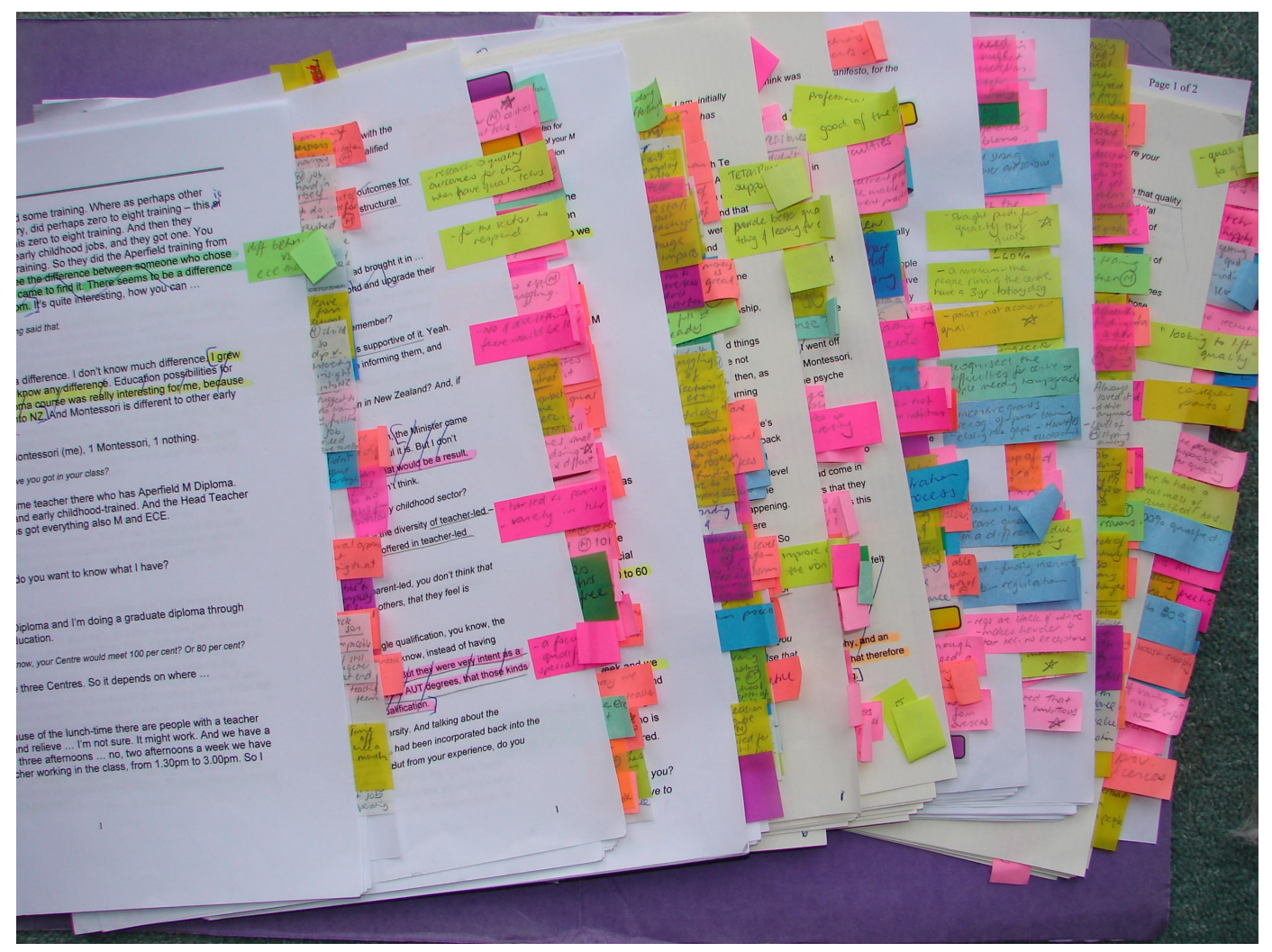




\section{Appendix 12:}

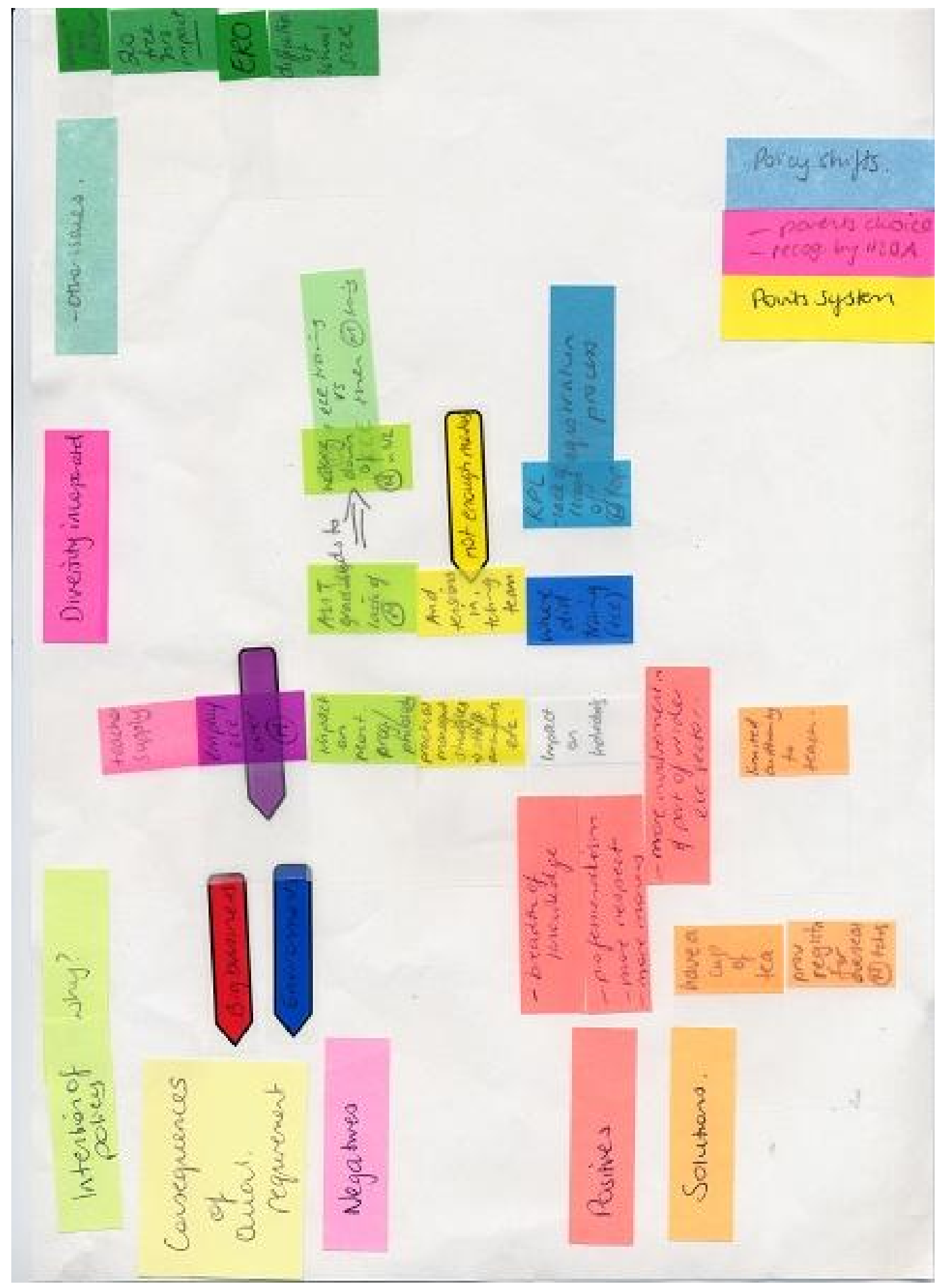




\section{Appendix 13:}

\section{Montessori Services 2005}

Number of Services on Provisional License Due to Persons(s) Responsible Regulation

Number of Teachers in Montessori Services that are ECE Qualified and Registered, as at 1 July 2005

\begin{tabular}{|l|l|l|l|}
\hline & $\begin{array}{l}\text { ECE Qualified } \\
\text { and Registered }\end{array}$ & $\begin{array}{l}\text { Not Registered } \\
\text { and Qualified }\end{array}$ & Total \\
\hline Full Day & 172 & 209 & 381 \\
\hline Sessional & 11 & 14 & 25 \\
\hline
\end{tabular}

Source: RS61 July 2005

Montessori ECE Services, by Percentage of Teachers that ECE Qualified and Registered, as at 1 July 2005

\begin{tabular}{|l|l|l|l|l|l|l|}
\hline & \multicolumn{4}{|l|}{ Percentage of teachers in Service that are ECE Qualified and Registered } & \multirow{2}{*}{ Total } \\
\hline & $0-24 \%$ & $25-49 \%$ & $50-79 \%$ & $80-99 \%$ & $100 \%$ & \\
\hline Full Day & 8 & 33 & 30 & 4 & 7 & 82 \\
\hline Sessional & 1 & 2 & 4 & 1 & 0 & 8 \\
\hline
\end{tabular}

Source: RS61 July 2005

Montessori ECE Services, by Percentage of Funded Staff Hours that are taught by ECE Qualified and Registered, as at 1 November 2005

\begin{tabular}{|l|l|l|l|l|l|l|}
\hline \multirow{2}{*}{} & \multicolumn{2}{|l|}{ Percentage of Funded Staff Hours taught by ECE Qualified and Registered Teachers } & \multirow{2}{*}{ Total } \\
\cline { 2 - 6 } & $0-24 \%$ & $25-49 \%$ & $50-79 \%$ & $80-99 \%$ & $100 \%$ & 8 \\
\hline Full Day & 2 & 29 & 27 & 15 & 8 & 81 \\
\hline Sessional & 0 & 2 & 5 & 0 & 0 & 7 \\
\hline
\end{tabular}

Source: RS7 November 2005, as at 8/12/2005 


\section{Montessori Services 2006}

Number of Services on Provisional License Due to Persons(s) Responsible Regulation

Number of Teachers in Montessori Services that are ECE Qualified and Registered, as at 1 July 2006

\begin{tabular}{|l|l|l|l|}
\hline & $\begin{array}{l}\text { ECE Qualified } \\
\text { and Registered }\end{array}$ & $\begin{array}{l}\text { Not Registered } \\
\text { and Qualified }\end{array}$ & Total \\
\hline Full Day & 199 & 191 & 390 \\
\hline Sessional & 8 & 8 & 16 \\
\hline
\end{tabular}

Source: RS61 July 2006

Montessori ECE Services, by Percentage of Teachers that ECE Qualified and Registered, as at 1 July 2006

\begin{tabular}{|c|c|c|c|c|c|c|}
\hline & \multicolumn{5}{|c|}{ Percentage of teachers in Service that are ECE Qualified and Registered } & \multirow[b]{2}{*}{ Total } \\
\hline & $0-24 \%$ & $25-49 \%$ & $50-79 \%$ & $80-99 \%$ & $100 \%$ & \\
\hline Full Day & 4 & 29 & 39 & 1 & 10 & 83 \\
\hline Sessional & 0 & 2 & 3 & 0 & 0 & 5 \\
\hline
\end{tabular}

Source: RS61 July 2006

Montessori ECE Services, by Percentage of Funded Staff Hours that are taught by ECE Qualified and Registered, as at 1 November 2006

\begin{tabular}{|c|c|c|c|c|c|c|}
\hline & \multicolumn{5}{|c|}{ Percentage of Funded Staff Hours taught by ECE Qualified and Registered Teachers } & \multirow[b]{2}{*}{ Total } \\
\hline & $0-24 \%$ & $25-49 \%$ & $50-79 \%$ & $80-99 \%$ & $100 \%$ & \\
\hline Full Day & 3 & 16 & 37 & 16 & 11 & 83 \\
\hline Sessional & 0 & 0 & 4 & 1 & 0 & 5 \\
\hline
\end{tabular}

Source: RS7 November 2006, as at 13/03/2007 


\section{Appendix 14:}

September 2002

MontessoriNew 2 page 15

\section{Characteristics of an authentic Montessori school}

Dr Nancy McCormack Rambush, founder of the American Montessori Society (AMS) and co-founder of the Montessori Foundation, identified the following characteristics of an "authentic" Montessori school. These are drawn from The Authentic American Montessori School: A Guide to the Self-Study, Evaluation, and Accreditation of American Schools Committed to Montessori Education, by Dr Nancy McCormack Rambush and Dr John Stoops, published in 1992 by the Commission on Elementary Schools of the Middle States Association of Colleges and Schools and AMS.

\section{THE MONTESSORI LEARNING ENVIRONMENT}

A child-centred environment: The focus of activity in the Montessori setting is on children's learning, not on teachers' teaching. Generally students will work individually or in small, self-selected groups. There will be very few whole group lessons.

A responsive prepared environment: The environment should be designed to meet the needs, interests, abilities, and development of the children in the class. The teachers should design and adapt the environment with this community of children in mind, rapidly modifying the selection of educational materials available, the physical layout, and the tone of the class to best fit the ever changing needs of the children.

A focus on individual progress and development: Within a Montessori programme, children progress at their own pace, moving on to the next step in each area of learning as they are ready. While the child lives within a larger community of children, each student is viewed as a universe of one.

\section{MONTESSORI LEARNING ACTIVITIES}

Hands-on learning: In Montessori, students rarely learn from texts or workbooks. In all cases, direct personal handson contact with either real things under study or with concrete models that bring abstract concepts to life, allows children to learn with much deeper understanding.

Spontaneous activity: It is natural for children to wiggle, touch things, and explore the world around them. Any true Montessori environment encourages children to move

about freely, within reasonable limits of appropriate behaviour. Much of the time they select work that captures their interest and attention, although teachers also strive to draw their attention and capture their interest in new challenges and areas of inquiry. And even within this atmosphere of spontaneous activity, students do eventually have to master the basic skills of their culture, even if they would prefer to avoid them.

Activity learning: In Montessori classrooms, children not only select their own work most of the time, but also continue to work with tasks, returning to continue their work over many weeks or months, until finally the work is "so easy for them" that they can teach it to younger children. This is one of many ways Montessori educators use to confirm that students have reached mastery of each skill.

Self-directed activity: One of Montessori's key concepts is the idea that children are driven by their desire to become independent and competent beings in the world to learn new things and master new skills. For this reason, outside rewards to create externa motivation are both unnecessary and potentially can lead to passive adults who are dependent on others for everything, from their self image to permission to follow their dreams. In the process of making independent choices and exploring concepts largely on their own, Montessori children construct their own sense of individual identity and right and wrong.

Freedom within limits: Montessori children enjoy considerable freedom of movement and choice however their freedom exists within carefully defined limits on the range of their behaviour. They are free to do anything appropriate to the ground rules of the community, but are redirected promptly and firmly if they cross over the line.

Intrinsic motivation to learn: In Montessor programmes children do not work for grades or external rewards, nor do they simply complete assignments given by their teachers. Children learn because they are interested in things, and because all children share desire to become competent and independent human beings.

\section{The Montessori teacher}

Authoritative: The teacher is firm at the edges and empathetic at the centre, the kind of adult who responds empathetically to children's feelings, while setting clear limits.

Observer: The Montessori teacher is a trainer observer of children's learning and behaviour. These careful observations are recorded and used to infer where each student is in terms of his or her development, and leads the teacher to know when to intervene in the child's learning with a new lesson, a fresh challenge, or a reinforcement of basic ground rules. Antessori teachers facilitate the learning process by serving as resource to whom the children can turn as they pull together information impressions, and experiences.

WHAT MONTESSORI TEACHERS DO Respectfully engage with the learner: The Montessori teacher recognises that her role is not so much to teach as to inspire, mentor, and facilitate the learning process. The rea work of learning belongs to the individual child. Because of this, the Montessori educator remains conscious of her role in helping each child to fulfill his potential as a human being and of creating an environment for learning within which children will feel safe, cherished, and empowered.
Facilitates the "match" between the learner and knowledge: Montessori teachers are trained to identify the best response to the changing interests and needs of each child as a unique individual. Because they truly accept that children learn in many different ways and at their own pace, Montessori ed-ucators understand that they must "follow the child", adjusting their strategies and timetable to fit the development of each of their pupils.

Environmental engineer: Montessori teachers organise appropriate social settings and academic programmes for children at their own level of development. They do this to a large degree through design of the classroom, selection and ign orisation of learning activities. organisation of learning

(-) Reprinted with permission from Tomorrow's Child magazine, Volume 6, No 3 . 